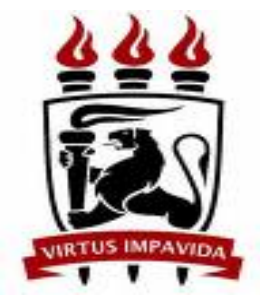

UNIVERSIDADE FEDERAL DE PERNAMBUCO

CENTRO ACADÊMICO DO AGRESTE

PROGRAMA DE PÓS-GRADUAÇÃO EM ENGENHARIA DE PRODUÇÃO

LAYRA NAYARA DAMACENA DE LIMA

MODELO MULTICRITÉRIO PARA SELEÇÃO DE INVESTIMENTOS PÚBLICOS EM PROJETOS VISANDO APOIAR O APL DE CONFECÇÕES NO AGRESTE CENTRAL DE PERNAMBUCO 


\section{MODELO MULTICRITÉRIO PARA SELEÇÃO DE INVESTIMENTOS PÚBLICOS EM PROJETOS VISANDO APOIAR O APL DE CONFECÇÕES NO AGRESTE CENTRAL DE PERNAMBUCO}

Dissertação de Mestrado apresentada à UFPE para a obtenção de grau de Mestre como parte das exigências do Programa de Pós-Graduação em Engenharia de Produção do Centro Acadêmico do Agreste.

Área de Concentração: Otimização e Gestão da Produção.

Orientador(a):Jônatas Araújo de Almeida, DSc.

Caruaru

2018 
Catalogação na fonte:

Bibliotecária - Simone Xavier - CRB/4 - 1242

L732m Lima, Layra Nayara Damacena de.

Modelo multicritério para seleção de investimentos públicos em projetos visando apoiar o APL de confecções no Agreste central de Pernambuco. / Layra Nayara Damacena de Lima. - 2018.

$110 \mathrm{f}$. il. : $30 \mathrm{~cm}$.

Orientador: Jônatas Araújo de Almeida

Dissertação (Mestrado) - Universidade Federal de Pernambuco, CAA, Programa de Pós-Graduação em Engenharia de Produção, 2018. Inclui Referências.

1. Aglomerados industriais. 2. Políticas públicas. 3. Multicritério. 4. Engenharia de produção. I. Almeida, Jônatas Araújo de (Orientador). II. Título.

658.5 CDD (23. ed.)

UFPE (CAA 2018-251) 


\section{MODELO MULTICRITÉRIO PARA SELEÇÃO DE INVESTIMENTOS PÚBLICOS EM PROJETOS VISANDO APOIAR O APL DE CONFECÇÕES NO AGRESTE CENTRAL DE PERNAMBUCO}

Dissertação apresentada ao Programa de PósGraduação em Engenharia de Produção da Universidade Federal de Pernambuco, como requisito parcial para a obtenção do título de mestre em Engenharia de Produção.

Aprovada em: 10/12/2018.

\section{BANCA EXAMINADORA}

Prof $^{\mathrm{o}}$. Dr. Jônatas Araújo de Almeida (Orientador) Universidade Federal de Pernambuco

Prof $^{\circ}$. Dr. Thalles Vitelli Garcez (Examinador Interno) Universidade Federal de Pernambuco

Prof $^{\circ}$. Dr. Renata Maciel de Melo (Examinador Externo) Universidade Federal de Pernambuco 


\section{AGRADECIMENTOS}

Primeiramente, agradeço à Deus por me permitir iniciar e encerrar esta etapa, e por me abençoar e proteger durante todo o percurso.

Agradeço também à minha família pelo apoio, carinho e compreensão.

Agradeço ao meu orientador, Professor Jônatas Almeida, pela disponibilidade em compartilhar seu conhecimento, mas também por se preocupar no meu desenvolvimento por completo, envolvendo aspectos pessoais que também possuem grande influência sobre a minha formação.

Novamente agradeço a Deus, por ter me direcionado para o melhor orientador que eu poderia ter, o qual tenho tremenda admiração e que ao fim da jornada do mestrado eu considero como meu mentor para as próximas etapas.

Agradeço aos amigos que encontrei durante o curso e que me apoiaram em tantos momentos difíceis e também compartilharam tantas alegrias, Keilane e Wesley. E também aos amigos de longa data que já me acompanham a tanto tempo e permanecem sempre presentes nos momentos de alegria, mas principalmente nos momentos difíceis, Marly e Eduarda.

Agradeço aos professores do PPGEP-CAA pelas instruções transmitidas.

Por fim, agradeço à FACEPE pelo apoio financeiro e à CAPES pelo apoio concedido ao PPGEP e que contribuiu para a elaboração dos trabalhos. 


\section{RESUMO}

Arranjos Produtivos Locais - APLs são agrupamento de empresas de um mesmo setor que cooperam entre si, de maneira que a estrutura formada beneficia principalmente o desenvolvimento de pequenas empresas, gerando um forte impacto na economia regional e até nacional. Por isso o poder público tem um grande interesse em realizar investimentos para apoiar os APLs, através de projetos que envolvam iniciativas de apoio e desenvolvimento, já que os APLs são extremamente singulares e é necessário se adequar as características e necessidades de cada um deles para alcançar os objetivos desejados. Dessa forma, a seleção de projetos para investimento utilizando a abordagem multicritério se torna importante para maximizar o retorno percebido esperado sobre os investimentos realizados. Os pesos representam a preferência do decisor e estão sujeitas a incerteza provenientes do processo de elicitação e modelagem ou até mesmo do próprio decisor, por isso deve ser analisada mais profundamente a forma como influenciam a recomendação, ou mais especificamente, a troca de recomendação. A realização da análise da variação mínima utilizando otimização inversa fornece ainda mais segurança, já que após identificar as soluções que podem se tornar ótimas é obtida a mínima diferença entre os pesos originais e os pesos necessários para que estas se tornem ótimas. No entanto, todos os estudos identificados apresentam lacunas que os tornam inadequados para tratar o problema multicritério de seleção de portfólio de projetos, visando fornecer mais confiança ao decisor. Sendo assim o modelo aqui proposto contribui para preencher estas lacunas utilizando a variação relativa, fornecendo a manutenção da ordenação dos critérios, o critério mais crítico e a transferência mais crítica. Para a avaliação multicritério, foi utilizado o SMARTS e os pesos foram convertidos para o contexto de escala de razão. Como resultado foi obtida a recomendação de um portfólio composto por 10 projetos denominado de solução original, e que consome o total dos recursos disponíveis. Em seguida, a análise de sensibilidade mostrou que outras duas soluções, denominadas A e B, surgiram como soluções para o problema de seleção. Por fim, a análise da mínima variação, realizada separadamente para cada uma destas novas soluções, avaliou quanto minimamente os pesos teriam que mudar para eleger A ou B como ótima, usando as normas $\mathrm{L}_{\infty} \mathrm{e} \mathrm{L}_{1}$.

Palavras-chave: Seleção de Projetos Públicos. Arranjos Produtivos Locais. MCDA. SMARTS. Otimização Inversa. 


\begin{abstract}
The Local Productive Arrangements - LPAs are companies grouping of a determined sector that cooperate each other, thus this structure benefits mainly development of small enterprises, generating a strong impact in the regional economic and until national. Wherefore the public power has a great interest in to accomplish investments to support LPAs across of projects that encompass development and support initiatives, since LPAs are extremely singular and is necessary fit the characteristics and necessities of each one for reach the goals desired. Thus, project selection for investments using multicriteria approach turn a important to maximize expected perceived return under investments accomplish. The weights represent decision maker preference and are subject to uncertainties coming of elicitation and modeling process or until even of decision maker, therefore must be analyzed more heavily the form like Scale constants influence the recommendation, or more specifically, the recommendation change. The accomplishing of minimal variation analysis using inverse optimization provides further safety, since after identifying solutions that can turn optimum is obtained the minimal difference between originals weights and the weights required for solutions turn optimum. However, all studies identified present gaps that turn unsuitable for treat the multicriteria problem of project selection, aiming provide more confidence to decision maker. Thus, the model here proposed contributes for fill in these gaps using relative variation, providing criteria ranking maintenance, the most critical criteria and most critical transfer, and criteria and alternatives robustness. For multicriteria evaluation, was used SMARTS and the weights was converted for context of ratio scale. Like result was obtained recommendation of a portfolio composed by 10 projects named original solution, and that consumes all available resource. Then, sensitivity analysis showed that others two solutions, named A and B, arise like solutions for selection problem. Lastly, the minimal variation analysis, accomplished separately for each of these new solutions, evaluated the minimal variation of weights to elect $A$ or $B$ like optimum using $L_{\infty}$ and $L_{1}$ norms.
\end{abstract}

Key-Words: Public Projects Selection. Local Productive Arrangements. MCDA.

SMARTS. Inverse Optimization. 


\section{LISTA DE FIGURAS}

Figura 1 -

Figura 2 -

Figura 3 -

Figura 4 -

Figura 5 -

Figura 6 -

Figura 7 -

Figura 8 -

Figura 9 -

Figura $10-$
Estrutura do modelo 55

Valores dos pesos originais................................................... $\quad 70$

Aumento independente do peso................................................ 70

Redução independente do peso.................................................. 71

Transferência de variação do peso.............................................. 71

Transferência de variação do peso............................................... 73

Transferência de variação do peso com violação de restrição........ 76

Transferência de variação do peso sem violar restrições............... 77

Variação dos pesos no L $\infty$.......................................................... 98

Variação dos pesos no L1 ......................................................... 98 
LISTA DE TABELAS

Tabela $1-$

Características da classificação de APLs

Tabela 2 Análise SWOT do APL de Confecções do Agreste.

Tabela 3 Características de estudos relevantes para o desenvolvimento do 50 modelo

Tabela 4 Comparando o desempenho fictício das soluções 67

Tabela 5 Comparando o desempenho fictício das soluções 73

Tabela 6 Comparando o desempenho fictício das soluções 75

Tabela 7 Comparando o desempenho fictício das soluções. 80

Tabela 8 Características dos critérios 84

Tabela 9 -

Dados para avaliar os projetos 86

Tabela 10 Avaliação intracritério 87

Tabela 11 Avaliação dos critérios 88

Tabela $12-$

Obtenção de função valor. 89

Tabela 13 Seleção de portfólio 90

Tabela 14 -

Output da análise de sensibilidade. 91

Tabela 15 Avaliação entre a solução A e a solução original para $L \infty$...... 92

Tabela 16 Avaliação entre a solução B e a solução original para L $\infty$...... 93

Tabela 17 Avaliação entre as soluções para L1. 94 


\section{LISTA DE ABREVIATURAS E SIGLAS}

APL

Arranjo Produtivo Local

OECD

Organisation for Economic Cooperation and Development

RedeSist

Rede de Pesquisa em Sistemas e Arranjos Produtivos e Inovativos Locais

$\mathrm{CNPq}$

Conselho Nacional de Desenvolvimento Científico e Tecnológico

FINEP

Financiadora de Estudos e Projetos

GTP APL

Grupo de Trabalho Permanente para Arranjos Produtivos Locais

SEBRAE

Serviço Brasileiro de Apoio às Micro e Pequenas Empresas

MDIC

Ministério do Desenvolvimento, Indústria e Comércio Exterior

UNCTAD

United Nations Conference on Trade and Development

MPEs

Micro e pequenas empresas

NEs

Núcleos Estaduais

P\&D

Pesquisa e Desenvolvimento

TI

Tecnologia da Informação

FITradeoff

Flexible and Interactive Tradeoff

AHP

Analytic Hierarchy Process

PROMETHEE

Preference Ranking Organization METHod for Enrichment of Evaluations

SMART

Simple Multi Attribute Rating Technique

WSM

Weighted sum Model

WPM

Weighted Product Model 


\section{SUMÁRIO}

1.1 Relevância e contribuiçãa do estudo........................................................... 12

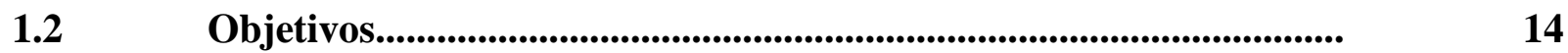

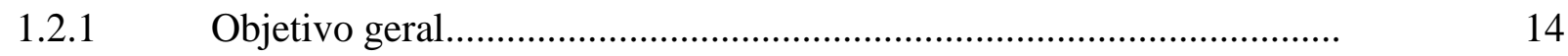

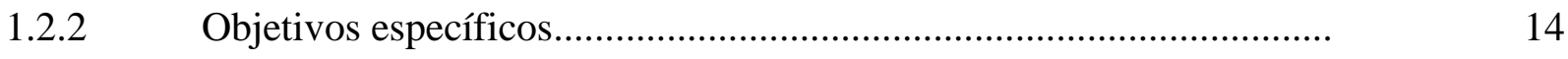

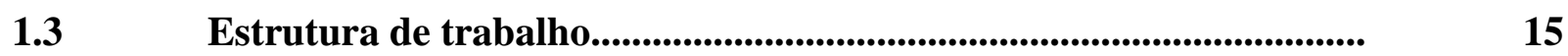

2 FUNDAMENTAÇÃO E REVISÃO DA LITERATURA......................... 16

$2.1 \quad$ APLs e políticas públicas.................................................................. 16

2.1.1 Características dos clusters e Arranjos Produtivos Locais..................... 16

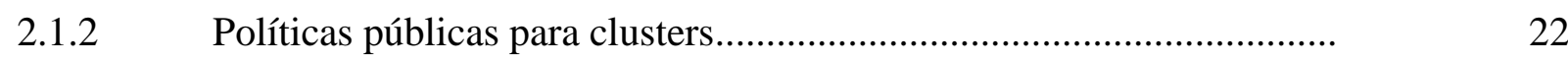

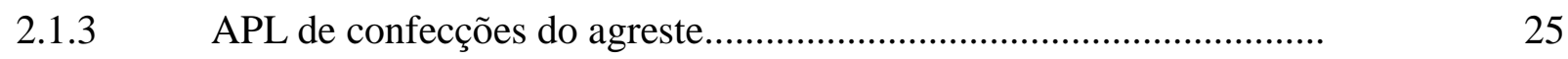

2.2 Seleção de portfólio de projetos e multicritério.................................... 28

$2.3 \quad$ Modelo aditivo e SMARTS................................................................ 32

2.4 Análise da variação com otimização inversa em problemas 38 multicritério

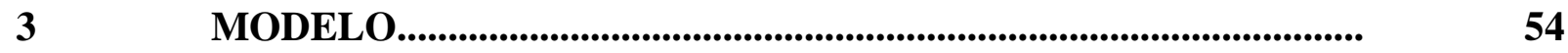

$3.1 \quad$ Etapas do modelo........................................................................ 54

3.2 Análise da variação das constantes de escala utilizando otimização 59 inversa..

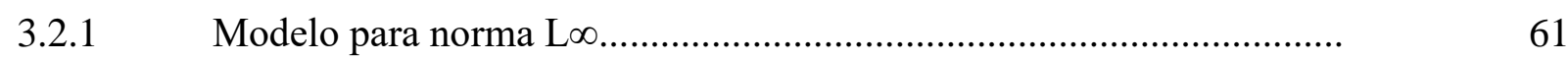

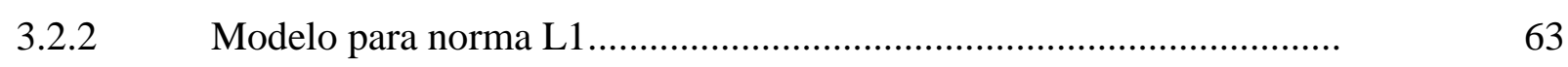

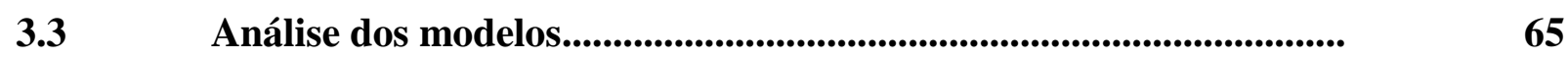

$4 \quad$ APLICAÇÃO

4.1 Discussão dos resultados............................................................. 94

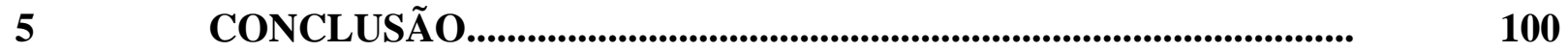

REFERÊNCIAS.............................................................................. 103 


\section{INTRODUÇÃO}

O desenvolvimento econômico de um país ocorre através de elementos originados de forma espontânea e outros propositalmente projetados pelo poder público para tal objetivo. Um exemplo disso, são os Arranjos Produtivos Locais (APLs) e as políticas direcionadas para os APLs, desenvolvidas pelo governo brasileiro (SCHMIEDEBERG, 2010; HOSPERS E BEUGELSDIJK, 2002; PORTER, 1998; CARDOSO, 2014).

O APL de confecções do Agreste é composto atualmente por dez municípios, mas inicialmente foi formado pelas cidades de Caruaru, Santa Cruz do Capibaribe e Toritama. Este núcleo apresenta elevada concentração espacial de unidades produtivas e trabalhadores. Estimase que há cerca de 18.803 empresas empregando cerca de 107.177 pessoas em todo o pólo de confecções. O faturamento total da indústria de confecções, em 2011, foi de aproximadamente R \$ 1 bilhão. As cidades do APL apresentam alto crescimento populacional, que é um indicador do dinamismo econômico resultado do forte movimento migratório, em sua maioria, de pessoas que buscam melhorias econômicas (PROAPL-PE, 2013).

Segundo Marshall (1920), grupos como os APLs, permitem que as empresas formem uma entidade que se torna mais forte para superar obstáculos e obter benefícios que são mais difíceis de alcançar individualmente. Porter (1998) junto com Hospers e Beugelsdijk (2002) afirmam que as políticas direcionadas para APLs surgem para assegurar os benefícios iniciais e promover benefícios adicionais que exigem recursos e direcionamento estratégico além do disponível no APL. Para a OECD (2010), tais políticas são desenvolvidas como projetos, já que precisam se adequar as especificidades de cada APL e da região na qual está inserido.

Nas instituições públicas, assim como nas privadas, a escassez de recursos financeiros torna necessária a seleção dos projetos que melhor se alinham e contribuem para a estratégia da organização, buscando assim obter maior retorno aos recursos investidos (ZANAKIS et al, 1995; TAVANA, 2015; SCHMIEDEBERG, 2010). O adequado investimento dos recursos em políticas públicas direcionadas aos clusters pode proporcionar grandes benefícios econômicos e sociais, podendo representar o fator de apoio para tornar uma região economicamente próspera com diversas oportunidades para a população ao invés de uma região fornecedora de mão de obra para empreendimentos das regiões vizinhas. A seleção adequada dos investimentos públicos para os APLs é uma questão ainda mais crítica, já que segundo Porter (1998) e OECD (2010) as políticas para os APLs representam um investimento localizado, mas com efeitos regionais e até mesmo nacional. 
De acordo com Fernandez et al (2009), a seleção de projetos para investimento no setor público, geralmente, é realizada a partir da análise de custo benefício, ou seja, não é realizada de acordo com a abordagem multicritério, que considera claramente os diversos objetivos que orientam a instituição, na qual há o suporte de uma metodologia bem estruturada que amplie a compreensão sobre o problema e, consequentemente, sobre as opções para solucioná-lo, ao mesmo tempo que direciona para uma avaliação integrada e consistente entre as opções, considerando as particularidades de cada uma em diversos aspectos (DE ALMEIDA, 2013; CAFISO et al, 2002; FERNANDEZ et al, 2009).

Buscar soluções para problema reais a partir da abordagem multicritério envolve lidar com as incertezas provenientes dos dados necessários para a resolução. Incertezas são inerentes ao problema multicritério e podem vir do método multicritério, de simplificações no modelo e da subjetividade relacionado a preferências do decisor, que é um elemento essencial dos problemas de decisão multicritério. Independente da fonte, as incertezas devem ser tratadas para fornecer maior segurança de que a recomendação está alinhada aos objetivos e preferências do decisor (HEUBERGER, 2004; HIFI e MHALLA, 2013; HYDE et al, 2005). A incerteza proveniente do decisor é especialmente interessante, por possuir uma influência mais direta e controlável, no sentido de que a partir da imprecisão declarada pelo decisor, a análise de sensibilidade pode estreitar ou expandir a gama de recomendações a serem consideradas, por isso a incerteza proveniente das preferências do decisor também é objeto de estudo no atual trabalho.

\subsection{Relevância e contribuição do estudo}

Este estudo se propõe a auxiliar o setor público na tomada de decisão relacionada com a seleção de projetos, que representam políticas públicas para investimento. Trata-se da aplicação da abordagem multicritério para apoiar, especificamente, o desenvolvimento e implementação de políticas municipais direcionadas aos APLs. De modo geral, o modelo colabora para o alcance dos objetivos das instituições públicas de modo a obter o maior retorno sobre investimento, de acordo com os objetivos estabelecidos e respeitando as restrições financeiras, porém há algumas contribuições mais específicas, exploradas adiante, que justificam a e ressaltam a importância do trabalho em outros aspectos.

Primeiramente, o estudo busca contribuir com a exploração de uma área de seleção de investimentos públicos que não havia sido abordada anteriormente, com exceção dos estudos desenvolvidos por Lima e Almeida (2018a) e (2018b), o que pode ser verificado através da ausência da exploração deste tópico na revisão da literatura. A seleção, atualmente realizada, 
das políticas públicas que vão apoiar e promover diretamente o desenvolvimento do APL não condizem com o impacto que os APLs representam para a economia regional e até mesmo nacional. O estudo busca tratar por meio da abordagem multicritério a seleção de investimentos públicos para apoiar o desenvolvimento dos APLs de maneira a fornecer a recomendação de um portfólio obtido a partir de uma metodologia consistente cientificamente, contribui retirando a informalidade e fundamentando as decisões em dados realísticos e metodologia embasada cientificamente, buscando assegurar dentro do possível o melhor resultado disponível

Segundo, o modelo contribui metodologicamente considerando que a seleção de políticas públicas tem suas próprias especificidades relacionadas, principalmente, com as particularidades de cada APL e do nível de poder público que está implementando a política. Características importantes para a abordagem multicritério que busca fornecer soluções personalizadas ao problema e decisor envolvido.

Além disso, a principal contribuição metodológica do modelo é a análise da mínima variação necessária nas constantes de escala, utilizando otimização inversa, para que ocorra a modificação da recomendação original para uma nova recomendação (HEUBERGER, 2004) apontada pela análise de sensibilidade. Esta análise é realizada como complemento à análise sensibilidade, com a finalidade de tratar as incertezas provenientes de alguns parâmetros (HEUBERGER, 2004) que neste caso, provêm do decisor ao declarar as suas preferências em relação aos critérios avaliados e/ou do procedimento na elicitação das constantes de escala. Uma análise específica para as constantes de escala é justificada pela função primordial que desempenham no processo de decisão e por se basear em subjetividade. Consiste em explorar a junção da otimização inversa combinatória com a abordagem multicritério que é uma aplicação relativamente explorada na literatura. No entanto, foi percebido que, geralmente, é realizada sem se referir ao conceito de otimização inversa. Como é o caso dos estudos desenvolvidos por Wolters e Mareschal (1995), Ringuest (1997), Sowlati et al (2010) e Hyde et al (2005), Insua e French (1991) e Barron e Schmidt (1987). Doan e Smet (2018) é o estudo mais recente utilizando otimização inversa para os pesos de problemas multicritério e o único que faz referência ao termo. Todos estes estudos analisam a variação sob a perspectiva da problemática de ordenação ou escolha e sugerindo uma abordagem que não é compatível com a proposta por este estudo, principalmente pelo fato de que apesar deles proporem o fornecimento de maior confiança a um único decisor, com exceção de Doan e Smet (2018), a maior parte deles não se compromete em respeitar a informação de preferência fornecida pelo decisor, expressa na forma de ordenação do pesos. Além disso, outros pontos que enriquecem a tomada de decisão são abordados pelo modelo proposto, como a limitação de variação dos 
pesos especificada pelo decisor e a limitação de variação do próprio modelo para impedir anulação ou negatividade de nenhum critério, a consideração da distância relativa ao invés da distância em módulo, a identificação do critério mais crítico e da transferência mais crítica.

De forma prática esta análise contribui para a avaliação da robustez da recomendação, que pode ser refletida no fornecimento de maior segurança ao decisor com relação a decisão recomendada (HIFI e MHALLA, 2013). A análise informa ao decisor o quanto de imprecisão é permitido em relação à determinado critério sem que a recomendação seja trocada. Assim, o decisor tem a possibilidade de verificar se sua incerteza afetaria a solução obtida originalmente. Outra informação fornecida é a nova recomendação resultante de uma incerteza que ultrapassa a variação mínima permitida para a recomendação original.

Por fim, todos estas contribuições fornecidas se refletem em maior desenvolvimento do APL de confecções e da economia regional, assim como crescimento e surgimento de empresas e melhoria do bem estar da população que vive na região do APL.

\subsection{Objetivos}

\subsubsection{Objetivo geral}

Desenvolver um modelo multicritério para apoiar a seleção de investimentos em projetos de políticas públicas que incentivam o desenvolvimento dos APLs, fornecendo maior segurança ao decisor em relação à solução recomendada, por meio da análise da variação nos pesos através de procedimento baseado na otimização inversa para proporcionar ao decisor a perspectiva de quanto sua incerteza sobre determinado critério pode influenciar na mudança da recomendação.

\subsubsection{Objetivos específicos}

- Desenvolver uma base teórica sólida para a compreensão do problema e proposição de solução adequada;

- Desenvolver uma revisão da literatura sobre a seleção de portfólio utilizando otimização inversa;

- Desenvolver um modelo multicritério que represente o problema e o sistema de preferências do decisor e viabilize sua resolução, incorporando a análise da variação mínima nas constantes com otimização inversa;

- Utilizar uma ou mais ferramentas computacionais que viabilizem a aplicação do modelo; 
- Utilizar dados de investimentos públicos de prefeitura relacionada ao APL de confecções para obter uma aplicação real do modelo desenvolvido;

\subsection{Estrutura de trabalho}

O capítulo inicial deste trabalho fornece um contexto mais amplo a respeito do tema abordado, assim como a relevância prática e teórica deste estudo, o objetivo geral e os objetivos específicos que o compõem.

Em seguida no capítulo 2 é fornecida a revisão da literatura abordando inicialmente na seção 2.1 a relação entre clusters e APLs e as caraterísticas que os APLs apresentam, buscando assim uma melhor compreensão sobre as ações que podem ser direcionadas para o seu desenvolvimento. Também são apresentados conceitos gerais sobre políticas públicas, finalizando esta seção com o contexto nacional de políticas públicas para os APLs. Finalizando esta seção, há uma breve apresentação do APL de confecções do Agreste. A seção 2.2 fornece uma perspectiva geral sobre a abordagem de multicritério direcionando para a seleção de projetos públicos. A seção 2.3 apresenta o método SMARTS enfatizando também características relacionadas à problemática de portfólio. Na seção 2.4 apresenta-se a otimização inversa e a sua utilização de forma associada com a abordagem multicritério.

No capítulo 3 é explanado o modelo multicritério para seleção de investimentos públicos em projetos que visam apoiar o desenvolvimento de APLs. Na seção 3.1 é apresentado o framework do modelo, na 3.2 é detalhadamente explorada a realização da análise da mínima variação sobre as constantes de escala utilizando otimização inversa e também é fornecido todo o desenvolvimento matemático que sustenta o modelo proposto.

O capítulo 4 apresenta a aplicação do modelo proposto, em um dos municípios que compõem o APL de confecções do Agreste, na qual é fornecida as informações de input e output relacionadas com a aplicação. Nele, também é realizada a discussão dos resultados obtidos.

No capítulo 5 é apresentado a conclusão e consideração finais, fornecendo o cruzamento do que foi proposto e do que foi alcançado pelo presente estudo, assim como outras observações relevantes. 


\section{FUNDAMENTAÇÃO E REVISÃO DA LITERATURA}

\subsection{APLs e políticas públicas}

Apesar de o conceito de APL estar em bastante uso no Brasil, Clusters é um termo mais amplo e poderia ser considerado equivalente quando se busca trabalhos internacionais. A partir dessas definições, é possível identificar características que auxiliem em ações de suporte, além de apresentar as principais iniciativas governamentais nacionais e internacionais relacionadas com o desenvolvimento de clusters e APLs.

\subsubsection{Características dos clusters e Arranjos Produtivos Locais}

Marshall (1920) abordou o agrupamento físico de empresas apresentando as causas e os benefícios da concentração física de indústrias de um mesmo setor, em sua obra "Princípios da economia" que foi lançada em 1890 na sua primeira edição. A partir de então, surgiram outros conceitos relacionados ao agrupamento de empresas, como o de clusters apresentado por Porter (1990a).

Clusters são definidos como agrupamentos de elementos que em alguns contextos compartilham características. No contexto deste trabalho, clusters são definidos como concentrações geográficas, em um território não necessariamente delimitado por um município ou estado, de empresas independentes que se relacionam e outras instituições interconectadas informalmente que cooperam entre si. As empresas pertencem a um mesmo setor produtivo e estão conectadas por relacionamentos verticais, que ocorrem entre compradores e fornecedores, ou horizontais, que ocorrem entre empresas que compartilham clientes, canais e tecnologias, ou seja, concorrentes. Entre as outras instituições que compõem o cluster estão entidades governamentais, universidades, organizações comerciais, agências reguladoras etc. que fornecem treinamento, educação, informação, pesquisa e suporte técnico para desenvolver um ambiente apropriado à geração de competitividade e melhoria da produtividade (PORTER, 1990b; PORTER, 1998).

No Brasil o termo mais difundido, em relação às concentrações de empresas, é Arranjo Produtivo Local - APL (GTP-APL, 2011). Segundo Cardoso (2014), as principais instituições públicas brasileiras com ações direcionadas para apoiar os APLs são: Rede de Pesquisa em Sistemas e Arranjos Produtivos e Inovativos Locais (RedeSist); Conselho Nacional de Desenvolvimento Científico e Tecnológico (CNPq); Financiadora de Estudos e Projetos (FINEP); Grupo de Trabalho Permanente para Arranjos Produtivos Locais (GTP APL); e o Serviço Brasileiro de Apoio às Micro e Pequenas Empresas (SEBRAE), algumas das quais, fornecem definições de Arranjos Produtivos Locais em seus documentos. 
Foram identificados cinco elementos chave que compõem a definição de cluster fornecida por Porter: concentração física, atividades econômicas relacionadas a um mesmo setor, agentes produtivos e agentes de suporte, cooperação/interação e aprendizado/inovação. Foi então realizada a comparação entre as definições fornecidas pelas instituições brasileiras com a definição de cluster fornecida por Porter, por meio dos cinco elementos estabelecidos.

Foi verificado que as definições referentes aos APLs fornecidas pela RedeSist ${ }^{1}$, SEBRAE$^{2}$, GTP-APL $^{3}$ e Ministério do Desenvolvimento, Indústria e Comércio Exterior $\mathrm{MDIC}^{4}$ apresentam os mesmos elementos da definição fornecida por Porter ${ }^{5}$. Os termos arranjo produtivo local, sistema produtivo local e cluster são considerados equivalentes, no sentido de se referirem à mesma entidade (GTP-APL, 2011; BRASIL, 2004b). Apesar disso, o termo APL também é considerado resultado de uma evolução ao longo do tempo, a qual se traduziu na abrangência de outras dimensões além da comumente mencionada concentração territorial (BRASIL, 2004b).

No entanto, os APLs apresentam um elemento que se diferencia da definição de cluster. A governança é citada explicitamente na definição ou como característica do APL pelas quatros instituições (LASTRES e CASSIOLATO, 2003; Cardoso, 2014; MDIC, 2018; BRASIL, 2014; BRASIL, 2004b), mas não é mencionada na definição de cluster (PORTER, 1990b; PORTER, 1998).

Observada a equivalência entre os termos pode-se agregar informações que são válidas para descrever características dos APLs mesmo que se referindo aos clusters. Sendo assim, serão utilizados os dois termos ao longo do texto, sem que isso represente alguma diferenciação de significado.

Cardoso (2014) apresenta cinco fatores que diferenciam os APLs de outras aglomerações: Dimensão territorial; Diversidade de atividades e atores econômicos, políticos e sociais; Conhecimento tácito; Inovação e aprendizado interativos; e a Governança. Já Brasil (2004b), apresenta quatro variáveis determinantes para que uma concentração seja reconhecida como APL pelo governo: A concentração setorial de empreendimentos no território, Concentração de indivíduos ocupados em atividades produtivas relacionadas com o setor de referência do APL, Cooperação entre os atores participantes do arranjo e Existência de mecanismos de governança.

\footnotetext{
${ }^{1}$ Disponível em Lastres e Cassiolato (2003).

2 Disponível em SEBRAE (2003).

${ }^{3}$ Disponível em Brasil (2014).

${ }^{4}$ Disponível em MDIC (2018).

${ }^{5}$ Disponível em Porter (1990b; 1998).
} 
Além da cooperação o cluster também necessita de competitividade entre as empresas para poder prosperar. A competição adequada dentro do cluster gera novas oportunidades e estimula as empresas a melhorarem seus produtos e processos. A competição e cooperação coexistem porque ocorrem em diferentes dimensões e entre diferentes atores. A rivalidade se propaga entre competidores indiretos e não competidores, assim como os seus benefícios. Inclusive, a entrada de novas empresas no cluster é considerada positiva já que estimula o aprimoramento devido ao estimulo à diversidade em P\&D e à facilitação da entrada de novas estratégias e habilidades (PORTER, 1990; 1998).

Nos estágios iniciais de industrialização, em regiões com poucos recursos disponíveis, o cluster facilita o desenvolvimento dos empreendimentos em pequenos passos permitindo menores quantidades de investimento financeiro e humano e menores riscos, através de economias de escala e complementaridade entre as atividades desempenhadas pelas empresas. Em estágios avançados de industrialização, auxilia na melhoria do desempenho e/ou aumento da competitividade, até mesmo em nível global, através da cooperação mais intensa e melhoria da produtividade (SCHMITZ e NADVI, 1999).

A United Nations Conference on Trade and Development -UNCTAD (1998), a partir da utilização dos critérios: nível geral de tecnologia das empresas, mudanças extensivas durante o tempo e grau de coordenação e networking fornece a seguinte classificação com cinco tipos de clusters ou networks:

- Informal- Predominantemente característico de países em desenvolvimento. Geralmente são compostas por micro e pequenas empresas com nível tecnológico relativamente baixo, trabalhadores que possuem baixa habilidade e pouco ou nenhum aprendizado contínuo para aprimorá-las. Possui barreiras baixas para entrada de novos agentes, mas isto não se reflete diretamente em melhorias ou evolução. Há baixa coordenação e networking entre as empresas com poucos indícios de parceria ou competitividade excessiva. Portanto, uma estrutura que reflete uma dinâmica de baixo crescimento.

- Organizado- Possui um processo de estruturação coletiva, principalmente em termos de infraestrutura e serviço, objetivando analisar e enfrentar problemas comuns ao grupo. Maioria das empresas são pequenas, mas já há algumas com tamanho relativamente maior. As habilidades dos trabalhadores tendem a aumentar através de treinamento e aprendizagem. Também apresentam aprimoramento da capacidade tecnológica. Se diferencia por meio da cooperação e network entre as firmas. Obtêm a perspectiva de 
que competir como um grupo fornece mais vantagem do que competir como unidades, implicando em mudança e evolução conjunta, estimulando o dinamismo.

- Inovativo- São encontrados principalmente em países desenvolvidos, mas há exceções. As empresas tendem a ser centradas em atividades que exigem conhecimento intensivo e possuem capacidades de realizar adaptações tecnológicas e de processos para projetar novos produtos e fornecer mais rapidamente ao mercado. Também possuem a capacidade de se manterem competitivos através de inovação continua em todas as funções de negócio, possibilitando que desempenhem papeis globais e com altas taxas de exportação. A sua capacidade inovativa não está relacionada apenas às empresas de alta tecnologia, empresas de qualquer setor podem conter inovações em tecnologia e processos.

As outras duas classes são os parques tecnológicos ou incubadoras e as zonas de processamento de exportações que são especificamente relacionadas com ações de incentivo à tecnologia e exportação. E como não apresentam uma significativa contribuição para o estudo não serão abordadas.

Cardoso (2014) fornece uma classificação dos APLs baseada no estágio de evolução, caracterizando-os como: incipiente, em desenvolvimento e desenvolvidos. A tabela 1 sintetiza a classificação fornecida por Cardoso (2014) enfatizando alguns fatores considerados relevantes para o atual estudo e fornece as características principais de cada classe:

Tabela 1 - Características da classificação de APLs.

\begin{tabular}{|c|c|c|c|}
\hline \multirow[b]{2}{*}{ Características } & \multicolumn{3}{|c|}{ Classificação } \\
\hline & Incipiente & Em desenvolvimento & Desenvolvidos \\
\hline $\begin{array}{l}\text { Liderança } \\
\text { Governança }\end{array}$ & $\begin{array}{l}\text { Pode ser não reconhecido } \\
\text { por todos, ou ainda pode } \\
\text { existir mais de um que } \\
\text { representam diferentes } \\
\text { grupos. Não possui } \\
\text { grandes capacidades, e } \\
\text { sua atuação e influência é } \\
\text { local. }\end{array}$ & $\begin{array}{l}\text { Existe de forma mais } \\
\text { reconhecida e capacitada. } \\
\text { Surgem ações conjuntas. } \\
\text { Possui poder e relações } \\
\text { consultivas e iniciativas } \\
\text { coletivas. }\end{array}$ & $\begin{array}{l}\text { Poder deliberativo } \\
\text { associado ao consultivo. } \\
\text { Atuação enfatizando o } \\
\text { arranjo. Atuação em } \\
\text { decisões externas (âmbito } \\
\text { municipal) ao arranjo } \\
\text { para defender os } \\
\text { interesses. }\end{array}$ \\
\hline $\begin{array}{l}\text { Integração entre } \\
\text { atores }\end{array}$ & 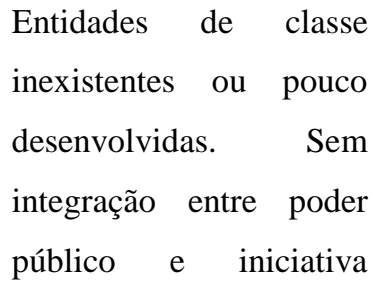 & $\begin{array}{l}\text { Entidades de classe em } \\
\text { desenvolvimento que } \\
\text { participam de decisões } \\
\text { políticas e com prestação } \\
\text { de serviços relevantes }\end{array}$ & $\begin{array}{lr}\text { Organização } & \text { em } \\
\text { entidades } & \text { bem } \\
\text { desenvolvidas } & \text { com } \\
\text { atuação } & \text { municipal, } \\
\text { regional, estadual e até }\end{array}$ \\
\hline
\end{tabular}




\begin{tabular}{|c|c|c|c|}
\hline & $\begin{array}{l}\text { privada. Falta de } \\
\text { consenso entre lideranças } \\
\text { locais. }\end{array}$ & $\begin{array}{l}\text { para o desenvolvimento } \\
\text { das empresas. Tímida } \\
\text { presença dos sindicatos. } \\
\text { Cooperação intersetorial. }\end{array}$ & $\begin{array}{lr}\text { nacional. } & \mathrm{O} \\
\text { reconhecimento } & \text { da } \\
\text { liderança facilita } & \text { a } \\
\text { integração. } & \end{array}$ \\
\hline $\begin{array}{l}\text { Suporte } \\
\text { financeiro }\end{array}$ & $\begin{array}{l}\text { Agentes presentes, mas } \\
\text { que não se envolvem de } \\
\text { forma proativa por falta } \\
\text { de informação ou } \\
\text { confiança. Análises } \\
\text { individualizadas. Por } \\
\text { necessidade busca-se } \\
\text { outras opções para } \\
\text { financiamento. }\end{array}$ & $\begin{array}{l}\text { Maior suporte já que os } \\
\text { agentes adquirem mais } \\
\text { informação e confiança. }\end{array}$ & $\begin{array}{l}\text { Atuação de instituições } \\
\text { públicas de fomento e } \\
\text { facilidade de obtenção de } \\
\text { crédito com instituições } \\
\text { do sistema financeiro. }\end{array}$ \\
\hline $\begin{array}{l}\text { Gestão do } \\
\text { desenvolvimento } \\
\text { do APL }\end{array}$ & $\begin{array}{l}\text { Ausência de um plano } \\
\text { para o desenvolvimento e } \\
\text { de ações integradas. }\end{array}$ & $\begin{array}{l}\text { Integração entre meio } \\
\text { empresarial e poder } \\
\text { público para tratar de } \\
\text { questões relacionadas. }\end{array}$ & $\begin{array}{l}\text { Existência de um plano } \\
\text { amplo e complexo, } \\
\text { elaborado pelos parceiros } \\
\text { governamentais } \\
\text { empresariais. }\end{array}$ \\
\hline $\begin{array}{l}\text { Inovação } \\
\text { tecnologia }\end{array}$ & 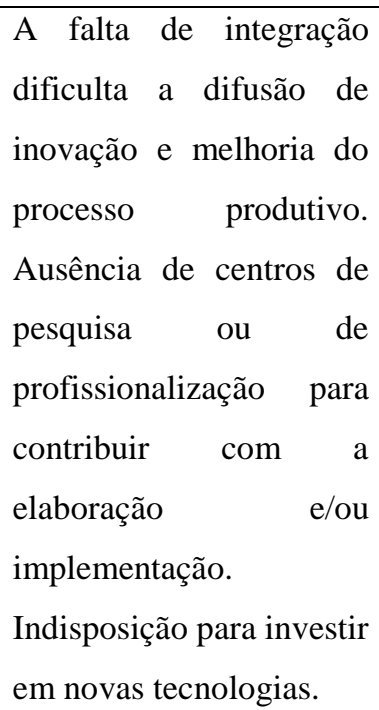 & $\begin{array}{l}\text { Presença e contato com } \\
\text { instituições de pesquisa, e } \\
\text { profissionalizantes. } \\
\text { Disposição para investir } \\
\text { em novas tecnologias. A } \\
\text { integração relativamente } \\
\text { maior facilita a difusão } \\
\text { entre empresas. }\end{array}$ & $\begin{array}{l}\text { Presença de instituições } \\
\text { de ensino superior com } \\
\text { propostas direcionadas ao } \\
\text { arranjo. Agentes de } \\
\text { suporte bem estruturados. }\end{array}$ \\
\hline $\begin{array}{l}\text { Contribuição } \\
\text { para o } \\
\text { desenvolvimento } \\
\text { local }\end{array}$ & $\begin{array}{l}\text { Gera empregos e renda de } \\
\text { forma bastante } \\
\text { localizada. }\end{array}$ & $\begin{array}{l}\text { Atrai novas empresas e } \\
\text { incentiva } \\
\text { empreendedorismo. } \\
\text { Novas atividades } \\
\text { econômicas } \\
\text { competitividade. }\end{array}$ & $\begin{array}{l}\text { Poder de atração maior e } \\
\text { maior intensidade dos } \\
\text { resultados. }\end{array}$ \\
\hline $\begin{array}{l}\text { Mercado e } \\
\text { competitividade }\end{array}$ & $\begin{array}{lr}\text { Produto sem } & \text { forte } \\
\text { identidade local } & \text { ou } \\
\text { microrregional. } & \text { Tem } \\
\text { acesso e } & \text { atende }\end{array}$ & $\begin{array}{l}\text { Produto com algumas } \\
\text { características } \\
\text { socioculturais. Busca } \\
\text { constante por inovação e }\end{array}$ & $\begin{array}{l}\text { Atuação das empresas em } \\
\text { nível regional, nacional e } \\
\text { internacional. }\end{array}$ \\
\hline
\end{tabular}




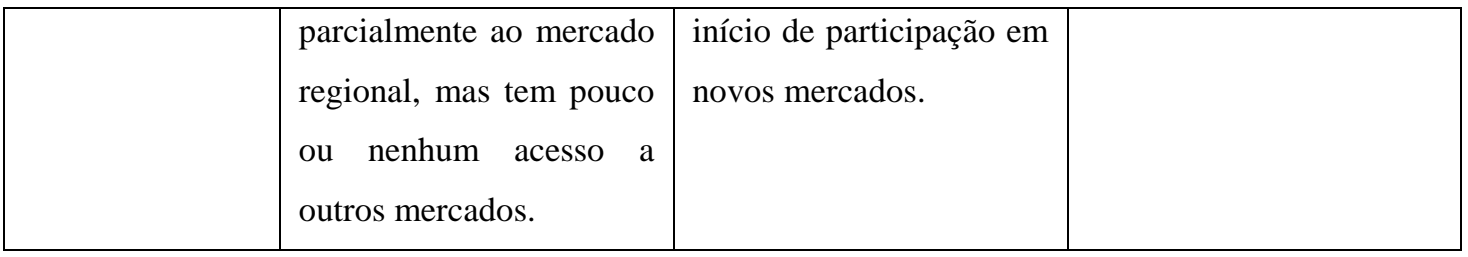

Fonte: Produzido pelo autor baseado em Cardoso (2014).

É interessante observar como os fatores que variam nos diferentes níveis de desenvolvimento de arranjo estão inter-relacionados e se influenciam, de modo que geram um emaranhado de causas e efeitos um sobre os outros. Observa-se também que as classificações apresentadas são complementares, a fornecida pela UNCTAD (1998) tem uma visão mais global, enquanto que a fornecida por Cardoso (2014) tem uma visão nacional e mais detalhada de alguns aspectos dos APLs. Mesmo assim, percebe-se que há um alinhamento da visão externa com a interna.

Os clusters atraem investimentos governamentais devido ao efeito positivo que causam sobre a competitividade das empresas no mercado interno e até internacional. O objetivo destes investimentos é aumentar a produtividade das empresas e desenvolver os clusters existentes, dado que a origem dos clusters ocorre, geralmente, a partir de características e vantagens que uma determinada região possui e sem relação com iniciativas governamentais (PORTER, 1998).

Exemplos desses investimentos são verificados em estudos desenvolvidos em diversas regiões do mundo como: na Europa (TÖPFER et al 2017), (LEHMANN e MENTER 2017) e (CRASS et al 2017), América latina (GARONE et al 2015) e na Ásia (NISHIMURA E OKAMURO 2011).

No caso das pequenas empresas, os clusters ajudam-nas a superar as restrições de crescimento e torna-las competitivas em outros mercados (SCHMITZ e NADVI, 1999). Em países subdesenvolvidos os clusters de Micro e pequenas empresas - MPEs têm atraído bastante atenção e são alvo de políticas públicas devido ao papel predominante que desempenham na economia desses países e contribuição significativa no produto interno bruto (UNCTAD, 1998), através da geração de emprego (SCHMITZ e NADVI, 1999).

\subsubsection{Políticas públicas para clusters}

Há entre os participantes do cluster mútua dependência e responsabilidade coletiva pela criação de condições de competição produtiva, uma vez que as ações governamentais não tornam por si próprias as empresas mais competitivas. O governo deve desempenhar um papel de suporte indireto para estimular a competitividade e o desenvolvimento das empresas, 
evitando gerar dependência de suas ações e resultados rápidos que posteriormente enfraquecerão a inovação (PORTER, 1990b).

As iniciativas públicas podem ser diretamente direcionadas para clusters ou podem ser direcionadas para outras áreas, mas que contemplam os clusters. Políticas para clusters podem estar relacionadas com: política de desenvolvimento econômico regional, política de tecnologia, ciência e inovação, política industrial, política empresarial e até mesmo política de ensino superior (HOSPERS e BEUGELSDIJK, 2002; OECD, 2010), podendo ser também a intersecção entre diferentes políticas que possuem objetivos compartilhados (OECD, 2010). Segundo Fromhold-Eisebith e Eisebith (2005), a promoção de um cluster pode ocorrer com iniciativas explicitas e implícitas. As iniciativas explicitas possuem o termo ou o conceito de cluster claramente em seu título. Já as iniciativas implícitas, englobam os objetivos relacionados com os clusters, mas sem uma referência direta sobre o termo ou conceito de cluster.

Políticas para cluster são definidas como todos os esforços desempenhados pelo governo para desenvolver e apoiar clusters com intuito de fortalecer as capacidades de inovação e tornar a região e os participantes mais competitivos (SCHMIEDEBERG, 2010; HOSPERS E BEUGELSDIJK, 2002). As políticas para cluster têm como objetivo fortalecer uma determinada economia regional e assim, fortalecer também a economia nacional. As iniciativas governamentais para clusters podem ser desenvolvidas em diferentes níveis, podendo ser nacional, regional e programas supranacionais (OECD, 2010).

As iniciativas para promover o cluster são categorizadas com base no setor ao qual pertencem os atores, os recursos financeiros e os interesses que conduzirão a estratégia implementada. Elas podem seguir uma abordagem top-down quando projetadas, implementadas, no mínimo co-financiadas temporariamente e dirigidas por órgãos governamentais ou agências públicas. Ou podem ser bottom-up quando são organizados, financiados e primariamente estimulados por grupos de empresas privadas (FROMHOLDEISEBITH E EISEBITH, 2005). A classificação fornecida por Nishimura e Okamuro (2011) divide as políticas direcionadas para cluster em suporte direto ou suporte indireto. O suporte direto é composto por intervenções governamentais mais fortes ilustradas por consórcios, subsídios e serviços de incubação, já o suporte indireto é composto por intervenções governamentais mais leves, como por exemplo, fornecimento de informações através de sites, organização de eventos e consultoria. Garone et al. (2015) classifica os beneficiários do suporte público em: beneficiários diretos, para se referir às empresas que escolheram participar ou foram selecionadas para as atividades que constituem a política. E os beneficiários indiretos são 
as empresas que não participaram das atividades, mas se beneficiaram de alguma forma devido a relação que possuem com beneficiários diretos.

Para Garone et al. (2015), políticas de desenvolvimento de cluster, geralmente, são constituídas por duas fases: Na primeira, busca-se desenvolver planos para estabelecer relações e interação entre os participantes privados do cluster em cooperação com os agentes públicos. Na segunda fase, os planos são executados geralmente envolvendo a combinação de recursos públicos e privados. O objetivo é promover inovação e aprendizado conjunto para superar restrições ambientais, de infraestrutura e tecnológicas.

$\mathrm{O}$ aumento da necessidade de dados baseados em cluster é motivado pelo apoio às pesquisas e decisões políticas, e pela facilitação de comparação entre clusters (Delgado et al, 2016). Sendo assim, a avaliação de políticas em geral e também daquelas direcionadas para os clusters reflete o interesse em obter informações para apoiar o desenvolvimento de políticas futuras, as lições aprendidas através da implementação são usadas para aprimorar o desenvolvimento das políticas posteriores. A necessidade de avaliação das políticas está relacionada com a busca por realizar seleções adequadas de investimentos (SCHMIEDEBERG, 2010). Schmiedeberg (2010) fornece uma visão geral sobre os métodos utilizados para avaliar medidas políticas direcionadas aos clusters. $\mathrm{O}$ autor também destaca os desafios que envolvem a avaliação de políticas em geral, e em especial, apresenta os desafios específicos da avaliação de políticas direcionadas aos clusters. O interesse em apoiar o desenvolvimento do suporte público aos clusters é percebido até em estudos que não possuem temática diretamente relacionada com as políticas de clusters. Delgado et al (2016), propõem uma metodologia que torna possível comparar clusters e ressalta a contribuição que seu estuda traz na avaliação de políticas implementadas ou no desenvolvimento de estratégias de suporte público.

A avaliação de políticas também é importante para verificar os efeitos que os instrumentos políticos causam em varáveis de interesse (TÖPFER et. al, 2017). Políticas direcionadas aos clusters são relativamente exploradas na literatura com abordagens referentes à: relação entre o agrupamento geográfico de empresas e a eficácia de programas públicos de apoio à inovação (CRASS et al, 2017), influência das políticas sobre a colaboração entre os membros do cluster (TÖPFER et al, 2017), o impacto e papel das políticas públicas de clusters (LEHMANN e MENTER, 2017), e o efeito das políticas de cluster sobre o desempenho de empresas locais (NISHIMURA e OKAMURO, 2011). Garone et al. (2015) explora o impacto direto e indireto de políticas direcionadas ao APL no desempenho de pequenas e médias empresas. De acordo com os autores, esta é a primeira, e de acordo com o levantamento 
realizado para este trabalho, continua sendo a única, avaliação rigorosa diretamente relacionada com o impacto de políticas de desenvolvimento de clusters na América latina.

Segundo Hospers e Beugelsdijk (2002), as autoridades buscam identificar e mapear as melhores práticas para aprender a partir das experiências de outros governos e clusters, de maneira que a comparação de políticas pode ampliar o entendimento sobre situações, restrições e opções de ação. As características que tornam cada cluster único e também desempenham papel importante no sucesso do cluster tornam, no entanto, bastante difícil comparar e extrair aprendizado que possibilite transferir as ações de um cluster para outro, dessa forma as ações bem sucedidas devem ser encaradas como inspirações e não se deve cometer o erro de copiálas, da mesma forma que as ações mal sucedidas também servem como um aprendizado. Porter (1998) defende que as iniciativas de desenvolvimento provenientes do poder público devem ser direcionadas para buscar vantagem competitiva e especialização, ao invés de focar em imitar o sucesso de outros clusters. Uma das abordagens de políticas para clusters é o apoio por meio de projetos dedicados, principalmente devido as particularidades de cada região e de cada cluster, sendo necessário que as políticas sejam adaptadas ao tipo de cluster e necessidades regionais (OECD, 2010).

Organizações internacionais como a United Nations Conference On Trade And Development (UNCTAD) e a Organisation for Economic Cooperation and Development (OECD) desempenham um papel importante na promoção de clusters. A OECD é uma organização composta por diversos países que possui o objetivo de promover políticas de melhoria do bem-estar social e da economia da população mundial. Atualmente contém 35 membros que compartilham experiências e buscam soluções para problemas em comum, o Brasil não é um membro, mas é considerado um parceiro importante (OECD,2011). A UNCTAD é um órgão intergovernamental das Nações Unidas responsável por tratar de questões sobre economia e desenvolvimento sustentável, focando no comércio, finanças, investimento e tecnologia (UNCTAD, 2017).

Baseado no importante papel de gerador de emprego e renda desempenhado pelas micro, pequenas e médias empresas, o governo brasileiro justifica sua escolha estratégica de apoiar os APLs devido ao reconhecimento de que há maior efetividade de políticas de fomento destas empresas quando direcionada a grupos de empresas ao invés de empresas individualizadas. Neste caso, o maior potencial competitivo está relacionado com a maior cooperação entre as empresas e não com o tamanho das empresas (Brasil, 2004b).

No Brasil, as ações de apoio aos APLs são desenvolvidas de forma transversal e interdisciplinar por diversos atores a nível nacional, estadual, municipal e nas dependências do 
APL. As principais instituições apoiadoras são RedeSist, CNPq, FINEP, SEBRAE e o GTP APL. O apoio aos APLs é baseado na coordenação entre os diversos atores para identificar as demandas coletivas e conquistar o comprometimento entre eles para buscar soluções e desenvolvimento para o APL (CARDOSO, 2014).

O Grupo de Trabalho Permanente para Arranjos Produtivos Locais (GTP-APL) é uma iniciativa governamental para atender todas as questões relacionada aos APLs e fornecer apoio integrado. Foi instituído por quatro ministérios, é coordenado pelo MDIC e possui uma secretária técnica exercida pela Departamento de Micro, Pequenas e Médias Empresas (BRASIL, 2004a). Sua composição enfatiza a interseção das políticas direcionadas para clusters com diversos setores econômicos e governamentais. Além de revelar a ênfase dada às micro, pequenas e médias empresas por meio da secretária técnica e da forte atuação do Sebrae na implementação das políticas (GARONE et al., 2015). Os Núcleos Estaduais (NEs) de apoio aos APLs facilitam a comunicação entre o GTP-APL e os arranjos produtivos em nível local e envolvem instituições estaduais no estímulo e comprometimento para o desenvolvimento e articulações do arranjo.

\subsubsection{APL de confecções do agreste}

No último levantamento realizado em 2015 foram reconhecidos 677 APLs em todo o Brasil, distribuídos em 59 setores produtivos, sendo o setor de vestuário (englobando têxtil, confecção e calçados) o terceiro maior (MDIC, 2018). O APL de Confecções do Agreste de Pernambuco, também conhecido como polo de confecções, é composto por empresas localizadas em dez cidades do interior pernambucano. Caruaru, Santa Cruz do Capibaribe e Toritama formam o núcleo principal do APL que apresenta elevada concentração espacial de unidades produtivas e trabalhadores. Elas apresentam o IDH maior do que o a média do estado de Pernambuco. É considerado um APL tradicional especializado em fabricação, predominantemente composto por micro e pequenas empresas concorrentes com intensa utilização de mão-de-obra especializada em: moda feminina, jeans, street, moda íntima, sportwear, moda praia, roupas profissionais e moda festa. Segundo os dados mais recentes disponíveis, estima-se que há cerca de 18.803 empresas empregando cerca de 107.177 pessoas em todo o APL. Em 2011, o faturamento total da indústria de confecções nessa região foi de aproximadamente R\$ 1 bilhão (PROAPL-PE, 2013; SEBRAE, 2013).

Grande parte dos empresários do APL atuam de forma passiva em relação a sua posição no mercado, no sentido de não fornecer um produto que passou por um processo criativo e 
possui uma marca que identifique sua origem e individualidade. Eles demonstram satisfação com sua atual posição e não se preocupam em melhorar seus produtos, já que acreditam que não faltarão clientes. Entretanto, o mercado se mostra cada vez mais competitivo. Os principais competidores externos do APL de confecções do agreste são a os países asiáticos, e em especial a China. O Brasil importa cada vez mais produtos de vestuário desses locais com o passar dos anos. Internamente, o APL compete com no mínimo 19 concentrações geográficas de indústria de confecções de alta relevância, espalhadas pelo Brasil. Além de aproximadamente outras 57 concentrações consideradas relativamente menos relevantes (PROAPL-PE, 2013; SEBRAE, 2013).

O estudo desenvolvido pela PROAPL-PE (2013) organizou as declarações dos empresários do APL em uma análise SWOT que permitiu observar algumas características.

Tabela 2: Análise SWOT do APL de Confecções do Agreste

\begin{tabular}{|c|c|}
\hline $\begin{array}{l}\text { Forças } \\
\text { 1. Preço baixo do produto } \\
\text { 2. Baixo custo da mão de obra } \\
\text { 3. Capacidade empreendedora } \\
\text { 4. Adaptabilidade à mudança } \\
\text { 5. "Pessoas bravas, guerreiras" } \\
\text { 6. Formas de negociar adotadas } \\
\text { 7. Capacidade produtiva das pessoas e } \\
\text { máquinas } \\
\text { 8. Localização do Polo } \\
\text { 9. Radiação do Polo } \\
\text { 10. Alta concentração de empresas em } \\
\text { pequeno espaço }\end{array}$ & $\begin{array}{l}\text { Oportunidades } \\
\text { 1. Formalização } \\
\text { 2. Conquista de mercados no Sul e Sudeste }\end{array}$ \\
\hline $\begin{array}{l}\text { Fraquezas } \\
\text { 1. Má formação da mão de obra } \\
\text { 2. Escassez de trabalhadores, especialmente, } \\
\text { qualificados } \\
\text { 3. Falta de profissionalismo } \\
\text { 4. Predominância de empresas informais; }\end{array}$ & $\begin{array}{l}\text { Ameaças } \\
\text { 1. Concorrência de fora (produtos chineses, } \\
\text { sobretudo) } \\
\text { 2. Informalidade, especialmente, nas } \\
\text { relações de trabalho } \\
\text { 3. Aumento da consciência ambiental }\end{array}$ \\
\hline
\end{tabular}




\begin{tabular}{|c|c|}
\hline 5. Carga tributária excessiva ; & 4. Carga tributária alta para os formais \\
\hline 6. Questão ambiental & 5. Especulação imobiliária \\
\hline 7. Imagem da região, como produtora de & 6. Guerra fiscal (ICMS de confecções \\
\hline bens de baixa qualidade & reduzido em vários estados, incluindo São \\
\hline 8. Falta de segurança & Paulo e Rio de Janeiro) \\
\hline
\end{tabular}

Fonte: Produzido pelo autor baseado em (PROAPL-PE, 2013).

Claramente o APL tem como força o preço baixo de seus produtos, no entanto uma outra face desta força é encarada como fraqueza já que a região é vista como produtora de bens de baixa qualidade e com necessidade de mão de obra qualificada. No geral, a vantagem competitiva do APL está baseada em fatores considerados básico e de fácil superação pelos concorrentes, como mão de obra pouco especializada e/ou barata, tecnologia acessível e incorporada a bens de baixo custo e liberalidade fiscal, o que não está alinhado com fatores que garantem a competividade afirmados por autores de renome como Porter (PROAPL-PE, 2013; SEBRAE, 2013).

O desenvolvimento do APL e as respostas relativas aos pontos fracos e ameaças são resultado da interação entre representantes dos empresários, do poder público e de outras instituições de apoio ao setor, como SEBRAE, SENAI, SENAC, e instituições acadêmicas públicas e privadas. $\mathrm{O}$ apoio do poder público veio inicialmente da infraestrutura básica, como rodovias e fornecimento de água, que permitiu condições básicas para o surgimento do APL (PROAPL-PE, 2013). Iniciativas mais modernas e direcionadas para as atividades econômicas do APL estão sendo desenvolvidas. Algumas ações se destacam como os eventos Rodada de Negócio realizada em Caruaru, Estilo Moda Pernambuco em Santa Cruz e Festival do Jeans em Toritama. Outras iniciativas foram o fornecimento de cursos relacionados à moda e administração por novas e antigas instituições de ensino superior e profissionalizantes nas cidades que compõem o APL.

O estudo do PROAPL-PE (2013) junto com o estudo do SEBRAE (2013) fornecem uma perspectiva mais completa sobre o APL de confecções do agreste, a partir da classificação sobre o desenvolvimento dos APLs fornecida por Cardoso (2014) é possível realizar o cruzamento de características importantes. Nele não constam informações sobre governança e/ou liderança; A integração entre os atores se restringe à aquela proporcionada pela proximidade geográfica; $\mathrm{O}$ suporte financeiro é existente, no entanto, a informalidade não permite que beneficie grande parte dos empreendimentos; A Gestão do desenvolvimento do APL começou a ser mais organizada a partir do estudo do PROAPL-PE (2013); Inovação e tecnologia são 
reconhecidamente pontos fracos do APL que apesar de tornarem os produtos mais baratos fazem com que esses produtos não evoluam e consigam alcançar outros mercados; Contribuição para o desenvolvimento local é baseada em benefícios localizados e menos intensos; A competitividade é baseada em fatores de fácil execução pelos concorrentes.

O estudo mais recente que não aborda especificamente o APL do agreste de Pernambuco, mas trás dados mais atuais foi desenvolvido pelo IEMI (2017).

\subsection{Seleção de portfólio de projetos e multicritério}

Problemas multicritério são caracterizados principalmente pela existência de duas ou mais alternativas e pelo desejo de alcançar um conjunto de objetivos, que geralmente são conflitantes entre si. Este conflito gera o que é chamado de tradeoff que é a incompatibilidade entre os objetivos que não permite que o máximo possível de todos sejam alcançados, de modo que é necessário sacrificar o nível de alcance de determinados objetivos em detrimento de alcançar outros (KEENEY E RAIFFA, 1976).

Implicitamente, o problema multicritério envolve objetivos que não podem ser representados por uma única métrica. Sendo assim, há a necessidade de utilização de métodos multicritério e, consequentemente, da incorporação das preferências de um decisor para agregar os diversos objetivos de modo que, as alternativas possam ser comparadas. Diversas recomendações podem surgir da comparação das alternativas, as problemáticas classificam um problema considerando o resultado que o decisor deseja obter da comparação entre elas. Dentre as problemáticas, está a de portfólio que realiza a seleção de um subconjunto de que atenda aos objetivos e se enquadre nas restrições impostas, que podem ser de orçamento ou outros recursos (DE ALMEIDA, 2013). Segundo Fernandez et al. (2013), a seleção de portfólio é caracterizada pela comparação entre portfólios viáveis ao invés da comparação entre os projetos de forma isolada. Desse modo, é possível que o melhor portfólio não tenha em sua composição o melhor projeto do conjunto avaliado. Isto porque, projetos que não são tão bons de forma isolada podem se tornar melhores quando avaliados em conjunto, superando inclusive o melhor projeto do conjunto.

A seleção de portfólio envolve projetos que disputam entre si por recursos, uma vez que existe a preocupação de alocar os recursos para apoiar a realização destes projetos, sem ultrapassar a disponibilidade ou infringir outras restrições e requisitos organizacionais (TAVANA, 2015). Como este processo é desenvolvido para alcançar os objetivos estabelecidos (DE ALMEIDA, 2013), as restrições de recursos para investimento tornam importante a seleção dos investimentos adequados para alcança-los (SCHMIEDEBERG, 2010). 
Fernandez et al. (2013) apresenta três abordagens diferentes para comparação a nível de portfólio: A primeira usa o valor do portfólio obtido da agregação do valor dos projetos que o compõem; A segunda considera o portfólio como uma maneira de transformar o atual estado do objeto social considerado dentro de um estado diferente; E a terceira trata da otimização de portfólio multi-objetivo que considera que cada projeto produz um determinado efeito no objeto social. A primeira abordagem, utilizada neste estudo, exige que os valores dos projetos estejam em escala razão para evitar recomendações enviesadas (DE ALMEIDA et al., 2014).

Segundo De Almeida et al. (2014), a seleção de portfólio possui duas abordagens, uma que gera e avalia todos os portfólios viáveis, exigindo muito esforço computacional, e outra que avalia os itens e constrói o portfólio ótimo. A segunda abordagem, considerada neste estudo, usa técnicas de programação matemática para construir os portfólios e exige menor esforço, já que lida com uma menor quantidade de itens para avaliação e as consequências são mais facilmente avaliadas (DE ALMEIDA et al., 2014). Os valores globais dos projetos são utilizados como coeficientes da função objetivo de um problema de programação linear binário.

A formulação geral da seleção de projetos é baseada na estrutura do problema da mochila e busca maximizar o valor do portfólio respeitando as restrições de recursos, como pode ser visualizado na equação 2.1 :

$$
\sum_{i=1}^{n} z_{i} v\left(x_{i}\right)
$$

Sujeito a:

$$
\sum_{i=1}^{n} r_{i q} \leq R_{q} \forall q
$$

Onde $\mathrm{v}\left(\mathrm{x}_{\mathrm{i}}\right)$ representa o valor da alternativa i e $\mathrm{z}_{\mathrm{i}}$ é a variável de decisão que representa se o projeto foi ou não inserido no portfólio, de forma que $z_{i}$ assume os valores de 0 , para a os projetos não inseridos e 1 para os projetos inseridos. A função objetivo para portfólio está sujeita às restrições de recursos, $r_{i q}$ são os recursos consumidos pelo projeto i na restrição q e $\mathrm{R}_{\mathrm{q}}$ é a quantidade disponível do recurso. Neste modelo é considerada apenas a restrição referente aos recursos financeiros.

Problemas de seleção de portfólio podem ser classificados em estáticos ou dinâmicos. Os problemas dinâmicos são compostos pelo grupo dos projetos ativos, que estão em execução, e o grupo dos projetos candidatos. Ambos são avaliados ao mesmo tempo, afim de decidir dentre eles quais serão ou continuarão a ser implementados. Nos problemas estáticos, todos os 
projetos são candidatos. O estático é característico de organizações com orçamento dedicado e que realizam chamadas de propostas de projetos, com intuito de realizar a seleção uma vez por período (EILAT et al., 2006).

Portfólio é um termo muito genérico, utilizado para um conjunto de um certo tipo de elementos, que pode ser aplicado a diversos contextos. Segundo Arratia et al (2016), a gestão de portfólio tem sua origem na área financeira nos anos de 1950, relacionado a orçamento de capital e ao mercado de ações. Nesta época foi produzida a obra de Markovitz (1952), denominado "Seleção de portfólio", considerado um marco na teoria moderna de portfólio. No entanto a abordagem utilizada por Markowitz é mais restrita à área financeira e suas características a tornam inadequada à abordagem de seleção de portfólio de projetos utilizada neste estudo. Ainda de acordo com Arratia et al (2016), a partir da década de 70 a gestão de portfólio evoluiu em direção ao planejamento e nos anos 2000 em direção a seleção de produto e alocação de recursos.

Segundo Danesh et al (2018), as situações que enfrentam a dificuldade de tomada de decisão de portfólio são: seleção de projetos, priorização e balanceamento de recursos (como custo e tempo) e gestão financeira. Segundo De Almeida et al (2014), problemas com estrutura de portfólio estão em outras áreas, além da área financeira, como em: novos produtos (JUGEND et al, 2016; ), pesquisa e desenvolvimento (JEFFERY e LELIVELD, 2004; MAVROTAS et al. 2006), TI (KUMAR et al, 2008; NEUBAUER e STUMMER, 2010) e no setor público (FERNANDEZ et al, 2013; HAKANEN et al, 2011).

Alguns surveys disponíveis fornecem uma perspectiva ampla sobre a tomada de decisão relacionada com recursos financeiros, dentre as categorias abordadas estão a alocação de recursos, planejamento financeiro e a otimização de portfólio, para os setores público e privado. Zopounidis et al. (1997) abordam a gestão financeira a partir do uso de sistemas de apoio à decisão baseados em conhecimento. Zanakis et al. (1995) abordam a alocação de recursos nos setores públicos e de serviços. Steuer e Na (2003), apresentam um estudo bibliográfico categorizado sobre técnicas de multicritério aplicadas em questões financeiras, abrangendo a literatura produzida de 1955 a 2001. Zopounidis et al. (2015), fornece um survey atualizado sobre multicritério aplicado ao campo financeiro, trata-se de uma extensão do survey de Steuer e Na, abrangendo os anos de 2002 à 2014. Um survey mais recente é o produzido por Danesh (2018), que trata da seleção de portfólio por meio de métodos multicritério.

Questões relacionadas à alocação de recursos públicos são apresentadas, mas não foi identificado nenhum estudo relacionado com iniciativas direcionadas para clusters nestes surveys, nem em outros estudos externos aos surveys citados, com exceção dos estudos 
desenvolvidos por Lima e Almeida (2018a; 2018b) que fazem parte dos resultados iniciais desta dissertação. Em Lima e Almeida (2018a) é apresentada a aplicação da abordagem multicritério junto com análise de sensibilidade para a seleção de projetos no APL de confecções de Pernambuco. E em Lima e Almeida (2018b) é realizada a seleção de projetos acrescentando a aplicação da análise da mínima variação.

A construção de portfólio que envolve alocação de recursos financeiros necessita de diversificação para evitar riscos inerentes e para refletir corretamente os diversos objetivos envolvidos na estratégia organizacional (EILAT, 2006). Para compor uma formulação mais geral capaz de lidar com diversos cenários de alocação de recursos públicos são considerados três fatores: atributos adequados que reflitam os interesses sociais, interação e sinergia entre os projetos e distribuição dos projetos dentro de um horizonte de planejamento (FERNANDEZ et. al, 2013).

O apoio governamental aos APLs pode surgir por meio de projetos (OECD, 2010). Para Zanakis et al. (1995) a seleção e financiamento de projetos é um problema vivenciado por todas as empresas em algum momento de sua existência. Em organizações não lucrativas a subjetividade dos critérios de seleção e o envolvimento de diversos atores de diferentes níveis hierárquicos tornam a seleção mais complexa e consensual. Segundo Fernandez et al (2009), projetos públicos são caracterizados por: primeiramente, possuírem efeitos indiretos e difíceis de quantificar, com efeitos provavelmente perceptíveis a longo prazo, podendo ser lucrativos; em segundo, trazem benefícios intangíveis de uma perspectiva social mais ampla que vai além da contribuição econômica para o bem estar social; Por último, considera imparcialmente os impactos centrais e condições sociais dos indivíduos beneficiados.

As áreas de aplicação da abordagem multicritério na seleção de investimentos públicos são diversificadas: Pujadas et al. (2017) propõem a avaliação para seleção ou priorização de projetos de investimento públicos heterogêneos para o planejamento urbano. Já Walczaka e Rutkowska (2017) abordam a decisão multicritério em um grupo formado por cidadãos para alocar recursos públicos entre as propostas de projetos. Medaglia (2008) propõe uma seleção de projetos de uma companhia de água e esgoto. Çağlar e Güre (2017) desenvolveram um modelo que considera o cancelamento de projetos, em processo de seleção de portfólio de projetos públicos para $\mathrm{R} \& \mathrm{D}$ baseado em chamada de projetos, objetivando aprimorar a utilização do orçamento que vai sendo liberado devido os cancelamentos. Fernandez et al. (2013) propõem um modelo para alocação de recursos públicos para programas, projetos ou políticas, considerando a concorrência pelos recursos, e possibilitando decisão em grupo ou individual. 
É conveniente priorizar projetos e construir portfólios de acordo com alguns princípios, como maximizar benefícios sociais, que estão alinhados com critérios normativos utilizados em políticas públicas e ideologia governamental, no entanto a avaliação e a comparação de impactos sociais são os maiores obstáculos para a definição de "melhor portfólio de projeto público". A análise de custo benefício é a abordagem mais utilizada para mensurar impacto social dos projetos, ela assume que as consequências sejam convertidas em unidades monetárias, gerando ganhos quando são positivas e perdas quando são negativas. $\mathrm{O}$ valor de um projeto pode ser considerado como uma estimativa do impacto social do projeto, ele é calculado, de forma simplificada, pela distribuição temporal dos custos e ganho. O valor e impacto do portfólio é composto pela agregação dos valores de todos os projetos que o compõe (FERNANDEZ et al, 2009).

A limitação desta abordagem se dá pela dificuldade de gerenciar multidimensionalidade, especialmente com necessidade de avaliação de elementos intangíveis. Isto porque algumas questões como vidas humanas ou danos ambientais não possuem valor definido no mercado ou não é ético estabelecer um valor (FERNANDEZ et al, 2009; BERIA et al, 2012; ELVIK, 2001). Cafiso et al (2002) enfatiza que os elementos quantificáveis, apesar da dificuldade de atribuição de valores, não são os únicos a serem considerados pelo decisor. Outros elementos que não são diretamente quantificáveis também são importantes para tomada de decisão.

Já a análise multicritério, através de suas abordagens de estruturação de preferências, explora o julgamento de valores do decisor e lida com a complexidade inerente a decisões reais. Sendo assim, é considerada uma boa opção para superar as limitações da análise de custobenefício, pois é capaz de manusear intangibilidade, preferências ambíguas e condições de veto (FERNANDEZ et al, 2009). A estruturação de um problema a partir da análise multicritério realiza o desmembramento do problema em suas partes constituintes no intuito de obter compreensão, buscando examinar as alternativas diante das prioridades conflitantes. As diversas metodologias de análise multicritério desenvolvidas ao longo do tempo auxiliam os decisores a descobrirem a solução mais desejável para os problemas (CAFISO et al, 2002).

\subsection{Modelo aditivo e SMARTS}

Diversas metodologias multicritério foram desenvolvidas ao longo do tempo objetivando o fornecimento de um framework sistemático que considera a natureza multidimensional de problemas reais (PUJADAS et al, 2017). A escolha de um método para 
realizar a avaliação multicritério deve ser baseada na natureza e contexto do problema e no objetivo da avaliação, implicitamente relacionado com a problemática. Outros fatores apontados que influenciam a escolha do método são: o tempo disponível para o processo de decisão, o esforço requerido, as informações disponíveis, o grau de precisão da recomendação, a estrutura de preferências e racionalidade do decisor, a necessidade de justificar a decisão e o desejo por minimizar conflitos (CAFISO et al, 2002; DE ALMEIDA, 2013). Problemas envolvendo seleção de projetos requererem avaliações de acordo com as suas necessidades, e consequentemente o uso de métodos a elas adequados, como pode ser verificado em Hsieh et al (2004), o qual aplicou a problemática de escolha para seleção de projeto, já García-Melón et al (2015) realizou a ordenação dos projetos para priorização.

De Almeida (2013) afirma que há poucos estudos desenvolvidos com o objetivo de direcionar/auxiliar a escolha de métodos multicritério. Os métodos possuem singularidades que os tornam tão específicos que não há sentido em comparar seus resultados. Algumas das características que os tornam tão singulares são: a maneira de realizar a parametrização, o modo de uso dos pesos e as estruturas axiomáticas ou hipóteses assumidas. Roy e Slowinski (2013) apresentam um dos poucos estudos voltados para orientar a escolha do método multicritério. Os autores propõem questões, que consideram aspectos do processo de decisão e a interação entre decisor e analista, para auxiliar na escolha do método multicritério adequado ao contexto de decisão.

Para Roy (1996), os métodos de critério único de síntese agregam critérios dentro de um único critério mais complexo que é composto por informações que não estão diretamente relacionadas com as consequências. Os critérios servem para estabelecer julgamentos de preferências relacionados a decisão. No entanto, esta é uma abordagem diferente da análise de critério único, na qual as consequências são reduzidas a unidades comuns por meio de um procedimento que envolve arbitrariedade e é influenciado por um sistema de valor pessoal. Assim, cada alternativa é avaliada em um eixo de significância único que pode ter um significado relativamente concreto, como: beneficio, lucratividade, ganho ou utilidade para o decisor. A análise de critério único é considerada uma simplificação que funciona bem para problemas simples, mas para problemas um pouco mais complexos representará apenas um menor esforço, além disso pode conduzir ao viés de eixos e exclusão de aspectos que são difíceis de mensurar. Além disso, a quantificação destes aspectos está relacionada a estabelecer valores particulares/únicos para o decisor e que refletem diretamente seu sistema de valores. Roy (1996) também apresenta as mais comuns funções de agregação aditiva que são utilizadas de acordo com diferentes situações. 
Segundo De Almeida (2013), o modelo aditivo se refere ao conjunto de métodos que utiliza o procedimento de agregação aditiva dos critérios, nos quais a função valor de cada alternativa é composta pela agregação das funções valor de cada critério através das informações de preferência do decisor. Ou seja, o valor global de cada alternativa, baseado nas consequências e constantes de escala, permite a comparação entre elas e a escolha de acordo com os maiores valores globais. A função valor de cada alternativa é obtido de acordo com a equação 2.2 .

$$
\mathrm{v}\left(x_{i}\right)=\sum_{j=1}^{m} k_{j} v_{j}\left(x_{i j}\right)
$$

onde

$$
\sum_{j=1}^{m} k_{j}=1
$$

No qual, $\mathrm{k}_{\mathrm{j}}$ é a constante de escala do critério $\mathrm{j}$, $\mathrm{v}_{\mathrm{j}}$ é a função valor do critério $\mathrm{j}$ e $\mathrm{x}_{\mathrm{ij}}$ é a consequência do projeto i no critério j.

Apesar do modelo aditivo ser considerado simples, muitos equívocos ocorrem devido à falta de conhecimento sobre a correta aplicação do mesmo. Os equívocos mais comuns estão relacionados com três características deste procedimento: a natureza compensatória, o conceito de constantes de escala (DE ALMEIDA, 2013) e especificamente para seleção multicritério de portfólio há três problemas causados pela utilização dos pesos em contexto de escala intervalar ao invés do escala razão, os problemas estão relacionadas com a quantidade de itens considerados no portfólio, com as consequências de não incluir um item e com a consistência de diferentes sequências de agregação (DE ALMEIDA et al., 2014).

Segundo Keeney e Raiffa (1976), a função valor representa a estrutura de preferências do decisor e associa um número real, que são o desempenho da alternativa, a cada ponto em um espaço de avaliação, havendo uma sútil interação entre formular a estrutura de preferência e encontrar a função valor.

A relação entre estrutura de preferência e função valor está relacionado com a compensação entre os critérios. De forma que no modelo de agregação aditiva é assumida a racionalidade compensatória para solucionar o problema, a qual, de acordo com De Almeida (2013), corresponde ao decisor admitir que um menor desempenho em um dos critérios é compensado por um desempenho melhor em outro critério. Alternativamente, uma racionalidade não compensatória não admite a compensação entre desempenhos. 
O modelo aditivo possui métodos para elicitação das constantes de escala que se diferenciam, principalmente, pelo modo como ocorre a modelagem de preferência do decisor para elicitar as constantes de escala (DE ALMEIDA, 2013). Dentre eles os principais são: o Tradeoff (KEENEY e RAIFFA, 1976) que possui uma estrutura axiomática mais rigorosa e robusta, implicando em maior esforço cognitivo pelo decisor, que pode conduzir a maiores erros nas declarações do decisor, o Flexible and Interactive Tradeoff - FITradeoff, (DE ALMEIDA et al, 2016) que usa a mesma estrutura axiomática do tradeoff, mas reduz o esforço cognitivo ao não exigir a informação completa, o Analytic Hierarchy Process-AHP possui um procedimento de comparação par a par das alternativas para cada critério que também realiza comparação entre os critérios (SAATY, 1980), também há o Simple Multi Attribute Rating Technique que subdivide-se em dois métodos aproximativos para a medida de utilidade multiatributo, o SMARTS que usa o procedimento de swing e o SMARTER que explora a ordenação dos critérios (EDWARDS E BARRON, 1994).

O método SMARTS realiza a obtenção dos pesos por meio do swing e representa uma aproximação realizada pelo próprio decisor. É um procedimento que utiliza função intracritério linear e é caracterizado por possuir uma estrutura axiomática mais simples que conduz a menos erros devido a um menor esforço cognitivo o que também simplifica a elicitação das constantes de escala reduzindo o tempo de aplicação, baseado na perspectiva de estratégia de aproximação heroica que busca ser mais simples que o julgamento de indiferenças entre pares de opções hipotéticas que é exigido pelo tradeoff. Para isto se baseia em julgamentos mais simples que utilizam avaliações mais diretas e mais próximas de valores desejados, sendo mais fácil e menos provável de produzir erros de elicitação (EDWARDS E BARRON, 1994).

O SMARTS (EDWARDS E BARRON, 1994) é composto por 8 passos, que guiam toda a sua elicitação iniciando na estruturação do problema até obter as constantes de escala. Os passos são apresentados abaixo:

1) Identificar os decisores e os objetivos envolvidos na resolução do problema;

2) Obtenção dos atributos que representam os objetivos e são capazes de mensurá-los;

3) Especificar as alternativas que serão avaliadas;

4) Construir a matriz de consequências, contendo o desempenho de cada alternativa para cada um dos critérios avaliados;

5) Eliminar as alternativas dominadas em termos de possuir um desempenho que claramente é superado por uma ou mais alternativas. No entanto, para a problemática de portfólio esta etapa deve ser desconsiderada; 
6) Construir a matriz de avaliação com obtenção da função valor e, consequentemente, conversão das consequências para uma mesma escala o que possibilita a agregação aditiva, a qual é uma medida de valor ou atratividade de um resultado para o decisor.

Os passos 1 ao 6, basicamente, lidam com a estruturação do problema para que possa ser realizada a avaliação multicritério. A elicitação dos pesos é realizada por meio do procedimento de swing que se refere a operações realizadas para conversão da pontuação de avaliação, geralmente utilizando uma escala de 0 a 100. O procedimento é abordado nos passos 7 e 8 a seguir.

7) Ordenação dos critérios: Corresponde ao passo 1 do swing. Pede-se para o decisor considerar uma alternativa hipotética a qual possui pontuação zero em todas as dimensões/critérios de avaliação, ou seja, esta alternativa possui o pior desempenho. Também considere que o decisor tem a possibilidade de escolher apenas um dos critérios para que nele a alternativa atinja seu melhor valor e pergunta-se ao decisor qual seria este critério. Realiza-se este procedimento para todos os critérios, excluindo os critérios escolhidas da rodada seguinte, ordenando-os em termos da atratividade ou importância para o decisor.

8) Obtenção dos pesos: Pode ser realizado de duas maneiras que são explanados a seguir: (Escolhidos de acordo com o desejado)

a. Baseado em estimar a magnitude: $O$ critério na primeira posição da ordenação recebe os 100 pontos e um outro critério que não é importante para o decisor recebe 0 pontos, este critério também pode ser hipotético. Então pede-se para o decisor definir qual a pontuação do segundo critério mais importante e assim sucessivamente para todos os critérios. Por fim, realiza-se a normalização e os pesos são obtidos.

b. Baseado em julgamentos de indiferença: Compara-se para qual valor de um critério x o decisor seria indiferente ao critério y que possui pontuação 100 . O julgamento é uma avaliação direta da relação dos pesos avaliados e é realizado para todos os pares de critérios na ordenação.

A maioria dos respondentes têm preferência e demonstram mais confiança no procedimento baseado em estimar a magnitude, os autores afirmam isto possivelmente é motivado por ser considerado um procedimento mais fácil de realizar e também de explicar. A diferença do SMARTS para o SMARTER é uma modificação no passo 8, no SMARTER obtêm-se os pesos a partir da aplicação do procedimento de Rank order centroid - ROC à ordenação, de modo que exige menos esforço e interação com o decisor do que o que ocorre no 
SMARTS, já que não exige outras informações de preferência do decisor além da ordenação dos critérios. Por fim, o passo 9 do método SMARTS corresponde a realização da agregação aditiva e tomada de decisão.

O modelo de agregação aditivo geralmente considera, devido às características da maior parte de seus procedimentos de elicitação, constantes de escala obtidas em contexto de escala intervalar, já que realiza a normalização das consequências por meio do uso de escala intervalar. O uso de normalização intervalar, no entanto, para a problemática de portfólio causa três efeitos indesejados que prejudicam a avaliação. De Almeida et al (2014) explora os requisitos necessários sobre a escala para que seja realizada uma agregação consistente de itens de um portfólio. Os três problemas causados são chamados de problema do tamanho do portfólio, problema de baseline e problema de consistência de diferentes sequências de agregação.

A escala intervalar para a seleção de portfólio faz com que o modelo forneça recomendações enviesadas para o problema, dependendo da quantidade de itens que compõem o portfólio, quanto maior a quantidade de projetos no portfólio mais ele será penalizado. E como os portfólios podem ser compostos por qualquer quantidade de projetos que respeite as restrições, os portfólios menores, em termos de quantidade, são menos penalizados enquanto os maiores sofrem penalização maior, fornecendo assim uma avaliação inconsistente. $\mathrm{O}$ problema de baseline implica que a não realização de um projeto tem utilidade zero assim com o resultado do pior projeto, mas esta condição nem sempre está correta. Então o uso da escala razão faz com que a utilidade zero seja atribuído apenas aos projetos não realizados, já que implementar os piores projetos podem trazer resultados piores do que não implementá-los. Assim, o resultado de não incluir um item é o mesmo para todos os itens. O problema de consistência de diferentes sequências de agregação consiste em diferentes formas de agregação na avaliação para selecionar portfólio, de forma que isto influencia o resultado obtido. Mas utilizar a escala razão faz com que independente da forma de agregação se obtenha o mesmo resultado. Estes problemas são solucionados pelo uso da escala razão, as constantes de escala se obtidas em contexto de elicitação intervalar são ajustadas para obter a avaliação equivalente na escala razão (DE ALMEIDA et al, 2014).

O método PROMETHEE V, desenvolvido especificamente para a problemática de portfólio, também possui um problema de escala. O qual impede que elementos com fluxo negativo, mesmo que agregando valor ao portfólio, sejam inseridos. Para superar o problema Mavrotas et al. (2006) propõe a translação na escala para tornar todos os fluxos positivos. No entanto, Almeida e Vetschera (2012) apontam que essa translação teria o efeito indesejado de qualquer projeto com fluxo zero nunca ser selecionado pelos algoritmos de programação linear. 
Além disso ainda há o problema de escala gerado pela translação, que é semelhante ao do modelo aditivo, interferindo no valor do portfólio de acordo com o número de projetos (VETSCHERA e DE ALMEIDA, 2012; DE ALMEIDA e VETSCHERA, 2012).

Por fim, é importante observar que a avaliação multicritério está envolvida por parâmetros que contêm incerteza proveniente de diversas fontes. E o tratamento desta incerteza é fundamental para fornecer uma recomendação mais confiável ao decisor. Sendo assim, de acordo com De Almeida (2013), a análise de sensibilidade verifica o impacto que variações em inputs e parâmetros causam na solução recomendada. Ela pode revelar pontos no modelo que são sensíveis às mudanças de valores resultando em mudança na recomendação, como por exemplo revelar a robustez da recomendação em relação aos pesos. A análise de sensibilidade por meio da Simulação Monte Carlo consiste em analisar a frequência com que os projetos aparecem nos portfólios gerados pelos dados aleatórios, simulando as diversas situações que podem ocorrer causadas pela variação nos parâmetros e que influenciam a seleção (DE ALMEIDA, 2013).

\subsection{Análise da variação com otimização inversa em problemas multicritério}

Na prática os parâmetros necessários para encontrar uma solução ótima para um problema são estimados, baseados muitas vezes em aproximações grosseiras, causando uma incerteza em torno de seus valores. Desta forma, a obtenção da solução ótima não é suficiente para fornecer a segurança necessária para o decisor (HEUBERGER, 2004; HIFI e MHALLA, 2013). Hyde et al (2005) afirma que há diversas fontes de incerteza na aplicação de metodologia multicritério, incluindo a escolha do método, a elicitação dos pesos dos critérios e a atribuição do desempenho das alternativas para cada critério.

O atual trabalho associa as abordagens de otimização inversa combinatória e de multicritério, que possuem o termo "peso" com significados completamente diferentes. Com o intuito de evitar equívocos é necessário esclarecer que o peso no problema da mochila está relacionado com a capacidade suportada pela mochila e com a capacidade que será exigido por cada item que for inserido nela. Analogamente em um problema real, o peso representa o custo de uma alternativa e a capacidade de arcar com os custos de um conjunto de alternativas, ou seja, um orçamento. Já no contexto de multicritério, o peso é a importância relativa entre os critérios de acordo com as preferências do decisor. Sendo assim, foi optado por substituir a o termo "peso" no contexto do problema da mochila pelo termo "custo", o qual segue a mesma 
lógica de disponibilidade da mochila e necessidade dos itens. E o termo "peso" segue associados ao contexto de multicritério.

Wolters e Mareschal (1995) apresentam três tipos de análise de sensibilidade que determinam:

- A sensibilidade da ordenação pra mudanças específicas em certo critério;

- A influência que mudanças em certos critérios geram no valor de uma determinada alternativa;

- A mínima modificação nos pesos para fazer uma alternativa ficar no topo da ordenação;

Segundo Heuberger (2004), a otimização inversa consiste em encontrar os valores dos parâmetros que tornam ótima uma das soluções conhecidas que não eram ótimas inicialmente, variando-os o mínimo possível das estimativas obtidas. Mais especificamente, um problema de otimização combinatória inverso pode buscar encontrar o mínimo ajuste na função custo para que uma determinada solução viável de um problema de otimização combinatória se torne ótima, como foi analisado por Ahuja e Orlin, (2001), Guan et al (2015), Guan et al (2018) e Gassner (2010), Li et al (2016) e Li et al (2018). O ajuste também pode ser realizado para os ganhos obtidos com a combinação, como desenvolvido por Roland et al (2013) e Roland et al (2016). Ou ainda para os pesos ou constantes de escala da avaliação multicritério, como no caso de Doan e Smet (2018), Wolters e Mareschal (1995), Sowlati et al (2010), Ringuest (1997) e Hyde et al (2005), Insua e French (1991) e Barron e Schmidt (1987). No presente estudo foi considerado, mais especificamente, a avaliação por meio da otimização inversa sobre as constantes de escala, já que se trata de uma metodologia compensatória multicritério. Mais informação sobre variações desse problema e métodos para resolução podem ser encontradas em HEUBERGER (2004).

Mousseau et al (2018) afirma que problemas de otimização inversa e problemas inversos multicritério não são abordagens novas na literatura. No entanto, foi constatada a dificuldade de rastrear estes estudos, devido à falta de padronização nos termos utilizados. O autor classifica os problemas de otimização inversa encontrados na literatura em três grupos:

- O primeiro grupo é relacionado com o uso do data envelopment analysis - DEA;

- O segundo grupo está relacionado com problemas de classificação inverso no contexto de aprendizado de máquina;

- O terceiro grupo está relacionado com problemas de otimização inversa em geral; 
Mousseau et al (2018) não estabelece um grupo para os problemas de otimização abordados neste estudo, que são os relacionados a análise dos parâmetros de importância relativa dos problemas multicritério.

Hifi e Mhalla (2013) afirmam que o decisor necessita saber a sensibilidade da solução quanto a variações, especialmente nos parâmetros de ganho e custo em problemas de otimização combinatória, como é o caso do problema da mochila que possui a mesma estrutura do problema de seleção de portfólios. No entanto, em problemas multicritério as constantes de escala são parâmetros tão importantes quanto os ganhos e os custos do problema de otimização combinatória. A maioria dos métodos requer a definição de pesos quantitativos para os critérios, a dificuldade em obtê-los está relacionada com a não precisão em defini-los e com a relação indireta com os valores fornecidos pelo decisor. São parâmetros que não possuem claro significado econômico e que o nível de influência no resultado depende do método utilizado. Os pesos permitem modelar os problemas de decisão de modo mais próximo da realidade. No entanto, é necessária uma boa estimativa dos verdadeiros valores destes parâmetros e também manuseio cuidadoso dos mesmos (MARESCHAL, 1988).

As constantes de escala envolvem incerteza em sua elicitação seja pelo método utilizado, por simplificações ao longo do processo de decisão ou, simplesmente, pela imprecisão inerente a questões de informação preferencial. Sendo assim, a realização da otimização inversa sobre as constantes de escala é um recurso adicional e desejável para aumentar a confiança de problemas de otimização combinatória que utilizam multicritério. Segundo Mareschal (1988) a verificação do quanto a solução é dependente e sensível a estas estimativas de parâmetros quase sempre se resume a uma grosseira análise de sensibilidade que, geralmente, é um procedimento incompleto e insatisfatório, podendo facilmente ser caro e demorado.

Hyde et al (2005) considera que os procedimentos de análise de sensibilidade em multicritério são, geralmente, incompletos e insatisfatórios, resultando em modificações arbitrárias e enviesadas. $\mathrm{O}$ autor destaca as principais desvantagens das técnicas de análise de sensibilidade desenvolvidas até o momento são:

- Variação de um ou mais critérios enquanto os outros critérios permanecem fixos, por isso importantes efeitos combinados de mudanças não podem ser verificados;

- Desenvolvimento específico para determinada metodologia multicritério, então o uso de diversos métodos multicritério implica na necessidade de utilização das análises de sensibilidade adequadas a cada um deles; 
- Não identificam os critérios que são mais críticos para determinar a ordenação das alternativas;

As áreas que utilizam a otimização inversa apresentam, em comum, a característica de possuírem parâmetros que são difíceis de determinar, justificando o interesse por ela. Segundo Ahuja e Orlin, (2001), problemas inversos foram estudados inicialmente por cientistas de geofísica com o livro de Tarantola (1987) como uma importante referência clássica do tema nesta área e que também fornece aplicações adicionais. A otimização inversa é considerada um modelo de programação matemática muito recente (ROLAND et al, 2013). Também de acordo com Ahuja e Orlin, (2001), o interesse em problemas de otimização inversa surgiu, na comunidade de programação matemática, a partir dos estudos de Burton e Toint (1992; 1994). Considerando a definição de otimização inversa fornecida acima, diversas áreas de aplicação foram identificadas. Em finanças, Bertsimas et al (2012) utilizam ideias de otimização inversa para substituir o framework estatístico no modelo Black Litterman (BL), permitindo uma maior flexibilidade em relação a abordagem original. No transporte, Chung e Demange (2012) analisam o problema do caixeiro viajante inverso. Em multicritério, Mousseau et al (2018) consideram o problema de classificação multicritério inverso, que atua sobre o custo de ações que devem ser implementadas para fornecer garantia sobre a classificação dos objetos, utilizando os métodos linear, UTADIS e MR-Sort de classificação. Um dos problemas estudados pelos autores busca o conjunto de ações com mínimo custo que garante a atribuição dos objetos a uma determinada classe. Em portfólio, Grechuk e Zabarankin, $(2014 ; 2016)$ estudam o problema de portfólio inverso, no qual o investidor assume suas preferências de risco com uma representação numérica e deseja identificar qual a mínima distância deste risco que resulta em um portfólio satisfatório. O problema de portfólio inverso não envolve a abordagem multicritério, e portanto, não está relacionado com as constantes de escala que expressam as preferências do decisor.

$\mathrm{Na}$ área de multicritério a otimização inversa é geralmente utilizada sem estar relacionada com este termo. Todos os estudos encontrados na literatura que utilizavam otimização inversa para analisar os pesos dos critérios fazem referência à análise de sensibilidade. Chen et al (2011) realiza uma revisão de métodos gerais de análise de incerteza em análise multicritério. Ele classifica os trabalhos que utilizam otimização inversa como método de análise de incerteza baseados em distância. No entanto, foi verificado que esta denominação não se refere apenas à utilização da otimização inversa. A utilização da distância também está relacionada com análises que consideram a distância da solução ideal e da solução 
ideal negativa para uma determinada solução viável (OPRICOVIC E TZENG, 2004), e isto por si só não se encaixa da definição de otimização inversa.

O ajuste na função objetivo do problema de otimização inversa é geralmente realizado a partir das normas $\mathrm{L}_{1}, \mathrm{~L}_{2}$ e $\mathrm{L}_{\infty}$ (ROLAND et al, 2013; GUAN et al, 2015). A família das métricas $L_{p}$, na qual $P \in\{1,2, \ldots, \infty\}$ é responsável por enfatizar a contribuição relativa dos desvios individuais. Quanto maior o valor de P maior a ênfase dada a maior das mudanças de valor que formam o vetor. Neste estudo o ajuste será mensurado a partir das normas $\mathrm{L}_{1}$ e $\mathrm{L}_{\infty}$, também conhecidas, respectivamente, como norma Manhattan e Chebyshev. A norma $\mathrm{L}_{\infty}$ usa a máxima mudança em qualquer uma das constantes de escala, ou seja, a maior distância entre as dimensões. A norma $L_{1}$ soma as mudanças de todas as constantes de escala, ou seja, soma as distâncias de cada dimensão (RINGUEST, 1997).

Vetschera (2009) fornece uma classificação para métodos de análise de sensibilidade que mensuram a extensão do conjunto de um determinado parâmetro, como:

- Abordagens de mensuração de única dimensão;

- Abordagens de mensuração multidimensional;

- Abordagens baseadas em volume.

Os estudos identificados na literatura alinhados com a proposta deste estudo se encaixam nas duas primeiras classificações.

Na literatura, pode-se verificar outros estudos de otimização inversa desenvolvidos usando a norma L $\infty$. Guan et al (2015) soluciona um inverse Max + Sum spanning tree problem, no qual pela primeira vez é utilizada a combinação de funções objetivo de maximização+soma. Li et al (2016) estuda uma versão restrita do constraint partial inverse matroid problem. Utilizando a norma L1 em problema de otimização inversa Guan et al, (2018) solucionou um inverse max+sum spanning tree problem a partir do problema dual e do proposto algoritmo de geração de coluna. Gassner (2010) resolve um partial inverse minimum cut problem. Ahuja e Orlin, (2001) utilizam as normas L1 e Lo para comprovar o comportamento sobre as características assumidas pelos problemas de otimização quando transformados em um problema de otimização inversa.

Diversos estudos com abordagens bastante interessantes, sobre análises nos pesos ou constantes de escala, foram identificados na literatura. Alguns deles apesar de não utilizarem o procedimento de otimização inversa influenciaram de alguma forma o desenvolvimento de outros trabalhos mais alinhados com a proposta deste estudo. Dentre os estudos pioneiros estão os estudos desenvolvidos por Mareschal (1988), Wolters e Mareschal (1995), Triantaphyllou e Sánchez (1997), Barron e Schmidt (1987) e Insua e French (1991). Estes fornecem uma base e 
insights para o desenvolvimento da maioria dos estudos posteriores sobre a utilização na otimização inversa que analisam a mínima variação nas constantes de escala ou pesos que permite uma determinada solução superar ou se igualar à ótima. Nenhum deste estudos se referem ao termo otimização inversa. A seguir são explicados mais detalhadamente estes estudos pioneiros e também estudos posteriores que estenderam suas propostas com novas contribuições.

Mareschal (1988) propõe o intervalo de estabilidade de pesos, apresentado como uma alternativa a análise de sensibilidade dos pesos comumente realizada. É uma abordagem proposta para os métodos aditivos, como aqueles com função utilidade aditiva e o PROMETHEE I e II, com a intenção de fornecer ao usuário um conhecimento mais aprofundado sobre o problema de decisão estudado. O intervalo de estabilidade de pesos, realiza a modificação em um critério por vez e distribui proporcionalmente a modificação nos outros critérios, com o objetivo de analisar a modificação nos pesos que pode ser realizada sem alterar a recomendação. A obtenção do intervalo de estabilidade de pesos é realizada de acordo com três tipos de estabilidade: completa, parcial e de subconjunto, relacionadas com o que é desejado pelo decisor. A principal diferença desse trabalho para o proposto neste estudo é a realização da modificação em um critério por vez e distribuição proporcional da modificação realizada para os outros critérios, dessa forma sendo totalmente diferente da abordagem de otimização inversa, na qual a modificação é realizada simultaneamente em mais de um critério e sem se limitar a distribuir proporcionalmente a modificação.

Triantaphyllou e Sánchez (1997) propõem uma metodologia para realizar a análise de sensibilidade nos pesos dos critérios e no desempenho das alternativas, utilizando os métodos WSM, WPM e AHP. Quanto a análise de sensibilidade dos pesos, a metodologia consiste em identificar o critério mais crítico por meio do valor absoluto ou do valor relativo da mudança entre o peso original e o novo, mas os autores declaram a preferência pelo valor relativo com a justificativa de que ele fornece mais informação. Esse critério vai ser identificado de acordo com interesse na mudança de ordenação apenas da primeira alternativa ou uma na ordenação para qualquer uma das alternativas. Na análise de sensibilidade dos pesos é determinado o quanto cada critério é crítico. Esta análise permite determinar a mínima alteração nos pesos que pode mudar a ordenação das alternativas. Este estudo tem a característica de analisar as alterações através de comparações par a par entre as alternativas e considerando a modificação do peso de um critério a cada vez, distribuindo a modificação para os outros pesos por meio de renormalização. No entanto, este não é um procedimento adequado para a problemática de portfólio já que numa seleção de portfólio as alternativas avaliadas, ou seja, os portfólios não 
são todos conhecidos e mesmo que sejam este é um procedimento bastante exaustivo e custoso. Esta é uma proposta que não utiliza programação linear, sendo mais próxima da abordagem de intervalo de sensibilidade de pesos proposta por Mareschal (1988). Além disso, não há nenhuma limitação quanto a variação que os pesos podem sofrer, de modo que é possível um critério seja anulado ou que se torne o único critério avaliado, tornando o problema monocritério.

Sowlati et al (2010) fornece uma extensão da proposta de Triantaphyllou e Sánchez (1997), aplicando os conceitos de otimização inversa provenientes de Wolters e Mareschal (1995) para realizar a análise sobre os pesos provenientes do método AHP, apresentando um modelo de programação matemática para análise de sensibilidade avaliando a mínima alteração nos pesos dos critérios necessária para alterar a ordenação das alternativas. Os autores buscam preencher uma lacuna do trabalho Triantaphyllou e Sánchez (1997), fornecendo mais informações a respeito de como a ordenação poderia mudar quando a variação excede o intervalo de variação que não gera mudança na ordenação, já que a análise de sensibilidade é direcionada para determinar a variação sobre a qual a ordenação é estável. Os autores também fornecem como output a distância relativa, no entanto esta é calculada de modo independente e não é utilizada como parâmetro da PL, na qual é utilizada a distância absoluta.

Hyde et al (2005) propõem uma abordagem determinística, que também é uma extensão da proposta de Triantaphyllou e Sánchez, para análise de incerteza baseada em distância, utilizando a norma L2, que supera as limitações das abordagens de análise sensibilidade propostas anteriormente, na qual, busca-se determinar a menor mudança nos pesos necessária para alcançar a igualdade de posição entre duas alternativas. A abordagem, proposta pelos autores, tem como benefícios a alteração simultânea dos pesos, a aplicabilidade a vários métodos multicritério e a identificação do critério mais crítico. Esta abordagem contribui com a inserção de limites para a variação dos pesos que não havia sido considerado em outros modelos. Já o procedimento para identificar o critério mais crítico é baseado na proposta Triantaphyllou e Sánchez (1997). Com esse procedimento é fornecida informação sobre a robustez entre os pares de alternativas considerando variação em todos os critérios.

Barron e Schmidt (1987) apresentam dois procedimentos de análise de sensibilidade para modelo aditivo, baseado na problemática de escolha, que calculam o conjunto de pesos mais próximos dos originais que visam igualar duas alternativas e o conjunto de pesos mais próximos dos originais que visam uma alternativa supere a outra por uma determinada quantidade. Em um deles, denominado de procedimento dos quadrados mínimos, utiliza-se programação não linear e mensuração da distância através da norma $\mathrm{L}_{2}$. Os autores sugerem um conjunto de restrições que podem ser utilizados no procedimento dos mínimos quadrados. 
As duas restrições que se destacam para este estudo são referentes a manutenção da ordenação dos pesos e a delimitação da variação das constantes de escala. Estas duas restrições fazem parte das melhorias propostas pelo modelo desenvolvido neste estudo, mas não restringindo as melhorias a estas. Os autores afirmam que em problemas de escolha é útil saber o quão diferentes os pesos seriam para escolher uma alternativa próxima da primeira. Essa afirmação gera um insight para justificar a transformação da problemática de portfólio para a problemática de escolha, a partir do momento que se tem a solução ótima original e a solução nova que se deseja tornar ótima. Essa afirmação fundamenta a análise da variação mínima sobre as constantes de escala das duas soluções analisadas.

Ringuest (1997) fornece uma extensão da proposta de Barron e Schmidt (1987) explorando a lacuna sobre a ordenação dos pesos, utilizando o modelo aditivo. O autor fornece uma nova perspectiva sobre a insensibilidade de uma alternativa que vai além do que é comumente definido. A abordagem de Ringuest (1997) se baseia na afirmação adicional de que uma alternativa é insensível se é necessário que haja a mudança da ordenação dos pesos para que uma outra alternativa seja a preferida, complementando a afirmação tradicional de que não há pesos próximos dos originais que causam a troca da alternativa preferida. $\mathrm{O}$ autor utiliza programação linear em conjunto com as normas $\mathrm{L}_{1}$ e $\mathrm{L}_{\infty}$. $\mathrm{O}$ modelo que utiliza a norma $\mathrm{L}_{\infty}$ fornece uma estrutura bastante interessante, no entanto como output é fornecido apenas o valor do $\mathrm{L}_{\infty}$, já que o modelo impõe que em uma única rodada seja encontrado o valor referente ao mínimo $\mathrm{L}_{\infty}$ para todos os critérios. Diferentemente do modelo proposto neste estudo, o qual fornece a robustez para cada critério e em seguida para cada alternativa, já que impõe que o modelo forneça o $\mathrm{L}_{\infty}$ para cada critério.

Como extensão dos trabalhos de Barron e Schmidt (1987) e Ringuest (1997), Nishizaki et al (2010) propõem um procedimento para análise de sensibilidade para funções utilidade multiatributo na forma multiplicativa.

Insua e French (1991) propõem um framework para análise de sensibilidade em problemas de decisão multi-objetivo através de variação simultânea nos parâmetros em análise. Os autores afirmam que sua abordagem permite descartar alternativas ruins e encontrar alternativas que competem com a alternativa ótima original. Além disso também é possível identificar a mínima variação nos pesos necessária para realizar uma mudança significativa no ranking a partir do modelo de agregação aditiva, utilizando as métricas $\mathrm{L}_{\infty}$ e L2. O modelo não fornece contribuições quanto às lacunas que foram identificadas em relação a manutenção da ordenação, limitação de variação e uso de distância relativa. No entanto, fornece uma estrutura matemática bastante consistente que fundamenta o framework proposto, onde os autores 
abordam algumas definições importante, como a de alternativas potencialmente ótimas adjacentes e exploram as condições que fazem com que a solução ótima original do problema seja igualada ou superada por uma solução potencialmente ótima adjacente. Eles ainda afirmam que resolver o problema para cada critério fornece mais informação sobre a sensibilidade. E esta observação forneceu o insight para o modelo proposto por este estudo analisar a robustez dos critérios e das alternativas.

Wolters e Mareschal (1995) fornecem uma análise enfatizando o método PROMETHEE, mas que podem ser aplicadas aos métodos aditivos. Propõem uma análise de sensibilidade que fornece um insight sobre como a ordenação é modificada quando os intervalos de variação permitida sem gerar mudança é excedido, e investiga como a mínima modificação nos pesos que modifica a ordenação de um modo proposital. O modelo fornecido pelos autores se diferencia pelo fornecimento de restrições de limitação da variação dos pesos, que no modelo proposto por este estudo pode ser a mesma limitação utilizada na análise de sensibilidade ou uma nova limitação imposta pelo decisor, de modo igual ou diferente seja para o aumento ou a redução, utilizando programação linear e a norma L1. No entanto possui algumas limitações como a comparação dos valores de apenas duas alternativas e a não preocupação em manter a ordenação dos critérios.

Outros estudos mais recentes como de Roland et al (2013) e Roland et al (2016) realizam a otimização inversa na função ganho, ao invés dos pesos ou constantes de escala, mas possuem abordagens bastante enriquecedoras sobre a aplicação do procedimento, portanto são mais detalhadamente explanados a seguir.

Roland et al (2013) desenvolveram um trabalho que utiliza duas abordagens para a realização do ajuste no vetor ganho. Na primeira utilizando a norma L $\infty$ é proposto um algoritmo de tempo pseudo-polinomial para resolução do problema, obtendo resultados que mostraram a tratabilidade do procedimento computacional. Na segunda é utilizada a norma L1, na qual as características dos problemas de otimização inversa reduzem o problema à resolução de um problema de programação inteira, como resultado mostrou-se uma limitação implicando no manuseio de pequenas instâncias. Em ambas houve a análise de complexidade, destacando as dificuldades teóricas dos problemas abordados.

No entanto, a metodologia utilizada por Roland et al (2013) não utiliza a abordagem multicritério e não é adequada para um problema multicritério para portfólio devido o ajuste ser realizado no parâmetro de ganhos, que são independentes entre os itens avaliados, enquanto que no problema investigado neste estudo os parâmetros utilizados são as constantes de escala que exercem influência uma sobre as outras devido à interação entre elas no processo de 
elicitação e devido ao fato que sua soma deve ser igual a 1. Além disso, o trabalho de Roland et al (2013) também utiliza uma abordagem com valores discretos para os parâmetros avaliados enquanto que no estudo atual é proposto uma abordagem com valores contínuos para lidar com o problema.

Roland et al (2016) aplicaram a otimização inversa sobre os ganhos para encontrar uma solução compromisso em uma seleção de portfólio realizada por um grupo de especialistas. $\mathrm{O}$ problema foi modelado como uma otimização combinatória multi-objetivo, no qual a perspectiva de cada especialista sobre um portfólio é uma função objetivo, e foram propostos dois procedimentos para solucioná-lo baseados em otimização inversa. Esta abordagem foca na divergência que os especialistas apresentam na avaliação dos portfólios, enquanto que a abordagem tradicional de consenso busca a agregação das avaliações. Para isto, os autores definem um novo conceito de solução compromisso, a qual está diretamente relacionada com o conceito de otimização inversa. Na primeira abordagem o problema é solucionado por meio da abordagem de plano de corte, para cada solução eficiente, e na segunda a resolução é realizada iterativamente por meio de uma programação inteira linear.

Para Roland et al (2016) se repetem as principais observações feitas para Roland et al (2013) em relação a não utilização de abordagem multicritério e realização de ajuste no parâmetro de ganhos, que são independentes um dos outros. Apesar disso, Roland et al (2016) já especificam que a abordagem é feita para seleção de portfólio de projetos, se aproximando mais do contexto de aplicação deste estudo.

Doan e Smet (2018), se baseiam nos estudos de Roland et al (2013) e Roland et al (2016), analisaram a estabilidade do ranking fornecido pelo PROMETHEE II, com o intuito de alcançar o consenso entre decisores, por meio de duas abordagens e em seguida realizam a comparação entre elas. A primeira abordagem é o intervalo de estabilidade de pesos, proposto por Mareschal (1988). A segunda é uma otimização inversa baseada em programação linear inteira mista com uso da norma L1, proposta pelos próprios autores. O intervalo de estabilidade de pesos, realiza a modificação em um critérios por vez e, em seguida, distribui proporcionalmente a modificação nos outros critérios, possui como objetivo a análise da modificação nos pesos que pode ser realizada sem alterar o ranking, já a programação linear inteira mista com otimização inversa considera mudanças simultâneas nos critérios e, devido os conceitos da otimização inversa, foca na mínima modificação que torna determinada alternativa a primeira do ranking, além disso também busca minimizar a quantidade de critérios modificados. 
A metodologia utilizada por Doan e Smet (2018) utiliza o valor absoluto das modificações nas constantes de escala e ainda limita, minimizando a quantidade de critérios que podem ser alterados, isto implica na possibilidade de haver tamanha alteração que cause a mudança de ordenação dos critérios, mostrando que para consenso entre decisores esta abordagem pode ser muito relevante. No entanto, para aumentar a segurança de um único decisor sobre a recomendação fornecida esta abordagem não se torna adequada, pois a incerteza que o decisor pode ter, em relação as constantes de escala, não deve ser suficiente para alterar a ordenação dos critérios. Esta alteração de ordem indicaria um procedimento mal realizado ou um decisor que não está mantendo um raciocínio coerente, já que, a ordenação dos critérios geralmente se baseia no estabelecimento de relações de preferência estrita, o que é mais fácil de ser determinado pelo decisor, de forma que ele possui maior segurança na declaração fornecida. Como exemplo disso há o método FITradeoff (DE ALMEIDA et al, 2016) que busca explorar exatamente as relações de preferência estrita para reduzir o espaço de pesos de maneira confiável. Outra questão é que a informação da ordenação é tão valiosa, importante e confiável que utilizando apenas ela é possível obter uma aproximação dos pesos, como é o caso do SMARTER que por meio do ROC e utilizando apenas a informação ordinal dos critérios consegue obter os pesos. Sarabando e Dias (2009), exploram e comparam o resultado fornecido por algumas regras que utilizam apenas a informação ordinal dos critérios para tomada de decisão. A intenção é fornecer um direcionamento para a escolha da regra no contexto de utilização do modelo de agregação aditiva. E mesmo em outros métodos que não utilizam apenas informação ordinal, obter a ordenação é um passo essencial para obtenção dos pesos.

Para corrigir esta característica, que para a proposta deste trabalho é considerada uma falha grave, é realizada a manutenção da ordenação das constantes utilizando uma restrição no problema de programação linear inverso. Além disso, é utilizada a variação em porcentagem das constantes de escala, devido a questão cognitiva, pois considera-se aqui que a variação dos parâmetros deve ser proporcional aos valores que eles assumem inicialmente, de forma que um critério que possui uma constante de escala maior poderia naturalmente ter uma maior variação em valor absoluto, desde que não inverta a ordenação dos critérios. Triantaphyllou e Sánchez (1997) explicam que uma mudança em termos de valor absoluto não significa muita coisa, a menos que também seja fornecido o valor original do peso. Portanto, o uso de mudanças relativas, ou seja, percentual de mudança são mais significantes.

Dentre os três tipos de análise de sensibilidade apresentadas por Wolters e Mareschal (1995) está a análise sobre a mínima modificação dos pesos para que uma alternativa seja a primeira na ordenação, que é considerada uma ferramenta para analisar o espaço total de pesos. 
A análise realizada é direcionada para os métodos PROMETHEE, mas pode ser estendida para os métodos aditivos. A proposta é fornecer insight sobre a maneira como a ordenação é alterada quando a alteração ultrapassa o intervalo, no qual os pesos podem variar sem causar alterações na ordenação. Ela é realizada através de um problema de programação linear com a norma L1. Além disso, são inseridas variáveis de variação para aumento e redução o que simplifica, fazendo com que seja necessário rodar o programa uma vez para cada critério.

Uma comparação mais sintetizada sobre o atual trabalho e os estudos de Roland et al (2013), Roland et al (2016), Doan e Smet (2018) e Wolters e Mareschal (1995), Ringuest (1997), Sowlati et al (2010) e Hyde et al (2005) é fornecida por meio da tabela 2. Estes estudos foram sintetizados por fornecerem semelhanças e diferenças interessantes que ressaltam a importância e contribuição do atual estudo. Todos eles utilizam programação matemática linear ou quadrática, e por isso variam simultaneamente mais de um parâmetro. 
Tabela 3 - Características de estudos relevantes para o desenvolvimento do modelo.

\begin{tabular}{|c|c|c|c|c|c|c|c|c|}
\hline Característica & $\begin{array}{l}\text { Trabalho } \\
\text { atual }\end{array}$ & $\begin{array}{l}\text { Doan e Smet } \\
\text { (2018) }\end{array}$ & $\begin{array}{l}\text { Roland et al } \\
\text { (2013) }\end{array}$ & $\begin{array}{l}\text { Roland et al } \\
\text { (2016) }\end{array}$ & $\begin{array}{l}\text { Wolters e } \\
\text { Mareschal } \\
(1995) \\
\end{array}$ & $\begin{array}{l}\text { Ringuest } \\
\text { (1997) }\end{array}$ & \begin{tabular}{|l} 
Sowlati et al \\
(2010)
\end{tabular} & $\begin{array}{l}\text { Hyde et al } \\
(2005)\end{array}$ \\
\hline $\begin{array}{l}\text { objetivo } \\
\text { relacionado ao } \\
\text { decisor }\end{array}$ & $\begin{array}{l}\text { Fornecer } \\
\text { mais } \\
\text { informação e } \\
\text { aumentar a } \\
\text { segurança de } \\
\text { um único } \\
\text { decisor }\end{array}$ & $\begin{array}{l}\text { Consenso } \\
\text { entre } \\
\text { decisores }\end{array}$ & $\begin{array}{l}\text { Não } \\
\text { considera } \\
\text { decisor }\end{array}$ & $\begin{array}{l}\text { Seleção de } \\
\text { um portfólio } \\
\text { com } \\
\text { otimização } \\
\text { inversa }\end{array}$ & $\begin{array}{l}\text { Fornecer } \\
\text { mais } \\
\text { informação e } \\
\text { aumentar a } \\
\text { segurança de } \\
\text { um único } \\
\text { decisor }\end{array}$ & $\begin{array}{l}\text { Fornecer } \\
\text { mais } \\
\text { informação e } \\
\text { aumentar a } \\
\text { segurança de } \\
\text { um único } \\
\text { decisor }\end{array}$ & \begin{tabular}{|l|} 
Fornecer \\
mais \\
informação e \\
aumentar a \\
segurança de \\
um único \\
decisor \\
\end{tabular} & $\begin{array}{l}\text { Fornecer } \\
\text { mais } \\
\text { informação e } \\
\text { aumentar a } \\
\text { segurança de } \\
\text { um único } \\
\text { decisor }\end{array}$ \\
\hline Tipo de problema & Multicritério & Multicritério & Monocritério & $\begin{array}{c}\text { Multi } \\
\text { objetivo }\end{array}$ & Multicritério & Multicritério & Multicritério & Multicritério \\
\hline Problemática & Portfólio & Ordenação & $\begin{array}{c}\text { Problema da } \\
\text { mochila }\end{array}$ & Portfólio & Ordenação & Escolha & Ordenação & Ordenação \\
\hline $\begin{array}{l}\text { Parâmetro de } \\
\text { ajuste }\end{array}$ & \begin{tabular}{l}
\multicolumn{2}{l}{ Pesos/consta } \\
ntes de \\
escala
\end{tabular} & $\begin{array}{l}\text { Pesos/consta } \\
\text { ntes de escala }\end{array}$ & Ganhos & Ganhos & $\begin{array}{l}\text { Pesos/consta } \\
\text { ntes de escala }\end{array}$ & \begin{tabular}{ll}
\multicolumn{2}{l}{ Pesos/consta } \\
ntes de \\
escala
\end{tabular} & $\begin{array}{l}\text { Pesos/consta } \\
\text { ntes de escala }\end{array}$ & $\begin{array}{l}\text { Pesos/consta } \\
\text { ntes de escala }\end{array}$ \\
\hline $\begin{array}{l}\text { Tipos de variáveis } \\
\text { de decisão }\end{array}$ & Contínua & Contínua & Discreta & Discreta & Contínua & Contínua & Contínua & Contínua \\
\hline $\begin{array}{l}\text { Mensuração da } \\
\text { distância }\end{array}$ & $\begin{array}{l}\text { Valor } \\
\text { relativo }\end{array}$ & $\begin{array}{l}\text { Valor } \\
\text { absoluto }\end{array}$ & $\begin{array}{l}\text { Valor } \\
\text { absoluto }\end{array}$ & $\begin{array}{l}\text { Valor } \\
\text { absoluto }\end{array}$ & $\begin{array}{l}\text { Valor } \\
\text { absoluto }\end{array}$ & \begin{tabular}{|l} 
Valor \\
absoluto \\
\end{tabular} & \begin{tabular}{|l|} 
Valor \\
absoluto \\
\end{tabular} & $\begin{array}{l}\text { Valor } \\
\text { absoluto }\end{array}$ \\
\hline Papel do decisor & $\begin{array}{l}\text { Um único } \\
\text { decisor }\end{array}$ & $\begin{array}{l}\text { Grupo de } \\
\text { decisores }\end{array}$ & $\begin{array}{l}\text { Não } \\
\text { considera } \\
\text { este papel }\end{array}$ & $\begin{array}{l}\text { Grupo de } \\
\text { especialistas } \\
\text { como } \\
\text { decisores } \\
\end{array}$ & $\begin{array}{l}\text { Um único } \\
\text { decisor }\end{array}$ & $\begin{array}{l}\text { Um único } \\
\text { decisor }\end{array}$ & $\begin{array}{l}\text { Um único } \\
\text { decisor }\end{array}$ & $\begin{array}{l}\text { Um único } \\
\text { decisor }\end{array}$ \\
\hline $\begin{array}{lr}\begin{array}{l}\text { Norma } \\
\text { mensuração }\end{array} & \text { para } \\
\end{array}$ & L1 e L $\infty$ & L1 & L1 e L $\infty$ & L1 & L1 & $\mathrm{Lp}$ & L1 & L2 \\
\hline $\begin{array}{l}\text { Método } \\
\text { multicritério }\end{array}$ & $\begin{array}{l}\text { Modelo } \\
\text { aditivo }\end{array}$ & $\begin{array}{l}\text { PROMETH } \\
\text { EE }\end{array}$ & - & - & $\begin{array}{l}\text { PROMETH } \\
\text { EE e modelo } \\
\text { aditivo }\end{array}$ & $\begin{array}{l}\text { Modelo } \\
\text { aditivo }\end{array}$ & AHP & $\begin{array}{l}\text { Vários: } \\
\text { WSM, } \\
\text { PROMETH } \\
\text { EE e outros } \\
\end{array}$ \\
\hline
\end{tabular}




\begin{tabular}{|c|c|c|c|c|c|c|c|c|}
\hline$\underbrace{\text { Estudo }}_{\text {Característica }}$ & $\begin{array}{l}\text { Trabalho } \\
\text { atual }\end{array}$ & $\begin{array}{l}\text { Doan e Smet } \\
(2018)\end{array}$ & $\begin{array}{l}\text { Roland et al } \\
(2013)\end{array}$ & $\begin{array}{l}\text { Roland et al } \\
\text { (2016) }\end{array}$ & $\begin{array}{l}\text { Wolters e } \\
\text { Mareschal } \\
(1995)\end{array}$ & $\begin{array}{l}\text { Ringuest } \\
(1997)\end{array}$ & $\begin{array}{l}\text { Sowlati et al } \\
(2010)\end{array}$ & $\begin{array}{l}\text { Hyde et al } \\
(2005)\end{array}$ \\
\hline $\begin{array}{l}\text { Utilização da } \\
\text { distância relativa }\end{array}$ & $\begin{array}{l}\text { Utiliza como } \\
\text { variáveis de } \\
\text { decisão no } \\
\text { PPL }\end{array}$ & $\begin{array}{l}\text { Não } \\
\text { considera }\end{array}$ & $\begin{array}{c}\text { Não } \\
\text { considera }\end{array}$ & $\begin{array}{c}\text { Não } \\
\text { considera }\end{array}$ & $\begin{array}{l}\text { Não } \\
\text { considera }\end{array}$ & $\begin{array}{l}\text { Não } \\
\text { considera }\end{array}$ & $\begin{array}{l}\text { Fornece } \\
\text { como output }\end{array}$ & $\begin{array}{l}\text { Fornece } \\
\text { como output }\end{array}$ \\
\hline $\begin{array}{lr}\text { Manutenção } & \text { da } \\
\text { ordenação } & \text { dos } \\
\text { critérios } & \end{array}$ & $\begin{array}{l}\text { Considera } \\
\text { uma restrição } \\
\text { que força a } \\
\text { manutenção } \\
\text { da ordem }\end{array}$ & $\begin{array}{c}\text { Não } \\
\text { considera }\end{array}$ & $\begin{array}{c}\text { Não } \\
\text { considera }\end{array}$ & $\begin{array}{c}\text { Não } \\
\text { considera }\end{array}$ & $\begin{array}{l}\text { Não } \\
\text { considera }\end{array}$ & $\begin{array}{l}\text { Considera } \\
\text { que não pode } \\
\text { haver, mas } \\
\text { não impõe } \\
\text { restrição }\end{array}$ & $\begin{array}{l}\text { Não } \\
\text { considera }\end{array}$ & $\begin{array}{l}\text { Não } \\
\text { considera }\end{array}$ \\
\hline $\begin{array}{lr}\text { Limitação } & \text { da } \\
\text { variação } & \text { dos } \\
\text { pesos } & \\
\end{array}$ & $\begin{array}{l}\text { Considera } \\
\text { restrição } \\
\text { para limitar } \\
\end{array}$ & $\begin{array}{c}\text { Não } \\
\text { considera }\end{array}$ & $\begin{array}{c}\text { Não } \\
\text { considera }\end{array}$ & $\begin{array}{c}\text { Não } \\
\text { considera }\end{array}$ & $\begin{array}{l}\text { Considera } \\
\text { restrição } \\
\text { para limitar }\end{array}$ & $\begin{array}{c}\text { Não } \\
\text { considera }\end{array}$ & $\begin{array}{c}\text { Não } \\
\text { considera }\end{array}$ & $\begin{array}{l}\text { Considera } \\
\text { restrição } \\
\text { para limitar } \\
\end{array}$ \\
\hline $\begin{array}{l}\text { Fornecimento de } \\
\text { informação sobre } \\
\text { a robustez }\end{array}$ & $\begin{array}{lr}\text { Fornece } & \text { a } \\
\text { robustez } & \\
\text { entre } & \text { os } \\
\text { critérios e o } & \text { par de } \\
\text { alternativas } \\
\text { original e } \\
\text { nova }\end{array}$ & $\begin{array}{c}\text { Não } \\
\text { considera }\end{array}$ & $\begin{array}{c}\text { Não } \\
\text { considera }\end{array}$ & $\begin{array}{c}\text { Não } \\
\text { considera }\end{array}$ & $\begin{array}{c}\text { Não } \\
\text { considera }\end{array}$ & $\begin{array}{c}\text { Não } \\
\text { considera }\end{array}$ & $\begin{array}{c}\text { Não } \\
\text { considera }\end{array}$ & $\begin{array}{l}\text { Fornece a } \\
\text { robustez } \\
\text { entre os pares } \\
\text { de } \\
\text { alternativas }\end{array}$ \\
\hline $\begin{array}{lr}\text { Identificação } & \text { do } \\
\text { critério } & \text { mais } \\
\text { crítico } & \end{array}$ & $\begin{array}{l}\text { Fornece o } \\
\text { critério e a } \\
\text { transferência } \\
\text { mais críticos } \\
\text { por meio da } \\
\text { PL }\end{array}$ & $\begin{array}{c}\text { Não } \\
\text { considera }\end{array}$ & $\begin{array}{c}\text { Não } \\
\text { considera }\end{array}$ & $\begin{array}{c}\text { Não } \\
\text { considera }\end{array}$ & $\begin{array}{c}\text { Não } \\
\text { considera }\end{array}$ & $\begin{array}{c}\text { Não } \\
\text { considera }\end{array}$ & $\begin{array}{c}\text { Não } \\
\text { considera }\end{array}$ & $\begin{array}{l}\text { Fornece o } \\
\text { critério mais } \\
\text { crítico e } \\
\text { procediment } \\
\text { o que não } \\
\text { utiliza PL }\end{array}$ \\
\hline
\end{tabular}

Fonte: Produzido pelo autor. 
Dessa forma fica mais fácil visualizar as semelhanças e diferenças entre os estudos, assim como obter insights sobre melhorias e novas abordagens que podem ser exploradas. É interessante observar que nenhuma das propostas foi desenvolvida para a problemática multicritério de portfólio. Também é interessante observar que a norma $\mathrm{L}_{\infty}$ é mais raramente utilizada, isso pode ser justificado por ser uma métrica mais complicada e que necessita de mais atenção. A maioria dos estudos multicritério objetiva o fornecimento de mais informação e assim aumentar a segurança de um decisor, no entanto apenas um deles realmente considera a manutenção da ordenação dos critérios. Por fim, pode-se perceber que nenhum deles integra as contribuições fornecidos no atual modelo proposto. No geral, eles apresentam as principais lacunas relacionadas a manutenção da ordenação, limitação de variação dos pesos e uso a distância relativa, além de não fornecerem a robustez, tanto para os critérios quanto para as alternativas, e a identificação do critério e da transferência mais críticos.

Outros trabalhos interessantes que não são baseados no conceito de otimização inversa, mas que realizam procedimentos com objetivos semelhantes de estabilidade das recomendações fornecidas são identificados na literatura. A Post Factum Analysis (PFA) é uma abordagem que tem semelhanças com a otimização e foi realizada por Kadzinski et al (2016) e Ciomek et al (2018). Kadzinski et al (2016) propõem um framework de PFA para avaliar a estabilidade das recomendações, realizando uma avaliação sobre o desempenho das alternativas em problemas multicritério de ordenação e classificação com o objetivo de verificar a mínima melhoria que asseguram alguns resultados se tornarem viáveis ou a mínima deterioração que assegura que os resultados serão mantidos, sendo as consequências no entanto independentes entre as alternativas ao contrário das constantes de escala que são consideradas nesse estudo. Ciomek et al (2018) trata um problema de ordenação multicritério em grupo relacionado a política pública, utilizando PFA, neste estudo o principal objetivo é avaliar a utilidade do PFA desenvolvido por Kadzinski et al (2016) e fornecer algumas melhorias para dar suporte a problemas reais. E como resultado conclui que PFA é útil para planejamento e formulação de diretrizes, assim como para verificar a robustez de recomendações alcançadas para os desempenhos considerados.

Dentre outros trabalhos identificados na literatura que não mencionam a otimização inversa, apesar de aplicarem esta abordagem para solucionar problemas, e que por estarem muito alinhados com a proposta deste estudo são explorados mais detalhadamente a seguir.

Há diversos estudos sobre análise de sensibilidade da solução ótima para o problema da mochila com variações em alguns parâmetros. Hifi e Mhalla (2010) analisam sensibilidade da solução ótima estabelecendo um intervalo de estabilidade para a perturbação dos custos para o 
problema da mochila. Hifi e Mhalla (2013) realizam a avaliação sobre a a variação dos pesos de um subconjunto de itens do problema da mochila para obter um intervalo que garanta que a solução ótima não será alterada aplicando um método de programação dinâmica. Hifi et al (2005) analisam a sensibilidade da solução ótima para perturbação nos pesos ou ganhos, fornecendo intervalos exatos ou aproximados a partir de vários algoritmos de tempo polinomial. Belgacem e Hifi (2008a), analisam a sensibilidade da solução ótima para um problema de otimização combinatória max-min, chamado de problema do compartilhamento da mochila, perturbando os pesos de um item aleatório e estabelecendo um intervalo. Belgacem e Hifi (2008b), analisaram a sensibilidade da solução ótima para perturbações no ganho, com dois casos, em um deles considerou-se que a perturbação do lucro em cada item requer a perturbação do lucro em outros itens. 


\section{MODELO}

Neste capítulo é apresentado inicialmente a descrição do problema e em seguida o modelo produzido a partir do procedimento fornecido por De Almeida (2013), composto originalmente por doze etapas genéricas que direcionam para o desenvolvimento da modelagem de problemas multicritério. Como a modelagem é um procedimento criativo e as doze etapas são genéricas, naturalmente, foram necessárias algumas modificações como retirada de etapas, acréscimo ou adaptações para que pudessem compreender mais detalhadamente a estruturação do problema, e assim fornecer uma melhor representação do problema analisado.

\subsection{Etapas do modelo}

Considere que há um conjunto de alternativas $A=\left\{a_{1}, a_{2}, \ldots, a_{p}\right\}$, um conjunto de critérios $\mathrm{C}=\{1,2, \ldots, \mathrm{m}\}$ e suas respectivas constantes de escala de escala $\mathrm{K}=\left\{\mathrm{k}_{1}, \mathrm{k}_{2}, \ldots, \mathrm{k}_{\mathrm{m}}\right\}$, um conjunto $S=\left\{S_{h} \in S \mid S_{h}=\left(S_{h} 1, S_{h}, \ldots S_{h m}\right)\right\}$ de soluções viáveis que surgem por meio da análise de sensibilidade utilizando simulação ou por meio de algoritmos de geração de soluções fronteira, um conjunto $\mathrm{O}$ de soluções ótimas para os pesos originais, de forma que $\mathrm{O} \subset \mathrm{S}$.

Seja então uma solução sh, uma solução ótima ou e uma variação $\Delta \mathrm{k}$ que representa a diferença relativa entre o valor assumido pela constante de escala ao eleger a solução ótima $\mathrm{O}_{u}$ e o valor que a constante de escala deve assumir para tornar sh uma solução ótima. O problema consiste em minimizar $\max _{\mathrm{j}}\left(\Delta \mathrm{k}_{\mathrm{j}}\right)$ para $\mathrm{L}_{\infty}$, ou minimizar $\sum_{\mathrm{j}}\left(\Delta \mathrm{k}_{\mathrm{j}}\right)$ para $\mathrm{L}_{\mathrm{l}}$, que torna $\mathrm{v}\left(\mathrm{S}_{\mathrm{h}}\right) \geq \mathrm{v}\left(\mathrm{o}_{\mathrm{u}}\right)$ e faz com que sh seja uma solução ótima.

O modelo para lidar com este problema é organizado em quatro estágios principais que envolvem, resumidamente, a estruturação do problema a partir das informações que o decisor e o contexto dispõem sobre as características do problema, a obtenção da solução inicial a partir da avaliação multicritério para portfólio, a análise de robustez para checar a sensibilidade da solução e potenciais novas soluções, em seguida ocorre a análise sobre as constantes de escala por meio da otimização inversa utilizando as normas $\mathrm{L}_{\infty}$ e $\mathrm{L}_{1} \mathrm{e}$, por fim, a análise dos resultados para elaborar e apresentar uma recomendação. A figura 1 ilustra o modelo, organizando todas as sub etapas que são descritas detalhadamente a seguir. 
Figura 1: Estrutura do modelo.

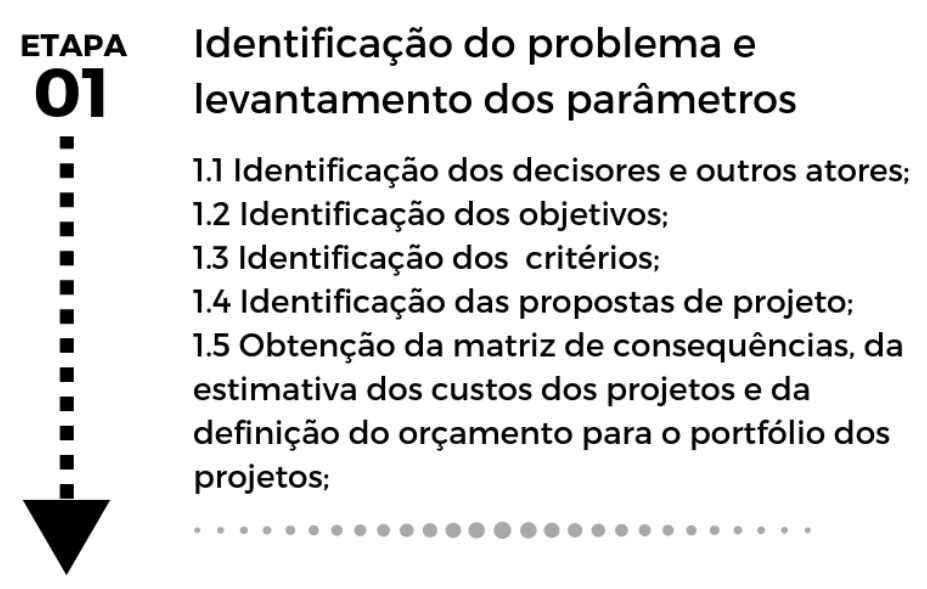

\section{ETAPA Seleção multicritério de 02 portfólio de projetos}

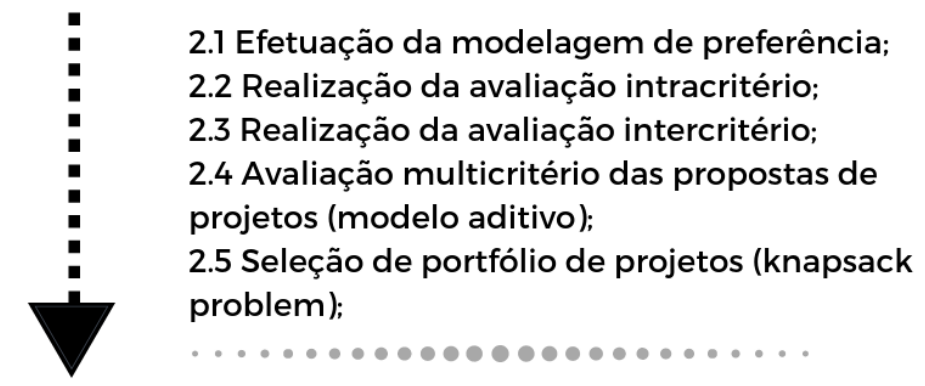

\section{ETAPA Análise de robustez \\ 03 3.1 Definição dos parâmetros da análise de sensibilidade; 3.2 Realização da análise de sensibilidade com Simulação Monte Carlo; \\ 3.3 Identificação de novas soluções; 3.4 Análise da variação mínima sobre os pesos para troca de recomendação usando a norma $\mathrm{L} \infty$ ou LI; \\ ETAPA Elaboração da recomendação \\ 04 4.1 Análise dos resultados e elaboração da recomendação;}

Fonte: Produzido pelo autor.

No estágio 1, de Identificação do problema e levantamento dos parâmetros, os principais dados de caracterização do problema são identificados. São obtidos do decisor e do ambiente de decisão informações importantes para estruturar o problema. As cinco etapas que o compõem são detalhadas a seguir. 
Etapa 1.1 - Identificação dos decisores e outros atores:

Compreender os atores que compõem o contexto da decisão, enfatizando os que podem atuar como decisores ou influenciadores da decisão e, também compreender suas características e as relações existentes entre eles.

Etapa 1.2- Identificação dos objetivos:

Compreender e estabelecer os objetivos que guiam as ações de decisão e, consequentemente, impactam profundamente na forma como o procedimento de decisão será realizado e na obtenção da recomendação. Pode-se utilizar métodos de estruturação de problema, como o VFT que envolve desde a estruturação dos objetivos até a criação das alternativas.

Etapa 1.3-Identificação dos critérios

Identificar os critérios que melhor representam os objetivos estabelecidos e que são capazes de mensurá-los. Estes devem ser utilizados para avaliar as alternativas, permitindo obter a recomendação mais alinhada com os objetivos da organização.

Etapa 1.4- Identificação das propostas de projetos

Obter as alternativas que são avaliadas na seleção, buscando em documentos internos e externos à organização os dados sobre projetos já executados, em execução, propostas de projetos em desenvolvimento e propostas que estão armazenadas ou foram descartadas em outras seleções.

Etapa 1.5- Obtenção da matriz de consequências, da estimativa dos custos dos projetos e da definição do orçamento para o portfólio dos projetos

Obter numericamente o quanto cada proposta de projeto satisfaz cada critério de decisão, formando assim a matriz de consequências do problema. Também devem ser obtidos os custos de cada proposta de projeto e o orçamento disponível para a seleção de projetos. Muitos destes dados são obtidos através de especialistas.

O Estágio 2 consiste na seleção multicritério do portfólio, na qual as propostas de projetos são avaliadas e é realizada a recomendação inicial sobre a seleção de projetos. 
Etapa 2.1- Efetuação da modelagem da preferência

Obter informações que permitam saber quais relações de preferência o decisor precisa utilizar para expressar suas preferências e qual o comportamento do decisor em relação a compensação de desempenho das alternativas entre critérios.

\section{Etapa 2.2- Realização da avaliação intracritério}

Considerando o uso do modelo aditivo, realizar a normalização para obter a função valor para cada critério. Sendo considerada função linear para todos os critérios, a qual converte os desempenhos das alternativas para a mesma escala, consequentemente, facilitando a identificação dos valores que representam ou não a atratividade do desempenho. E posteriormente, colaborando para possibilitar a comparação entre os critérios.

\section{Etapa 2.3- Realização da avaliação intercritério}

Como parte fundamental da avaliação intercritério para o modelo aditivo as constantes de escala devem ser obtidas, diversos métodos multicritério para elicitação das constantes de escala podem ser utilizados. Além disso, a problemática de portfólio necessita de um cuidado especial que é utilizar as constantes de escala em contexto de escala razão (DE ALMEIDA et al. 2014). Sendo assim, é necessário realizar a conversão das constantes de escala do contexto intervalar para o contexto de razão, com o procedimento fornecido por De Almeida et al. (2014).

Etapa 2.4- Avaliação das propostas de projetos

Realizar a avaliação multicritério sobre os projetos por meio do modelo aditivo, usando a equação (2.2) para o cálculo do valor global de cada projeto. Estes valores serão considerados os coeficientes da função objetivo do problema de otimização binária que selecionará os projetos para compor o portfólio.

Etapa 2.5- Seleção do portfólio de projetos

Obter a solução que representa o melhor portfólio, através do problema de programação binária representado pela equação (2.1), aquele que dentre todos os portfólios viáveis satisfaz as restrições de recursos e fornece o maior ganho ao decisor, considerando os dados iniciais.

O Estágio 3 corresponde à Análise de robustez, onde são tratadas incertezas que estão relacionadas com alguns parâmetros que podem estar sujeitos a variação devido à subjetividade e até mesmo simplificações, como a obtenção das constantes de escala para o do modelo aditivo. 
Etapa 3.1- Definição dos parâmetros da análise de sensibilidade

Definir e justificar, a escolha de determinados parâmetros para serem avaliados na análise de sensibilidade, enfatizando a principal motivação que é o tratamento de incerteza e o forte impacto que causam na obtenção da solução.

Etapa 3.2- Realização da análise de sensibilidade

Realizar a análise de sensibilidade para verificar o comportamento da solução encontrada quando há variações, as quais podem ser expressas pelo decisor relacionadas com a sua imprecisão, nos parâmetros selecionados para análise de sensibilidade. Como opção podem ser utilizados procedimentos estatísticos, como a simulação Monte Carlo. Ou como alternativa ao próprio procedimento de análise de sensibilidade podem ser utilizados algoritmos geradores de combinações de fronteira para portfólio (Vetschera, 1994), e assim prosseguir normalmente para a etapa 3.4 de análise da variação mínima.

Etapa 3.3- Identificação de novas soluções

A partir da análise de sensibilidade, identificar quais as combinações de projetos que poderiam ser recomendadas dentro de uma variação aceitável nos parâmetros por parte do decisor. Para cada combinação s nova de projetos que surge na análise de sensibilidade, podese considerar que há um subespaço de pesos $\Phi_{\mathrm{s}}$ que elege essa combinação e tal subespaço está, por sua vez, contido no subespaço delimitado pelos limites das variações de pesos definidos junto ao decisor e usados na análise de sensibilidade. A análise de sensibilidade pode ser substituída pela utilização de algoritmos geradores de combinações de fronteira para portfólio (Vetschera, 1994), porém, uma definição sobre uma fronteira de soluções deverá ser feita para limitar a aceitação de soluções em $\mathrm{S}$.

Etapa 3.4- Análise da variação mínima sobre os pesos

Para cada solução nova, diferente da original, que surge na etapa 3.3, deve ser realizada uma análise de variação mínima, baseada na distância relativa, sobre os pesos para a troca de recomendação, utilizando a otimização inversa. A troca entre a solução original e a solução nova, acaba funcionando nesta etapa como uma simplificação da problemática de portfólio para a problemática de escolha. De modo que sem perda de informação há a comparação entre portfólios, se baseando no que há de diferente entre as soluções analisadas. A análise se divide em duas partes, são duas formas alternativas de análise da variação. A diferença entre eles é a 
norma que será utilizada, de modo que a norma influencia na informação que será utilizada e na solução obtida. Todo o procedimento é melhor detalhado na seção 4.2.

Etapa 3.4.1- Otimização inversa com norma $\mathrm{L}_{\infty}$

Utilização da norma $\mathrm{L}_{\infty}$ para realizar o ajuste na função valor, a qual buscará o critério que possua a mínima variação dentre as máximas variações fornecidas por todos os critérios.

Etapa 3.4.2- Otimização inversa com norma $\mathrm{L}_{1}$

Utilização da norma $L_{1}$ para realizar o ajuste na função valor, a qual buscará o vetor de distâncias com a soma mínima.

O estágio 4 consiste na elaboração da recomendação, a qual reúne os dados de input e de output do modelo. Os dados de input também consideram as informações relevantes, como suposições e simplificações assumidas, para obter a recomendação. Os dados de output informam ao decisor sobre a recomendação original obtida de acordo com os pesos elicitados, sobre as novas recomendações sugeridas pela análise de sensibilidade, enfatizando os projetos trocados nas novas recomendações em comparação com a original, além da frequência de cada solução e, por fim, o quanto que as preferências declaradas pelo decisor precisariam mudar para que a recomendação fosse alterada.

Etapa 4.1- Analisar resultados e elaborar recomendação

É realizada a análise e apresentação dos resultados, a análise é especialmente importante para extrair e esclarecer tudo que pode ser fornecido da estruturação e resolução do problema para o decisor ficar mais seguro quanto a recomendação fornecida. Além disso, é enfatizado o impacto que o recurso adicional de avaliação da variação mínima sobre os pesos exerce sobre a confiança para o decisor.

\subsection{Análise da variação das constantes de escala utilizando otimização inversa}

Para qualquer solução nova, diferente da original, seja ela proveniente de análise de sensibilidade ou de algoritmos construtivos, como é o caso da árvore de Vetschera (1994) que fornece todas as soluções fronteira, deve ser realizada uma análise de variação mínima em percentual sobre os pesos, para uma análise mais aprofundada que vai tornar a recomendação mais confiável, utilizando a otimização inversa para tornar ótima a nova solução. A otimização 
inversa consiste em calcular a distância mínima entre o ponto do espaço de pesos referente aos pesos dos critérios originais e o subespaço de pesos que elege a nova solução. Para isso, foram utilizadas as normas $\mathrm{L}_{\infty}$ e $\mathrm{L}_{1}$, através de problemas de programação linear, para calcular a variação mínima sobre as constantes de escala de forma que a nova solução superasse o valor da solução original sem violar a ordenação dos critérios, utilizando a distância relativa e permitindo ao decisor estabelecer limite de variação, inclusive com valores diferentes para o aumento e redução das novas constantes de escala.

Outros estudos realizaram análises semelhantes a esta proposta, mas que apresentam diferenças fundamentais incompatíveis com os fins e os resultados que o modelo aqui proposto objetiva alcançar. Doan e Smet (2018), Wolters e Mareschal (1995), Ringuest (1997), Sowlati et al (2010) e Hyde et al (2005) minimizam a variação, considerando o módulo da diferença de valor entre os pesos originais e os pesos para eleger a nova solução, o que implica em uma não adequação a proposta deste estudo, já que a informação sobre a porcentagem de mudança é perdida. No estudo de Doan e Smet (2018) a inversão não é preocupante, pois o objetivo é fornecer uma solução de consenso entre um grupo de decisores. No entanto, a inversão de ordem nos estudos de Wolters e Mareschal (1995), Ringuest (1997), Sowlati et al (2010), Hyde et al (2005) e no presente estudo, que objetivam fornecer mais confiança a um único decisor, entra em conflito com uma informação básica e essencial de ordenação dos critérios que foi estabelecida pelo próprio decisor.

Triantaphyllou e Sánchez (1997) utilizam a variação relativa, considerando a relação entre o valor original do peso e valor que o peso necessita assumir, justificado por ser uma informação mais significante, pois considera a proporção da mudança diante do peso original, no entanto realizam um procedimento que não utiliza PL e modifica um critério por vez, diferentemente do presente trabalho. O presente estudo utiliza a variação relativa na mensuração da distância entre as alternativas, realizada pelas normas $\mathrm{L}_{\infty}$ e $\mathrm{L}_{1}$ fornecendo mais informações sobre as variações. Sowlati et al (2010), Hyde et al (2005) fornecem a variação relativa apenas como informação adicional de seus procedimentos.

Além disso, Triantaphyllou e Sánchez (1997) fornecem o conceito de critério mais crítico que está alinhado com o procedimento de lidar com um critério por vez, Hyde et al (2005) seguem a mesma linha do estudo anterior quanto ao critério mais crítico. Porém, no presente estudo esta abordagem não é adequada já que realiza a mudança simultânea nos pesos, de forma que o mais adequado é analisar a transferência mais crítica que ocorre entre dois ou mais critérios. Além disso, no modelo do $\mathrm{L}_{\infty}$ fornece o critério mais crítico através da identificação do critério com a mínima variação, dentre as máximas de todos os critérios, e em 
seguida fornece a robustez para todas as alternativas. Apenas Hyde et al (2005) e Wolters e Mareschal (1995) impõem uma limitação de variação que o decisor pode declarar de acordo com sua crença sobre a imprecisão do que o próprio declarou em relação aos pesos, semelhante ao que é proposto no presente trabalho. Por fim, todos estes trabalhos tratam do impacto que esta mínima variação, seja em modulo ou em porcentagem, causa na ordenação ou escolha das alternativas de um problema multicritério. E nenhum deles reúne todas as contribuições que o atual estudo se propõe.

\subsubsection{Modelo para norma $\mathrm{L}_{\infty}$}

O problema de PL, composto pelas equações (3.1-3.6) a seguir, é rodado para cada critério, resultando no fornecimento dos m vetores que contêm as distâncias relativas tais que minimiza a distância máxima, garantindo que ocorrerá para o critério w considerado na PL, em relação ao valor necessário que as mesmas devem alcançar para igualar ou superar uma determinada solução à solução ótima do problema original e torna-la a nova ótima. A partir de todos os vetores, contendo em cada um deles a máxima variação de cada critério w analisado, é realizada a comparação e a identificação da constante de escala com a mínima distância relativa, dentre as máximas, necessária para eleger como ótima a solução escolhida. Justificase o uso da norma $\mathrm{L}_{\infty}$ para minimizar as distâncias máximas por meio da afirmação de Ringuest (1997), a qual diz que a utilização da maior distância tem relação com ser mais provável haver inversão da ordenação das constantes de escala quando a distância é maior. Como o objetivo deste modelo é evitar a mudança na ordenação dos critérios, ao utilizar a norma $\mathrm{L}_{\infty}$ deseja-se obter a mínima dentre as máximas variações que resulte em uma solução que não altere a ordenação. Além disso a mínima variação máxima expõe qual o critério que faz com que a solução nova se torne ótima com uma menor variação de peso, sem depender de uma variação ainda maior em outros critérios.

$$
\text { Min } \Delta_{w}^{+}+\Delta_{w}^{-}+\sum 0\left(\Delta_{j}^{+}+\Delta_{j}^{-}\right) \quad \forall \mathrm{j} \neq \mathrm{w}
$$

S. a.

$$
\begin{array}{cc}
\sum_{j=1}^{m}\left(v_{j}\left(s_{t j}\right)-v_{j}\left(s_{h j}\right)\right) k_{j}\left(1+\Delta_{j}^{+}-\Delta_{j}^{-}\right) \geq 0 & \forall \mathrm{h} \neq \mathrm{t} \\
\left(\Delta_{w}^{+}+\Delta_{w}^{-}\right)-\left(\Delta_{j}^{+}+\Delta_{j}^{-}\right) \geq 0 & \forall \mathrm{j} \neq \mathrm{w} \\
k_{j}\left(1+\Delta_{j}^{+}-\Delta_{j}^{-}\right)-k_{j+1}\left(1+\Delta_{j+1}^{+}-\Delta_{j+1}^{-}\right) \geq 0 & \forall \mathrm{j} \neq \mathrm{m} \\
\sum k_{j}\left(\Delta_{j}^{+}-\Delta_{j}^{-}\right)=0 & \\
\Delta_{j}^{+}+\Delta_{j}^{-} \leq d_{j} & \forall \mathrm{j}
\end{array}
$$


No qual, $\Delta_{\mathrm{W}}{ }^{+}$e $\Delta_{\mathrm{w}}{ }^{-}$são as variáveis de decisão que representam a variação na distância relativa das constantes de escala para realizar, respectivamente, o aumento ou a redução necessária para eleger a solução desejada como ótima no problema inverso. Doan e Smet (2018) e Wolters e Mareschal (1995) também consideram as variáveis de aumento e redução dos pesos. Estas variáveis em um problema de minimização garantem que pelo menos uma delas será zero já que se as duas se modificam haveria um efeito de anulação dos valores.

No problema de PL representado, a função objetivo (3.1) consiste na minimização das máximas distâncias relativas das constantes de escala de todos os critérios que, devido ao uso da norma $\mathrm{L}_{\infty}$, força cada um dos critérios w por vez a ter maior distância relativa que os outros critérios entre a solução do problema original e a solução do problema inverso. Nela também são consideradas as variações nos demais critérios $\mathrm{j}$, de modo que são anulados na função objetivo, mas atuam nas restrições. A solução eleita como ótima está sujeita às restrições que correspondem a otimalidade, normalização e não negatividade das constantes, norma de mensuração da distância, manutenção da ordenação dos critérios e limitação da variação.

A equação (3.2) expressa que o valor global assumido pela solução desejada, a partir do aumento ou redução das novas constantes de escala, deve ser maior ou igual ao valor das outras soluções que sofreram a mesma variação, ou seja, a solução nova deve ser melhor ou pelo menos igual a qualquer outras solução avaliada, impondo que a solução seja a ótima para o problema. Esta restrição também impede que ao reduzir a distância entre duas soluções, uma terceira acabasse sendo eleita como ótima. Já que a verificação do valor global é feita em comparação com todas as soluções em $\mathrm{S}$, ao invés de apenas entre a solução nova e a solução ótima original.

A equação (3.3) implica que um critério por vez seja avaliado de modo a forçar que no critério w haja uma variação maior ou igual a dos outros critérios, para assim obter a maior distância necessária, especificamente neste critério, que contribui para que a nova solução se torne ótima, isto está relacionado com a característica da norma $\mathrm{L}_{\infty}$ de trabalhar com a maior distância identificada. É uma forma de obter as máximas distâncias para em seguida identificar a mínima dentre elas.

A equação (3.4) evita que as variações na distância relativa causem uma mudança nos valores das constantes de escala que resulte na inversão na ordenação das mesmas, de modo que um determinado critério deve continuar maior ou igual ao seu sucessor na ordenação. Esta restrição é extremamente importante para o objetivo de aumento da confiança do decisor quanto a recomendação fornecida. É considerado como princípio básico deste estudo, que não há como 
fornecer mais confiança ao decisor se há uma quebra da informação mais segura proveniente dele, que é a relação estrita de preferência entre os critérios.

A equação (3.5) impõe que as constantes de escala após sofrerem variação em seus valores, devem somar 1, ou seja, devem manter a normalização. De modo que as variações entre aumentos e reduções sejam compensadas entre as constantes de escala e a normalização não seja alterada.

A equação (3.6) expressa a limitação $d_{j}$, definida pelo decisor para a variação das constantes de escala, relacionada a um intervalo de imprecisão que o decisor acredita existir. Ela também atua impedindo que qualquer critério fique negativo, já que $d_{\mathrm{j}}$ assume valores menores que $100 \%$. A equação (3.6) considera a mesma limitação de variação para o aumento e a redução, mas caso o decisor opte por limites diferentes para cada uma das ações de variação a mesma deve ser substituída pelas equações (3.7) e (3.8), as quais permitem impor limites diferentes.

$$
\begin{gathered}
\Delta_{j}^{+} \leq d_{j}^{+} \\
\Delta_{j}^{-} \leq d_{j}^{-}
\end{gathered}
$$

Como output deste modelo é fornecido todas as mínimas variações em cada critério w de forma que satisfaça duas condições: 1) Seja a maior variação dentre todos os critérios; 2) Torne ótima a solução sh testada. A partir desta informação é possível identificar o critério mais crítico.

\subsubsection{Modelo para norma $\mathrm{L}_{1}$}

O problema de PL, composto pelas equações (3.9-3.13) a seguir, roda uma única vez para construir o vetor com a soma mínima das distâncias relativas de cada uma das constantes de escala em relação às constantes de escala originais que iguale ou supere o valor de uma determinada solução, identificada como relevante para uma recomendação mais robusta, à solução ótima do problema original. A partir da soma dos elementos deste vetor obtêm-se a mínima variação necessária das somas das distâncias relativas que vai eleger como ótima a solução escolhida.

$$
\operatorname{Min} \sum_{j=1}^{m}\left(\Delta_{j}^{+}+\Delta_{j}^{-}\right)
$$

S. a.

$$
\begin{aligned}
& \sum_{j=1}^{m}\left(v_{j}\left(s_{t j}\right)-v_{j}\left(s_{h j}\right)\right) k_{j}\left(1+\Delta_{j}^{+}-\Delta_{j}^{-}\right) \geq 0 \quad \forall \mathrm{h} \neq \mathrm{t} \\
& k_{j}\left(1+\Delta_{j}^{+}-\Delta_{j}^{-}\right)-k_{j+1}\left(1+\Delta_{j+1}^{+}-\Delta_{j+1}^{-}\right) \geq 0 \quad \forall \mathrm{j} \neq \mathrm{m}
\end{aligned}
$$




$$
\begin{aligned}
& \sum k_{j}\left(\Delta_{j}^{+}-\Delta_{j}^{-}\right)=0 \\
& \Delta_{j}^{+}+\Delta_{j}^{-} \leq d_{j} \forall \mathrm{j}
\end{aligned}
$$

No qual, $\Delta_{j}^{+}$e $\Delta_{j}^{-}$são as variáveis de decisão que representam a variação na distância relativa das constantes de escala para realizar, respectivamente, o aumento ou redução necessários para tornar ótima a solução desejada no problema inverso. Considerando que duas variáveis $\Delta_{\mathrm{j}}^{+}$e $\Delta_{\mathrm{j}}{ }^{-}$que possuem efeitos de aumento e redução de um parâmetro em um problema de minimização de programação linear, uma das variáveis será sempre zero, para que o efeito delas sobre o parâmetro não se anule parcialmente ou completamente.

No problema de PL representado, a função objetivo (3.9) consiste na minimização do somatório das distâncias relativas entre a solução do problema original e a solução do problema inverso, devido ao uso da norma $\mathrm{L}_{1}$. A solução eleita como ótima está sujeita às restrições que correspondem a otimalidade, normalização e não negatividade das constantes, manutenção da ordenação dos critérios e limitação da variação.

A equação (3.10) expressa que o valor global assumido pela solução desejada, a partir da variação dos valores das constantes de escala, deve ser maior ou igual ao valor das outras soluções quando sofrem a mesma variação, ou seja, a alternativa deve ser melhor ou pelo menos igual a qualquer outra solução em $S$, impondo que a solução seja a ótima para o problema. Desta forma, esta restrição também impede que ao reduzir a distância entre duas soluções, uma terceira acabasse se tornando a ótima no lugar da solução testada, já que a verificação do valor global é feita em comparação com todas as soluções, ao invés de apenas entre as soluções avaliadas.

A equação (3.11) evita que as variações na distância relativa causem uma mudança nos valores das constantes de escala que resulte na inversão na ordenação das mesmas, de modo que um determinado critério deve continuar maior ou igual ao seu sucessor na ordenação. Esta restrição é extremamente importante para o objetivo de aumento da confiança do decisor quanto a recomendação fornecida. É considerado como princípio básico deste estudo, que não há como fornecer mais confiança ao decisor se há uma quebra da informação mais segura proveniente dele, que é a relação estrita de preferência entre os critérios.

A equação (3.12) impõe que as constantes de escala após sofrerem variação em seus valores, devem somar 1, ou seja, devem manter a normalização. De modo que as variações entre aumentos e reduções de sejam compensadas e a normalização não seja alterada. 
A equação (3.13) expressa a limitação $d_{j}$, definida pelo decisor para a variação de aumento e redução das constantes de escala, relacionada a um intervalo de imprecisão que o decisor acredita existir. A atuação dela também impede que qualquer critério fique negativo, já que $d_{\mathrm{j}}$ assume valores menores que $100 \%$. Esta equação considera a mesma limitação de variação para o aumento e a redução, caso o decisor opte por limites diferentes para cada uma das ações de variação a equação (3.13) deve ser substituída pelas equações (3.14) e (3.15), as quais permitem impor limites diferentes.

$$
\begin{aligned}
& \Delta_{j}^{+} \leq d_{j}^{+} \\
& \Delta_{j}^{-} \leq d_{j}^{-}
\end{aligned}
$$

\subsection{Análise dos modelos}

Definição 1: Problema Irrestrito de Otimização Inversa sobre os Pesos dos critérios da Seleção de Portfólio de projetos - PIOISP é caracterizado por não fazer nenhuma imposição de restrições além da normalização e da não negatividade dos pesos.

Definição 2: O Problema Restrito de Otimização Inversa sobre os Pesos dos critérios da Seleção de Portfólio de projetos - PROISP é caracterizado por considerar restrições sobre a manutenção da ordenação, a limitação de variação, a otimalidade, norma de mensuração da distância, além da normalização e não negatividade dos pesos.

Postulado 1: Uma solução dominada pela solução ótima original jamais a superará diante de qualquer mudança nos pesos não importando a distância para os pesos originais nem a norma utilizada (RINGUEST, 1997).

Postulado 2: Uma solução P' jamais poderá ser uma solução ótima do problema com os pesos modificados, se for dominada por uma outra solução viável P', independentemente de P' ' ser ou não a ótima original.

Os postulados 1 e 2 são úteis para alguns casos de geração de soluções, como algoritmos geradores de combinações de fronteira propostos por Vetschera (1994), para identificar as soluções que podem ser descartadas, pois é necessária que a mudança nos pesos em conjunto com o desempenho da alternativa permitam melhorar o valor global da mesma de modo que ela seja capaz de superar a ótima original e qualquer outra solução viável. 
Postulado 3: No PIOISP para $\mathrm{L}_{\infty}$, a maior distância em módulo não ocorrerá para um critério em que as duas soluções possuam o mesmo desempenho, exceto quando houver uma distância igual para outro critério no qual as duas soluções não possuam o mesmo desempenho.

Definição 3: Contribuição é o valor obtido por meio da variação nos pesos que se reflete nos valores globais (ou nas funções valor) das soluções e, consequentemente, na redução da distância entre as soluções avaliadas;

Definição 4: Contribuição relativa de mudança de peso de critério é o valor da redução, da distância entre duas soluções, proporcionada pela variação em apenas um critério, considerando a diferença entre o peso original e o peso necessário para aproximar as soluções.

Definição 5: Contribuição relativa de mudança de peso de transferência é o valor da redução, da distância entre duas soluções, proporcionada pela variação em forma de fluxo/troca entre dois ou mais critérios, considerando a diferença entre os pesos originais e os pesos necessários para aproximar as soluções.

Teorema 1: A contribuição relativa da mudança de peso de um critério para a aproximação do valor de uma solução nova com o valor da solução ótima original é proporcional ao módulo diferença no valor das duas alternativas neste critério. Para $\mathrm{L}_{1}$ no PIOISP e/ou PROISP

Prova:

Seja $s$ a solução nova e $o$ a solução ótima original. Considerando que para os pesos originais, o é a solução ótima e s não é ótima, então podemos considerar que $\mathrm{v}(\mathrm{s})<\mathrm{v}(\mathrm{o})$. A contribuição relativa da mudança de peso de um critério para a aproximação do valor de uma solução nova com o valor da solução ótima original consiste no valor da redução da diferença do valor das duas soluções com a variação do peso de um critério j, dividido pelo módulo da variação de peso de $\mathrm{j}$, conforme a equação 3.16

$$
\frac{\Delta v(s)-\Delta v(o)}{\left|\Delta k_{j}\right|}
$$

Onde

$$
\Delta v(a)=v^{\text {final }}(a)-v^{\text {inicial }}(a)
$$


Sendo $v^{\text {final }}(a)$ e $v^{\text {inicial }}(a)$ o valor após a mudança de peso e o valor antes da mudança de peso respectivamente.

Considerando que hipoteticamente apenas o peso de um critério $\mathrm{j}$ foi modificado, as parcelas da soma do modelo aditivo, referentes aos critérios não modificados, se anulam, de forma que resta como contribuição a equação 3.17

$$
\frac{\Delta k_{j}\left(v_{j}\left(s_{j}\right)-v_{j}\left(o_{j}\right)\right)}{\left|\Delta k_{j}\right|}
$$

Onde $\Delta \mathrm{k}_{\mathrm{j}}$ é a variação do peso do critério $\mathrm{j}, \mathrm{v}_{\mathrm{j}}\left(\mathrm{s}_{\mathrm{j}}\right)$ e $\mathrm{v}_{\mathrm{j}}\left(\mathrm{o}_{\mathrm{j}}\right)$ é o valor da solução nova e da original, respectivamente, para o critério j.

Para provar que o a contribuição cresce com o módulo da diferença dos valores das soluções em $\mathrm{j}$, deve-se considerar que $\Delta \mathrm{k}_{\mathrm{j}}$ pode ser positivo ou negativo, de forma que a contribuição se dará aumentando o peso se a solução nova tiver desempenho melhor que a original e reduzindo se a solução nova tiver desempenho pior que a original,, provando o teorema 1.

O teorema 1 mostra que quanto maior o módulo da diferença entre os valores das soluções, mais indicado esse critério é para ter seu peso variado.

É necessário considerar, no entanto, que há uma restrição de normalização dos pesos dos critérios, de forma que a soma dos pesos deve permanecer igual a 1. Baseado nesta restrição, o teorema 2 demonstra que não é possível um critério ter seu peso variado de maneira independente e que a mudança nos pesos ocorrerá na forma de transferência entre os critérios.

Exemplificando nós temos a tabela 4 a qual permite analisar as soluções diante dos critérios:

Tabela 4: Comparando o desempenho fictício das soluções.

\begin{tabular}{|l|l|l|l|l|l|l|}
\hline $\begin{array}{l}\text { Critério } \\
\text { Alternativa }\end{array}$ & C1 & C2 & C3 & C4 & C5 & C6 \\
\hline Original:E & 1 & 2 & 3 & 5 & 3 & 4 \\
\hline Nova:F & 1 & 2 & 3 & 4 & 5 & 5 \\
\hline
\end{tabular}

Fonte: produzido pelo autor.

Os critérios C5 e C6 trazem vantagem para a solução nova pois nestes critérios a solução nova possui um desempenho melhor que a solução original, mas observando a diferença de desempenho entre as soluções em cada critério percebe-se que em C5 a solução nova possui duas unidades de vantagem, enquanto que em C6 ela possui apenas uma unidade. Sendo assim, C5 contribui mais para aproximar s soluções. 
Teorema 2: No PIOISP e/ou PROISP tanto para $\mathrm{L}_{\infty}$ quanto para $\mathrm{L}_{1}$, a variação de pesos ocorre através de transferência de pesos entre critérios, de forma que a soma das variações dos pesos em todos os critérios será sempre igual a zero.

Prova:

Seja $\mathrm{k}_{\mathrm{j}}$ o peso original do critério $\mathrm{j}$ e $\mathrm{k}_{\mathrm{j}}$ o peso modificado, de forma que

$$
k_{j}^{\prime}=k_{j}+\Delta k_{j}
$$

A restrição de normalização dos pesos faz com que a soma dos pesos dos critérios seja igual a 1, tanto antes quanto depois da variação, de forma que

$$
\begin{gathered}
\sum_{j=1}^{m} k_{j}=\sum_{j=1}^{m} k_{j}^{\prime}=1 \\
\sum_{j=1}^{m} k_{j}=\sum_{j=1}^{m}\left(k_{j}+\Delta k_{j}\right) \\
\sum_{j=1}^{m} k_{j}=\sum_{j=1}^{m} k_{j}+\sum_{j=1}^{m} \Delta k_{j} \\
\sum_{j=1}^{m} \Delta k_{j}=0
\end{gathered}
$$

Provando o teorema 2.

A partir do teorema 2, é possível perceber que a análise da contribuição isolada de um critério não faz sentido, visto que seu peso não pode variar sozinho. É possível, no entanto, analisar a contribuição de uma transferência de pesos entre critérios, de forma que derivando do Teorema 1, temos que a contribuição relativa da transferência para a aproximação do valor de uma solução nova para o valor da solução ótima original pode ser calculada através da equação 3.18

$$
\frac{v\left(s_{j}\right)-v\left(o_{j}\right)}{\sum|\Delta k|}=\frac{\sum \Delta k_{j}\left(v\left(s_{j}\right)-v\left(o_{j}\right)\right)}{\sum\left|\Delta k_{j}\right|}
$$

Onde é considerada a soma dos produtos da variação do peso pela diferença de valor entre as soluções para cada critério, dividido pela soma dos módulos das variações dos pesos.

Um ponto importante a ser considerado é que não necessariamente apenas a solução original possui valor superior ao da solução nova para os pesos originais. Considerando que o objetivo da otimização inversa sobre os pesos é tornar ótima a solução nova para os novos pesos, significa que ela deve ter seu valor no mínimo igual ao valor de qualquer outra solução.

Seja B o conjunto das soluções $a_{b}$ cujos valores superam o valor da solução nova. É possível verificar que o valor da solução nova deverá crescer de forma que: 


$$
\Delta v(s)-\Delta v\left(a_{b}\right) \geq v\left(a_{b}\right)-v(n) \quad \forall b \in B
$$

De forma que quando o valor da solução nova se iguala ao valor de uma solução em $B$, tal solução deixa de superar o valor da solução nova e consequentemente é excluída do conjunto B. Adicionalmente, uma restrição deve ser considerada no problema de otimização inversa, tal que o valor da solução excluída de B não volte a superar o valor da solução nova para as próximas variações de peso. Quando B se tornar um conjunto vazio, a otimização inversa terá encontrado uma solução.

Considerando que a solução nova deve ter seu valor igual ou maior que toda a solução em B, é possível calcular a contribuição relativa da transferência de pesos para tornar B um conjunto vazio através da equação (3.19), adaptada da equação (3.18):

$$
\frac{\sum_{b \in B} \Delta v(s, b)}{\sum\left|\Delta k_{j}\right|}
$$

Tal que

$$
\Delta v(s, b)=\left\{\begin{array}{lll}
\sum \Delta k_{j}\left(v\left(s_{j}\right)-v\left(a_{b j}\right)\right) & \text { para } & \sum \Delta k_{j}\left(v\left(s_{j}\right)-v\left(a_{b j}\right)\right)<v(s)-v\left(a_{b}\right) \\
v(s)-v\left(b_{l}\right) & \text { para } & \sum \Delta k_{j}\left(v\left(s_{j}\right)-v\left(a_{b j}\right)\right) \geq v(s)-v\left(a_{b}\right)
\end{array}\right.
$$

Deve-se levar em consideração que ao variar os pesos com o objetivo de esvaziar B, ou seja, de fazer com que o valor da solução nova se iguale ou supere o valor de qualquer solução ab, é possível que uma solução que não estava em B inicialmente supere o valor da solução nova. Neste caso, a solução antes não identificada passa a compor B, tornando-o um conjunto não vazio. Isso significa que a otimização inversa ainda não encontrou uma solução e que a transferência de pesos deve continuar.

É possível que nenhuma transferência de pesos possa ser realizada sem violar alguma das restrições que foram impostas, tanto da não negatividade, quanto da ordenação, dos limites de variação de peso e da imposição do valor da solução nova maior ou igual ao das soluções que saíram de B. Neste caso a otimização inversa não possui solução e não há variação de peso que torne ótima a solução s sem violar a ordenação e nem os limites de variação de pesos.

Exemplificando o teorema 2 podemos verificar a figura 2 que apresenta os pesos de cinco critérios fictícios que estão devidamente normalizados. 
Figura 2: Valores dos pesos originais.

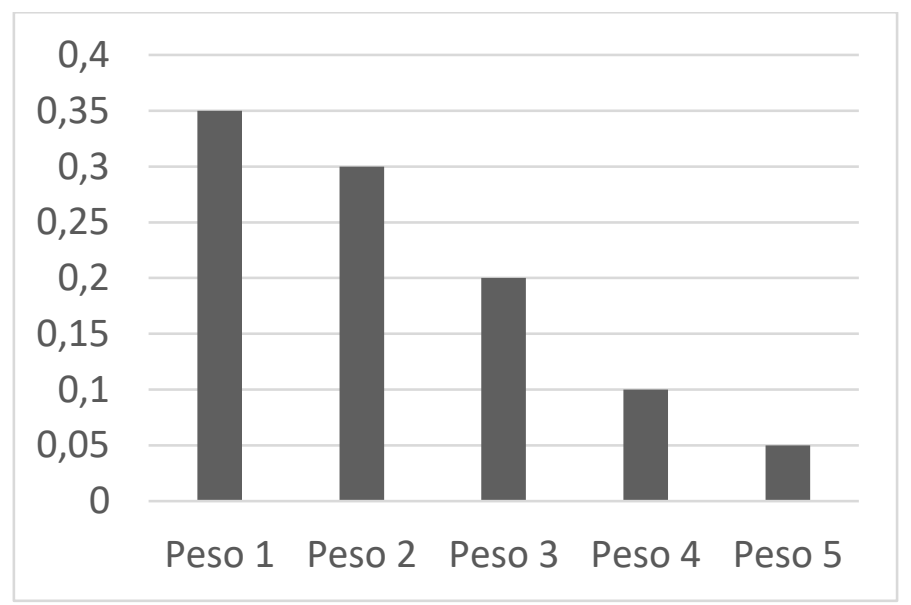

Fonte: Produzido pelo autor.

Em seguida verificamos nas figuras 3 e 4 que ao realizar o aumento (cor verde) ou redução (cor branca) em um critério de forma independente faria com que os pesos deixassem a normalização.

Figura 3: Aumento independente do peso.

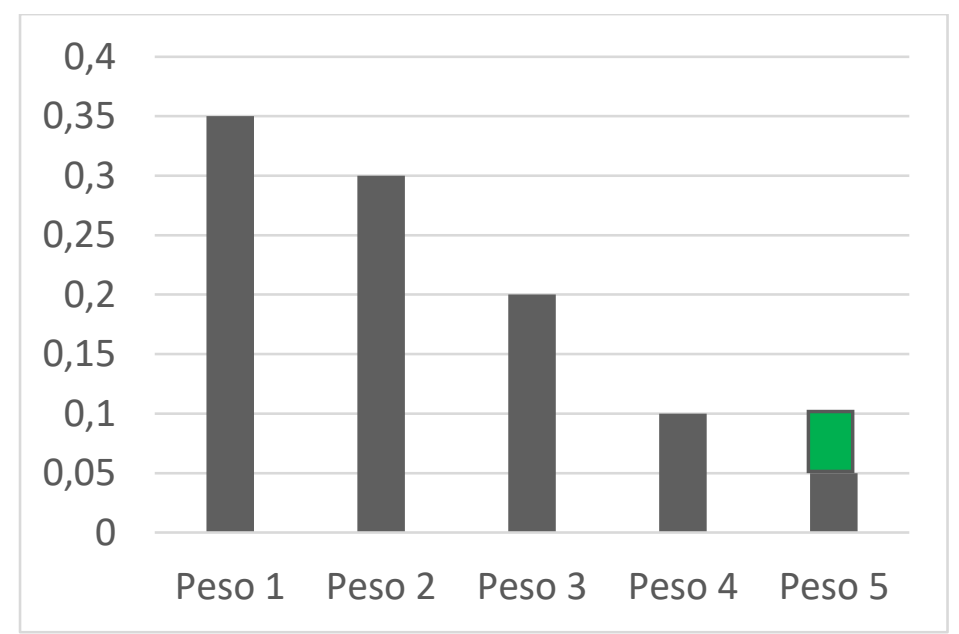

Fonte: Produzido pelo autor. 
Figura 4: Redução independente do peso.

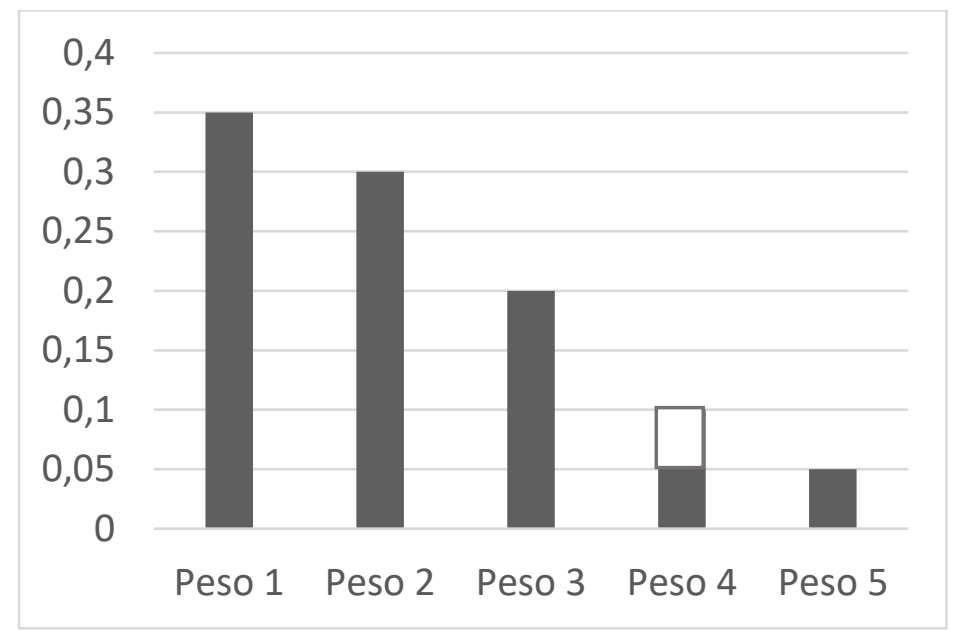

Fonte: Produzido pelo autor.

De modo que o problema na verdade realiza a transferência reduzindo (branco) e aumentando (verde) determinados critérios. Como é mostrado na figura 5.

Figura 5: Transferência de variação do peso.

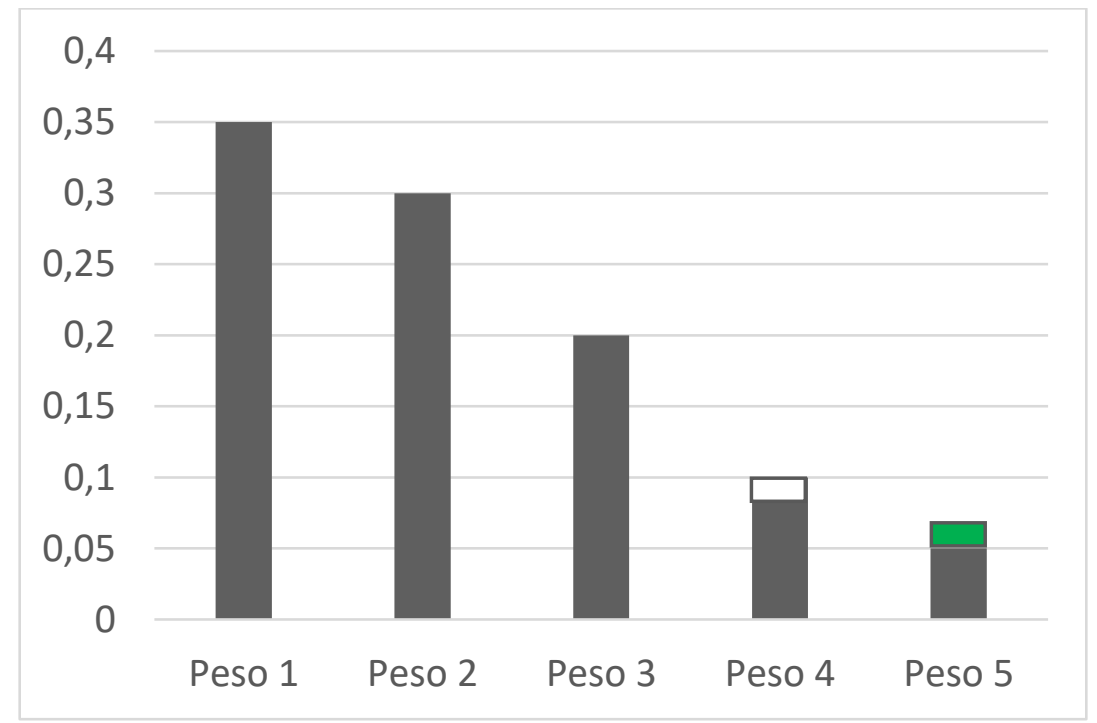

Fonte: Produzido pelo autor.

Teorema 3: Para $\mathrm{L}_{1}$ em um PIOISP com o objetivo de igualar o valor de uma solução nova com o valor da solução ótima original, não haverá variação dos pesos para um critério em que as soluções possuam o mesmo desempenho, de modo que é priorizado o fluxo de transferência de um critério no qual a solução ótima original tem melhor desempenho que a solução nova para um critério em que a solução ótima original tem pior desempenho que a 
solução nova, descartando-se a hipótese da solução nova ser dominada, de acordo com os postulados 1 e 2 .

Prova:

Considere três tipos de critérios em um problema de seleção de portfólio de projetos: $\mathrm{C}^{>}, \mathrm{C}^{<}$e $\mathrm{C}^{=}$, onde o primeiro representa os critérios em que a solução ótima original possui desempenho superior ao da solução nova, o segundo tipo representa os critérios em que a solução ótima original tem desempenho inferior ao da solução nova e o terceiro tipo representa os critérios em que ambas soluções possuem o mesmo desempenho.

Sejam $\mathrm{T}^{><}, \mathrm{T}^{>=}$e $\mathrm{T}^{=<}$respectivamente a transferência de pesos de $\mathrm{C}^{>}$para $\mathrm{C}^{<}$, a transferência de pesos de $C^{>}$para $C^{=}$e a transferência de pesos de $C^{=}$para $C^{<}$.

Usando a equação (3.18) que representa a contribuição de uma transferência em $\mathrm{L}_{1}$ para o PIOISP, é possível verificar que, para uma mesma transferência de pesos entre dois critérios, o valor para os três tipos de transferências é definido por:

$$
\begin{aligned}
& v\left(T^{><}\right)=\frac{\Delta k^{>}\left(v_{j}^{>}\left(s_{j}\right)-v_{j}^{>}\left(o_{j}\right)\right)+\Delta k^{<}\left(v_{j}^{<}\left(s_{j}\right)-v_{j}^{<}\left(o_{j}\right)\right)}{\sum\left|\Delta k_{j}\right|} \\
& v\left(T^{>=}\right)=\frac{\Delta k^{>}\left(v_{j}^{>}\left(s_{j}\right)-v_{j}^{>}\left(o_{j}\right)\right)+\Delta k^{=}\left(v_{j}^{=}\left(s_{j}\right)-v_{j}^{=}\left(o_{j}\right)\right)}{\sum\left|\Delta k_{j}\right|} \\
& v\left(T^{=<}\right)=\frac{\Delta k^{=}\left(v_{j}^{=}\left(s_{j}\right)-v_{j}^{=}\left(o_{j}\right)\right)+\Delta k^{<}\left(v_{j}^{<}\left(s_{j}\right)-v_{j}^{<}\left(o_{j}\right)\right)}{\sum\left|\Delta k_{j}\right|}
\end{aligned}
$$

Para aproximar o valor das duas soluções, $C^{>}$cederá peso para $\mathrm{C}^{<}$em $\mathrm{T}^{><}, \mathrm{C}^{>}$cederá peso para $\mathrm{C}^{=}$em $\mathrm{T}^{>=}$e $\mathrm{C}^{=}$cederá peso para $\mathrm{C}^{<}$em $\mathrm{T}^{=<}$, de forma que $\Delta \mathrm{k}^{>}<0, \Delta \mathrm{k}^{<}>0, \Delta \mathrm{k}^{=}>0$ para $\mathrm{T}^{>=}$e $\Delta \mathrm{k}^{=}<0$ para $\mathrm{T}^{=<}$. Pela definição de $\mathrm{C}^{>}, \mathrm{C}^{<}$e $\mathrm{C}^{=}$, é possível concluir também que:

$$
\begin{aligned}
& \left(v_{j}^{>}\left(s_{j}\right)-v_{j}^{>}\left(o_{j}\right)\right)<0 \\
& \left(v_{j}^{<}\left(s_{j}\right)-v_{j}^{<}\left(o_{j}\right)\right)>0 \\
& \left(v_{j}^{=}\left(s_{j}\right)-v_{j}^{=}\left(o_{j}\right)\right)=0
\end{aligned}
$$

De forma que:

$$
\begin{aligned}
& \Delta k^{>}\left(v_{j}^{>}\left(s_{j}\right)-v_{j}^{>}\left(o_{j}\right)\right)>0 \\
& \Delta k^{<}\left(v_{j}^{<}\left(s_{j}\right)-v_{j}^{<}\left(o_{j}\right)\right)>0 \\
& \Delta k^{=}\left(v_{j}^{=}\left(s_{j}\right)-v_{j}^{=}\left(o_{j}\right)\right)=0
\end{aligned}
$$

Logo 


$$
\begin{aligned}
& v\left(T^{><}\right)-v\left(T^{>=}\right)=\frac{\Delta k^{<}\left(v_{j}^{<}\left(s_{j}\right)-v_{j}^{<}\left(o_{j}\right)\right)}{\Sigma\left|\Delta k_{j}\right|}>0 \\
& v\left(T^{><}\right)-v\left(T^{=<}\right)=\frac{\Delta k^{>}\left(v_{j}^{>}\left(s_{j}\right)-v_{j}^{>}\left(o_{j}\right)\right)}{\sum\left|\Delta k_{j}\right|}>0
\end{aligned}
$$

E o teorema 3 está provado.

Exemplificando, na tabela 5 é possível verificar os critérios em que a solução original ganha e os critérios em que a solução nova ganha.

Tabela 5: Comparando o desempenho fictício das soluções.

\begin{tabular}{|l|l|l|l|l|l|}
\hline $\begin{array}{l}\text { Critério } \\
\text { Alternativa }\end{array}$ & $\mathrm{C} 1$ & $\mathrm{C} 2$ & $\mathrm{C} 3$ & $\mathrm{C} 4$ & $\mathrm{C5}$ \\
\hline Original:E & 1 & 2 & 3 & 5 & 3 \\
\hline Nova:F & 1 & 2 & 3 & 4 & 5 \\
\hline
\end{tabular}

Fonte: produzido pelo autor.

Então o problema realiza a transferência de modo que há redução (em branco) do peso de C4 que é transferido para aumentar (em verde) o peso de C5, como mostrado na figura 6. Já que o problema só considera as restrições de não negatividade e normalização, os critérios $\mathrm{C} 1$, C2 e C3 não sofrem variação pois são critérios nos quais as soluções possuem desempenho igual.

Figura 6: Transferência de variação do peso.

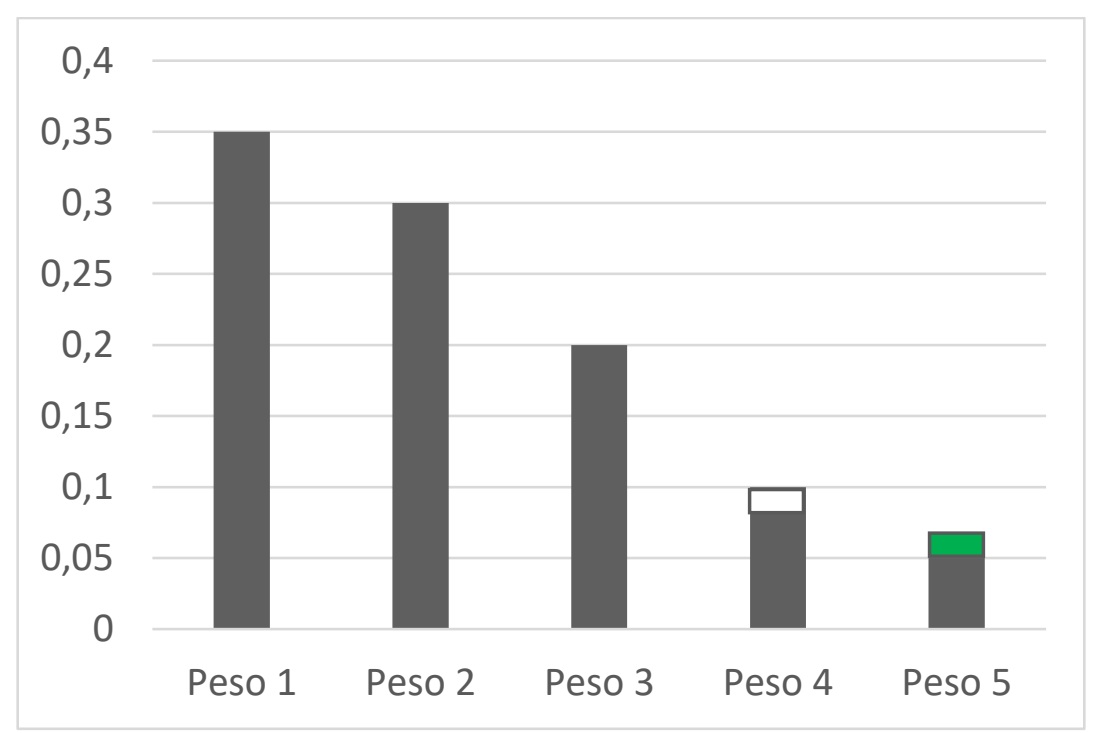

Fonte: Produzido pelo autor. 
O Lema 1 demonstra que sempre haverá pelo menos um critério $\mathrm{C}^{>}$e um critério $\mathrm{C}^{<}$ permitindo que $\mathrm{T}^{><}$seja sempre possível.

Lema 1: Para PIOISP e/ou PROISP, sempre haverá pelo menos um critério $\mathrm{C}^{>}$e um critério $C^{<}$para o par de soluções composto pela solução ótima original e a solução nova não dominada.

Prova: Sejam consideradas as três suposições abaixo:

Suposição 1: Não há critérios $C^{>}$para o par de soluções composto pela solução ótima original e a solução nova não dominada, mas existem critérios $\mathrm{C}^{<} \mathrm{e} \mathrm{C}^{=}$.

Suposição 2: Não há critérios $C^{<}$para o par de soluções composto pela solução ótima original e a solução nova não dominada, mas existem critérios $\mathrm{C}^{>} \mathrm{e} \mathrm{C}^{=}$.

Suposição 3: Não há critérios $C^{<}$nem $C^{>}$para o par de soluções composto pela solução ótima original e a solução nova não dominada, mas existem critérios $\mathrm{C}^{=}$.

Para a suposição 1, a solução nova dominaria a solução ótima original, de forma que a suposição 1 é impossível por reductio ad absurdum.

Para a suposição 2, a solução ótima original dominaria a solução nova, de forma que a suposição contradiz a condição necessária de não dominância do Postulado 1 para a solução nova e a otimização inversa não teria solução.

Para a suposição 3, a solução ótima e a original teriam o mesmo valor independentemente dos pesos, de forma que o problema de otimização inversa não faria sentido.

Eliminando as três suposições, o Lema 1 está provado por exclusão.

Teorema 4: Para $\mathrm{L}_{1}$ em um PROISP, a distância nos critérios que as soluções possuem o mesmo desempenho será igual a zero, a não ser que as restrições de ordenação ou de limitação da variação dos pesos obrigue a sair de zero.

Prova:

De acordo com o Teorema 3, no problema de otimização inversa irrestrito, um critério em que as duas soluções possuem a mesma performance não terá variação no seu peso, uma vez que aumenta L1 sem contribuir para a aproximação do valor das duas soluções.

Para o problema restrito, no entanto, a transferência de peso de um critério C> para um critério $\mathrm{C}<$ possui limitações. Tal transferência pode cessar caso uma das duas condições abaixo se torne verdadeira

$$
\begin{gathered}
\Delta \mathrm{k}_{\mathrm{j}}=d_{j}^{+} \mathrm{k}_{\mathrm{j}} \text { ou } \Delta \mathrm{k}_{\mathrm{j}}=d_{j}^{-} \mathrm{k}_{\mathrm{j}} \\
\mathrm{k}_{\mathrm{j}}+\Delta \mathrm{k}_{\mathrm{j}}=\mathrm{k}_{\mathrm{j}}-1 \text { ou } \mathrm{k}_{\mathrm{j}}+\Delta \mathrm{k}_{\mathrm{j}}=\mathrm{k}_{\mathrm{j}}+1
\end{gathered}
$$


Isto é, seja por que a variação em um dos critérios atingiu o limite de variação considerado pelo intervalo de variação dos pesos, ou por que o valor do peso de um dos critérios envolvidos na transferência alcançou o valor do peso de um critério vizinho na ordenação, de forma que se a transferência de peso continuar, haverá uma inversão de ordem dos critérios.

Para o caso em que a primeira condição se verifique, tal critério não deve mais ter seu peso variado com o objetivo de aproximar as duas soluções.

Por outro lado, quando apenas a condição 2 se verifica, a transferência só poderá prosseguir se o valor do critério vizinho também variar. Desta forma a transferência agora passa a envolver mais de dois critérios e sua contribuição deve ser calculada pela equação 3.18, considerando os três critérios envolvidos.

Seja $\mathrm{k}_{\mathrm{j}}$ o peso de um critério $\mathrm{c}_{\mathrm{j}} \in \mathrm{C}^{>}$que perde valor em uma transferência de pesos entre dois critérios. Seja $k_{j+1}$ o peso do critério $c_{j+1} \in C^{=}$, imediatamente abaixo de $c_{j}$ na ordenação, de forma que se verifique a seguinte condição:

$$
d_{j}^{-} k_{j}>k_{j}-k_{j+1}
$$

Ou seja, o intervalo de variação de $\mathrm{k}_{\mathrm{j}}$ permite que seu valor seja inferior ao valor original de $\mathrm{k}_{\mathrm{j}+1}$, mesmo que $\mathrm{k}_{\mathrm{j}}$ não possa ser menor que $\mathrm{k}_{\mathrm{j}+1}$.

Seja $d_{j}^{-} k_{j}=\Delta^{\prime} \mathrm{k}_{\mathrm{j}}^{-}+\Delta^{\prime \prime} \mathrm{k}_{\mathrm{j}}^{-}$, de forma que:

$$
\Delta^{\prime} k_{j}^{-}=k_{j}-k_{j+1}
$$

Significa que $\mathrm{k}_{\mathrm{j}}$ pode ser reduzido em até $\Delta^{\prime} \mathrm{k}_{\mathrm{j}}{ }^{-}$sem que a ordenação dos pesos seja invertida. Seja $\mathrm{k}_{\mathrm{j}}$ ' o peso de $\mathrm{c}_{\mathrm{j}}$ após ter sido reduzido em $\Delta^{\prime} \mathrm{k}_{\mathrm{j}}^{-}$. É fácil verificar que o peso de $\mathrm{c}_{\mathrm{j}}$ terá atingido tal valor que $\mathrm{k}_{\mathrm{j}}{ }^{\prime}=\mathrm{k}_{\mathrm{j}+1}$. Dado que o peso de $\mathrm{c}_{\mathrm{j}}$ não pode ser inferior ao de $\mathrm{c}_{\mathrm{j}+1}$, então a partir de $\mathrm{k}_{\mathrm{j}}$ ', uma redução do peso do critério $\mathrm{c}_{\mathrm{j}}$ terá que ser acompanhada de uma redução de pelo menos mesmo valor em módulo para o critério $c_{j+1}$. Seja $k_{j}$ " o valor do peso do critério $\mathrm{c}_{\mathrm{j}}$, reduzido de forma que $\mathrm{k}_{\mathrm{j}}$ " $<\mathrm{k}_{\mathrm{j}+1}$. Para que isso aconteça, o valor do peso do critério $\mathrm{c}_{\mathrm{j}+1}$ terá que assumir um valor $\mathrm{k}_{\mathrm{j}+1}$ ', tal que

$$
\begin{gathered}
k_{j+1}^{\prime} \leq k_{j} " \\
k_{j}{ }^{\prime}=k_{j}{ }^{\prime}-\Delta k=k_{j+1}-\Delta k \\
0 \leq \Delta k \leq \Delta " k_{j} \\
k_{j+1}^{\prime} \leq k_{j+1}-\Delta k
\end{gathered}
$$

Provando-se o teorema 4 por indução.

Exemplificando, na tabela 6 é possível verificar os critérios em que a solução original ganha e os critérios em que a solução nova ganha. 
Tabela 6: Comparando o desempenho fictício das soluções.

\begin{tabular}{|l|l|l|l|l|l|}
\hline $\begin{array}{l}\text { Critério } \\
\text { Alternativa }\end{array}$ & $\mathrm{C} 1$ & $\mathrm{C} 2$ & $\mathrm{C} 3$ & $\mathrm{C} 4$ & $\mathrm{C} 5$ \\
\hline Original:E & 1 & 2 & 3 & 5 & 3 \\
\hline Nova: $\mathrm{F}$ & 1 & 2 & 3 & 4 & 5 \\
\hline
\end{tabular}

Fonte: produzido pelo autor.

Com o problema considerando também as restrições de manutenção da ordenação e limitação da variação. Ao realizar a transferência de todo o valor que é reduzido (branco) de um critério para aumentar (verde) o peso de outro critério pode ser que ocorra violação de uma dessas restrições, como ocorre na figura 7 , na qual a restrição de manutenção da ordenação é violada quando o peso de $\mathrm{C} 5$ supera o peso de $\mathrm{C} 4$.

Figura 7: Transferência de variação do peso com violação de restrição.

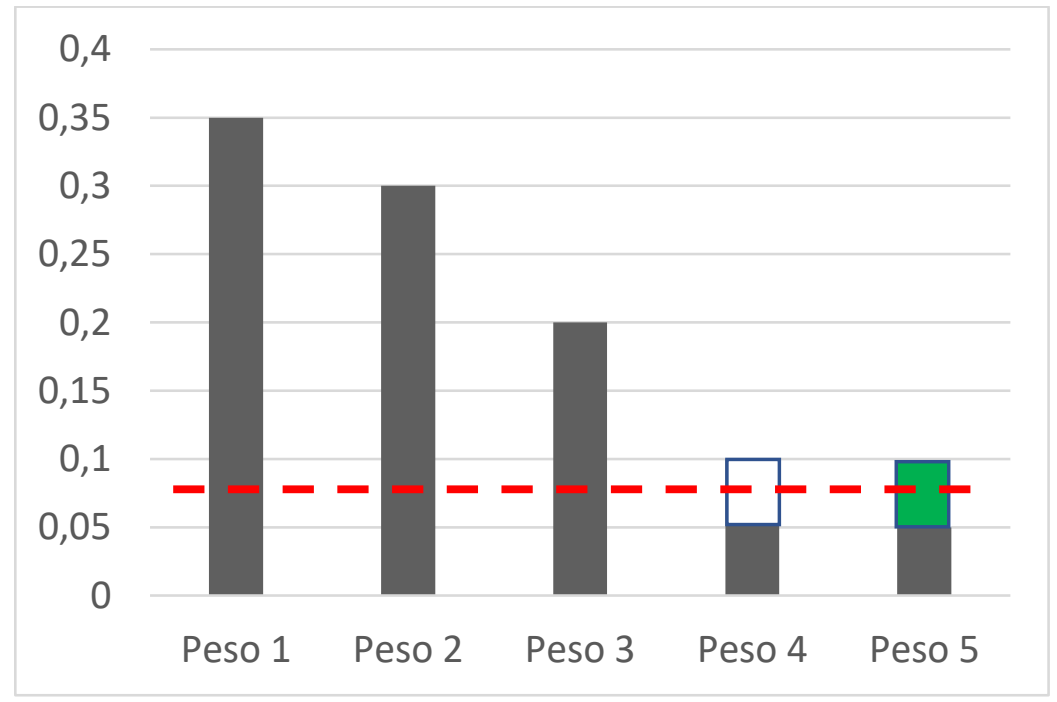

Fonte: Produzido pelo autor.

Então a transferência deve ocorrer de modo que nenhuma restrição seja violada. Como mostrado na figura 8. 
Figura 8: Transferência de variação do peso sem violar restrições.

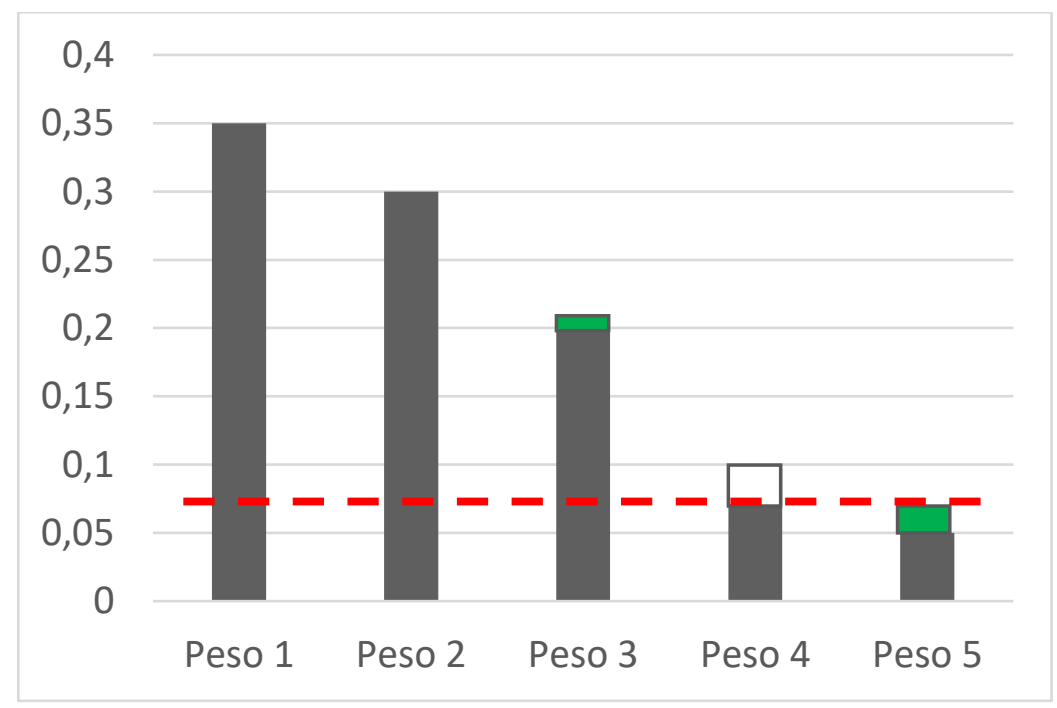

Fonte: Produzido pelo autor.

De modo que ao reduzir $\mathrm{C} 4$, uma parte da variação vai para $\mathrm{C5}$, desde que não viole nenhuma restrição, e o excedente é acomodado em um critério no qual as soluções possuem desempenho igual.

Corolário 1: Para o PROISP, a continuidade de uma transferência de pesos com a inclusão de um critério no qual as duas soluções possuam o mesmo desempenho, como o caso citado pelo teorema 4 , fará com que a contribuição relativa da transferência seja reduzida ao considerar a inclusão da distância no novo critério.

Prova:

O teorema 4 mostra que se o peso de um critério se iguala ao peso do critério vizinho durante a transferência de pesos, a partir desse momento, o peso do critério vizinho deve se distanciar junto com o critério que o alcançou, para que não haja inversão de ordem. É fácil verificar que quando as duas soluções possuem o mesmo desempenho para o critério vizinho que foi alcançado, a variação nos dois critérios deve ser igual a partir deste ponto, mantendo os dois pesos iguais, caso contrário não se minimiza a distância em $\mathrm{L}_{1}$.

Seja $k_{w}$ e $k_{y}$ os pesos dos dois critérios envolvidos inicialmente na transferência, de forma que y cede peso para w. Seja $\mathrm{k}_{\mathrm{y}+1}$ o peso do terceiro critério, alcançado por $\mathrm{k}_{\mathrm{y}}$, e no qual as duas soluções possuem o mesmo desempenho. De acordo com a equação 3.18 que descreve a contribuição de uma transferência, a contribuição da nova transferência será igual a: 


$$
\frac{\Delta k_{w}\left(v_{w}\left(s_{w}\right)-v_{w}\left(o_{w}\right)\right)+\Delta k_{y}\left(v_{y}\left(s_{y}\right)-v_{y}\left(o_{y}\right)\right)+\Delta k_{y+1}\left(v_{y+1}\left(s_{y+1}\right)-v_{y+1}\left(o_{y+1}\right)\right)}{\left|\Delta k_{w}+\Delta k_{y}+\Delta k_{y+1}\right|}
$$

Dado que w recebe peso de y e de $\mathrm{y}+1$, e que $\Delta \mathrm{k}_{\mathrm{y}}=\Delta \mathrm{k}_{\mathrm{y}}+1$, é fácil verificar que

$$
\begin{gathered}
\left|\Delta k_{w}\right|=\left|\Delta k_{y}+\Delta k_{y+1}\right| \\
\left|\Delta k_{w}\right|+\left|\Delta k_{y}\right|+\left|\Delta k_{y+1}\right|=4\left|\Delta k_{y}\right|
\end{gathered}
$$

Seguindo a ideia do teorema 1 , é fácil verificar também que

$$
\Delta k_{y+1}\left(v_{y+1}\left(s_{y+1}\right)-v_{y+1}\left(o_{y+1}\right)\right)=0
$$

Consequentemente a contribuição da transferência pode ser simplificada, considerando $\Delta \mathrm{k}=\left|\Delta \mathrm{k}_{\mathrm{y}}\right|$ para

$$
\frac{2 \Delta k\left|\left(v_{w}\left(s_{w}\right)-v_{w}\left(o_{w}\right)\right)\right|+\Delta k\left|\left(v_{y}\left(s_{y}\right)-v_{y}\left(o_{y}\right)\right)\right|}{4 \Delta k}
$$

A transferência antes de igualar o peso do critério vizinho possuía a seguinte contribuição:

$$
\begin{aligned}
& \frac{\Delta k\left|\left(v_{w}\left(s_{w}\right)-v_{w}\left(o_{w}\right)\right)\right|+\Delta k\left|\left(v_{y}\left(s_{y}\right)-v_{y}\left(o_{y}\right)\right)\right|}{2 \Delta k} \\
= & \frac{2 \Delta k\left|\left(v_{w}\left(s_{w}\right)-v_{w}\left(o_{w}\right)\right)\right|+2 \Delta k\left|\left(v_{y}\left(s_{y}\right)-v_{y}\left(o_{y}\right)\right)\right|}{4 \Delta k}
\end{aligned}
$$

A diferença entre contribuição relativa nova e a anterior à inclusão do terceiro critério é

$$
\begin{gathered}
\frac{2 \Delta k\left|\left(v_{w}\left(s_{w}\right)-v_{w}\left(o_{w}\right)\right)\right|+\Delta k\left|\left(v_{y}\left(s_{y}\right)-v_{y}\left(o_{y}\right)\right)\right|-2 \Delta k\left|\left(v_{w}\left(s_{w}\right)-v_{w}\left(o_{w}\right)\right)\right|+2 \Delta k\left|\left(v_{y}\left(s_{y}\right)-v_{y}\left(o_{y}\right)\right)\right|}{4 \Delta k} \\
=\frac{-\Delta k\left|\left(v_{y}\left(s_{y}\right)-v_{y}\left(o_{y}\right)\right)\right|}{4 \Delta k}=-\frac{\left|\left(v_{y}\left(s_{y}\right)-v_{y}\left(o_{y}\right)\right)\right|}{4}<0
\end{gathered}
$$

Provando o corolário 1 por indução.

Para exemplificar, considera-se uma transferência que envolve apenas critérios nos quais as soluções possuem desempenhos diferentes, esta vai utilizar uma determinada variação dos pesos para realizar uma determinada variação para aproximação das alternativas. E considera-se outra transferência que envolve critérios nos quais as soluções possuem desempenho igual, nesta será utilizada uma variação dos pesos maior que na anterior para realizar a mesma variação na aproximação das soluções que no caso anterior.

Triantaphyllou e Sánchez (1997) explicam que uma mudança em termos de valor absoluto não fornece informação suficiente para conclusões já que é necessário saber o valor original do peso. Portanto, o uso de mudanças relativas, ou seja, percentual de mudança são mais informativos. 
Definição 6: Distância relativa é a razão entre a diferença, do valor do peso originalmente conhecido e o valor requerido que o peso atinja para uma determinada solução se tornar ótima, e o valor original do peso.

Teorema 5: Para PIOISP e/ou PROISP em $\mathrm{L}_{1}$ e $\mathrm{L}_{\infty}$, a contribuição da variação do peso de um critério para aproximar o valor da solução nova e o valor da solução ótima original é proporcional ao peso original do critério e ao módulo diferença no valor das duas alternativas neste critério.

Prova:

Como resultado do teorema 1, temos a equação (3.21) que demonstra que a variação será proporcional ao módulo da diferença de valor entre as alternativas para o critério j.

$$
\frac{\Delta k_{j}\left(v_{j}\left(s_{j}\right)-v_{j}\left(o_{j}\right)\right)}{\left|\Delta k_{j}\right|}
$$

Pela definição de distância relativa, temos que

$$
\Delta_{j}=\frac{\Delta k_{j}}{k_{j}} \quad \longrightarrow \quad \Delta k_{j}=\Delta_{j} k_{j}
$$

Substituindo na equação (3.21), temos que

$$
\frac{\Delta v(s)-\Delta v(o)}{\left|\Delta_{j}\right|}=\frac{\Delta_{j}^{\prime} k_{j}\left(v_{j}\left(s_{j}\right)-v_{j}\left(o_{j}\right)\right)}{\left|\Delta^{\prime} j^{\prime}\right|}
$$

$\Delta{ }^{\prime}$ j considerado na equação (3.22) representa a variação relativa de peso que o critério j pode ter sem violar nenhuma restrição. Como $\mathrm{L}_{1}$ está sendo medido em distância relativa, então a contribuição relativa também deve considerar a mesma unidade no denominador.

Desta forma, o teorema 5 está provado.

Como consequência do teorema 5 , temos que um critério que possui um módulo elevado de diferença entre o valor das duas soluções não necessariamente é um bom critério para ser variado, uma vez que se o peso original deste critério for pequeno, a contribuição ao final será bastante reduzida.

De maneira similar é possível adaptar as equações (3.21) e (3.22) para calcular a contribuição relativa de uma transferência para a aproximação do valor das duas soluções e para tornar B um conjunto vazio, considerando a distância relativa em $\mathrm{L}_{1}$.

$$
\begin{gathered}
\frac{v(s)-v(o)}{\sum\left|\Delta_{j}^{\prime}\right|}=\frac{\sum \Delta_{j}^{\prime} k_{j} v\left(s_{j}\right)-v\left(o_{j}\right)}{\sum\left|\Delta_{j}^{\prime}\right|} \\
\frac{\sum_{b \in B} \Delta v(s, b)}{\sum\left|\Delta_{j}^{\prime}\right|}=\frac{\sum_{b \in B} \sum \Delta_{j}^{\prime} k_{j}\left(v\left(s_{j}\right)-v\left(a_{b j}\right)\right)}{\sum\left|\Delta_{j}^{\prime}\right|}
\end{gathered}
$$

Tal que 


$$
\Delta v(s, b)=\left\{\begin{array}{lll}
\sum \Delta_{j}^{\prime} k_{j}\left(v\left(s_{j}\right)-v\left(a_{b j}\right)\right) & \text { para } & \sum \Delta_{j}^{\prime} k_{j}\left(v\left(s_{j}\right)-v\left(a_{b j}\right)\right)<v(s)-v\left(a_{b}\right) \\
v(s)-v\left(a_{b}\right) & \text { para } & \sum \Delta_{j}^{\prime} k_{j}\left(v\left(s_{j}\right)-v\left(a_{b j}\right)\right) \geq v(s)-v\left(a_{b}\right)
\end{array}\right.
$$

Como consequência do teorema 5, temos o corolário 2 que prova que a soma das variações relativas poderá ser diferente de zero, ao contrário do problema abordado no teorema 2, e o corolário 3 que prova que há uma menor necessidade de considerar a restrição de não negatividade no PROISP, quando considerada a variação relativa.

Como exemplo, a tabela 7 destaca os critérios que trazem vantagem para a solução nova ser eleita como ótima.

Tabela 7: Comparando o desempenho fictício das soluções.

\begin{tabular}{|l|l|l|l|l|l|l|}
\hline $\begin{array}{l}\text { Critério } \\
\text { Alternativa }\end{array}$ & C1 & C2 & C3 & C4 & C5 & C6 \\
\hline Original:E & 1 & 2 & 3 & 5 & 3 & 4 \\
\hline Nova:F & 1 & 2 & 3 & 4 & 5 & 5 \\
\hline
\end{tabular}

Fonte: Produzido pelo autor.

Pode-se perceber que C5 já contribui mais, devido uma diferença maior entre as soluções. Mas comparando C5 e C6, verifica-se que C5 também contribui mais devido o seu peso ser maior que o peso de C6. Assim, este critério consegue receber mais peso de uma transferência, já que considera-se a variação relativa ao seu peso. Se no exemplo fossem considerados critérios que trazem vantagem para a solução original, o C5 também conseguiria doar mais peso para a transferência.

Corolário 2: A soma das variações relativas poderá ser diferente de zero para o PIOISP e/ou PROISP considerando a variação relativa, sem violar a restrição de normalização dos pesos, ao contrário do que ocorre no problema abordado no teorema 2.

Prova:

Do teorema 2, temos que

$$
\sum_{j=1}^{m} \Delta k_{j}=0
$$

No entanto, temos do teorema 5, que quando é considerada a variação relativa, temos que considerar que a variação dos pesos é explicada por:

$$
\Delta k_{j}=\Delta_{j} k_{j}
$$

E consequentemente 


$$
\sum_{j=1}^{m} \Delta_{j} k_{j}=0
$$

Para completar a prova, vamos considerar um exemplo onde a transferência ocorre apenas entre dois critérios. Seja $\mathrm{k}_{1}=0,8$ e $\mathrm{k}_{2}=0,2$, de forma que na transferência, o primeiro será reduzido e o segundo aumentado, de forma que k' ${ }_{1}=0,75$ e k' ${ }_{2}=0,25$. Para atingir os novos pesos, $\Delta \mathrm{k}_{1}=-0,05$ e $\Delta \mathrm{k}_{2}=0,05$. Percebe-se que:

$$
\sum_{j=1}^{m} \Delta k_{j}=-0,05+0,05=0
$$

No entanto

$$
\begin{gathered}
\Delta k_{1}=\Delta_{1} k_{1}=0,8 \Delta_{1}=-0,05 \\
\Delta_{1}=-0,0625 \\
\Delta k_{2}=\Delta_{2} k_{2}=0,2 \Delta_{1}=0,05 \\
\Delta_{2}=0,25 \\
\Delta_{1}+\Delta_{2}=0,1875 \neq 0
\end{gathered}
$$

Provando o Corolário 2 por contradição.

Corolário 3: No PIOISP e/ou PROISP, quando considerada a variação relativa, a restrição de não negatividade é desnecessária, desde que a variação relativa tenha um limite inferior maior que -1 para o problema de otimização inversa.

Prova:

Uma variação relativa com valor em módulo igual a 1 representa que o parâmetro pode variar em até $100 \%$, variação bastante alta e incomum para as análises de sensibilidade e de robustez aplicadas sobre os pesos dos critérios.

Considerando que o decisor conheça de maneira suficiente sua estrutura de preferências de forma que seja capaz de definir um intervalo que seja limitado por baixo a um valor $\mathrm{X}>$ $100 \%$, então temos que, dado que os pesos originais são todos maiores que zero, então, para qualquer $\mathrm{j}$

$$
k_{j}^{M I N}=\left(1+X_{j}\right) k_{j}
$$

Onde $\mathrm{k}_{\mathrm{j}}^{\mathrm{MIN}}$ é o menor valor que o novo peso de j pode assumir de acordo com a restrição do limite de variação. Se $\mathrm{X}_{\mathrm{j}}>-100 \%$, então

$$
\left(1+X_{j}\right)>0
$$

E consequentemente

$$
k_{j}^{M I N}=\left(1+X_{j}\right) k_{j}>0
$$


Provando o corolário 3.

Para o PIOISP e/ou PROISP com distância medida através de $\mathrm{L}_{\infty}$, é considerada apenas a maior distância. Desta forma, qualquer critério cujo peso possua variação em módulo inferior ao máximo em módulo pode ter sua variação ampliada sem mudar a distância em $\mathrm{L}_{\infty}$.

Como consequência, qualquer transferência que envolva apenas critérios com variação inferior ao máximo e que possua contribuição para a aproximação da solução nova para o ótimo deverá ser realizada com o objetivo de reduzir a variação máxima ou pelo menos evitar que aumente.

Como consequência do teorema 1 , é fácil perceber que o critério que possui a maior diferença entre o valor da solução nova e da solução original terá maior contribuição na aproximação das duas soluções. De maneira similar é possível identificar o critério que possui maior contribuição para tornar B um conjunto vazio. Tal critério deverá fazer parte da transferência que será priorizada com o objetivo de tornar ótima a nova solução minimizando Lo e consequentemente terá a maior distância, exceto se restrições, como a de não negatividade ou de limite de variação, impedirem esse critério de ter a maior variação de peso. 


\section{APLICAÇÃO}

A partir da etapa 1.1 de identificação dos decisores e outros atores, foi percebido que devido a forma como o APL de confecções de Pernambuco está organizado, o mais adequado é realizar a aplicação do modelo junto a uma das prefeituras que compõem o APL, por questões éticas e devido o manuseio de informações vista como estratégicas a prefeitura não foi divulgada. A partir da estrutura organizacional da prefeitura que se disponibilizou a participar, foi identificado que o decisor mais indicado seria o prefeito, no entanto é do conhecimento de todos as restrições e responsabilidades que tornam difícil o envolvimento direto do prefeito como decisor neste processo. Foi então avaliada a possibilidade do decisor ser de uma das secretarias deste município. As secretarias deste município possuem autonomia para desenvolver, selecionar e implementar projetos. Foi então, identificada uma secretaria diretamente relacionada com as decisões de suporte ao desenvolvimento do APL, e que também tem a função de suporte para as outras secretarias do município, com relação ao desenvolvimento de projetos. A equipe responsável pelo trabalho desta secretaria, possui autonomia para decidir em grupo sobre seus projetos e também influencia os projetos das outras secretarias. Apesar das decisões serem tomadas em grupo, optou-se junto com esta secretaria em definir um representante para assumir o papel de decisor, o qual possui o cargo de coordenador de uma das subáreas da secretaria que é fortemente relacionada com o desenvolvimento do APL. Os dados fornecidos pelo decisor para a estruturação do problema neste modelo foram provenientes de entrevista e também de documentos.

A forma como ocorre a seleção dos projetos neste município, atualmente, não é a mais adequada para maximizar o retorno percebido sobre os investimentos realizados pelo poder público municipal, já que a seleção ocorre de maneira interna e independente em cada secretaria, inclusive sem nenhuma integração entre elas sobre o que está sendo desenvolvido. Dessa forma, foi verificado em conjunto com a secretaria envolvida no estudo que seria mais eficiente a avaliação de todos os projetos desenvolvidos por todas as secretarias. Sendo assim, este estudo realiza uma avaliação conjunta com os projetos provenientes de todas as secretarias, baseando-se em dados reais, resultando em uma seleção integrada que busca maximizar o retorno sobre o investimento. Então, a aplicação da problemática de portfólio é bastante adequada, para lidar com o problema de forma coerente, devido a sua forma de avaliação e as características do problema serem compatíveis.

Vale ressaltar que só estão sendo consideradas informações sobre a atual gestão, que está em seu segundo ano de mandato. Assim busca-se manter a coerência sobre a avaliação, 
além de haver uma maior facilidade de acesso as informações necessárias para avaliar os projetos.

Na etapa 1.2 correspondente a identificação dos objetivos, foram obtidos os objetivos envolvidos na resolução do problema por meio do decisor, não sendo necessário a aplicação de nenhum método para estruturação. Foi informado pelo decisor que estes objetivos são definidos e disseminados, fazendo parte da cultura organizacional e visando o alinhamento das ações da secretaria com os objetivos estratégicos desenvolvidos pela prefeitura para todo o município. Os objetivos declarados foram:

1) Identificar as prioridades de planejamento e implantação de projetos para que uma estrutura sólida e coerente seja estabelecida para dar suporte a melhorias posteriores;

2) Atrair novos empreendimentos, assim como atrair novos consumidores, sejam como pessoa física ou jurídica, relacionados aos bens e serviços do APL;

3) Gerar empregos (formais e informais) relacionados com atividades de produção, comércio e serviço para o ramo de confecção;

4) Aumentar o valor referente à contribuição que a produção e o comércio de confecções representam para o PIB municipal;

5) Incentivar a formalização das empresas, assim como a formalização dos empregos e das contratações para apoiar o suporte financeiro às empresas e as facilidades de credito pessoal;

Os cinco objetivos se convertem em benefícios econômicos para o município e em mais investimento para apoiar o desenvolvimento do APL. Apoio que é proveniente do poder municipal, da iniciativa privada e, até mesmo, da população que vai consumir mais os produtos do APL, contribuindo assim para o desenvolvimento das empresas e do APL como um todo.

A etapa 1.3 de identificação dos critérios permitiu que com base nos objetivos declarados anteriormente o decisor definisse os 5 critérios, considerados relevantes e passíveis de mensuração, na seleção dos projetos ou investimentos que ele realiza para apoiar o APL. Vale ressaltar que apesar da dimensão regional do APL, o esforço municipal tem suas limitações de alcance e de mensuração, portanto os critérios foram estabelecidos dentro dessas limitações. Os critérios estão enumerados de acordo com o respectivo objetivo ao qual estão relacionados, como pode ser visualizado na tabela 3 .

Tabela 8 - Características dos critérios.

\begin{tabular}{|c|c|}
\hline $\begin{array}{c}\text { Objetivo ao } \\
\text { qual se refere }\end{array}$ & Critérios \\
\hline
\end{tabular}




\begin{tabular}{|l|l|}
\hline 1 & Urgência da implantação \\
\hline 2 & Atração de empreendimentos e consumidores \\
\hline 3 & Geração de empregos \\
\hline 4 & Aumento da contribuição para o PIB municipal; \\
\hline 5 & Aumento do poder de compra dos indivíduos \\
\hline
\end{tabular}

Fonte: Produzido pelo autor.

Os critérios 2, 3, 4 e 5 refletem o impacto claramente econômico que é esperado dos investimentos realizados no APL. A priori, já se esperava a presença deste tipo de critério dado o impacto econômico que o APL causa no municipio. Visto que a economia da cidade é, majoritariamente, baseada em atividades relacionadas com produção e comercialização de confecções, todos estes critérios estão fortemente relacionados com indicadores que refletem o fortalecimento do APL. Então ao investir em ações para desenvolver o APL espera-se um impacto positivo nesses indicadores.

Os projetos tiveram suas consequências mensuradas para cada critério sob uma escala Likert de cinco níveis (LIKERT, 1932) correspondentes à 5-'Muito Alto', 4-'Alto', 3'Razoável', 2-'Pouco' e 1-'Muito Pouco'. A escolha desta forma de mensuração para os critérios 2, 3, 4 e 5 é motivada por proporcionar maior comodidade ao decisor e agilidade ao processo de obtenção dos dados. Já o critério 1 é inerentemente qualitativo. A natureza desses critérios implica que quanto maior a consequência no critério maior é o benefício que trará ao decisor, dessa forma esses critérios são de maximização, ou seja, quanto maior a consequência nos critérios, melhor a alternativa é considerada.

Na etapa 1.4 de identificação das propostas de projetos foi realizado um levantamento documental interno às secretarias municipais para obter os projetos já executados e as propostas de projetos em desenvolvimento e as propostas armazenadas, na atual gestão que está em seu segundo ano, o que facilita a coerência dos projetos obtidos, para compor o espaço de alternativas. No total, foram obtidos dados sobre 18 projetos municipais de apoio ao desenvolvimento do APL, dos quais 8 projetos já foram selecionados, e estão sendo implementados e os outros 10 projetos que não foram selecionados para investimento e implementação.

A etapa 1.5 de obtenção da matriz de consequências, da estimativa dos custos dos projetos e da definição do orçamento para o portfólio dos projetos, é resumida na tabela 4 a seguir, que contém os dados necessários para a avaliação multicritério e seleção do portfólio. 
Tabela 9 - Dados para avaliar os projetos.

\begin{tabular}{|c|c|c|c|c|c|c|c|}
\hline Cod & \begin{tabular}{|lc} 
& Critérios \\
Alternativas & \\
\end{tabular} & $\mathrm{C} 1$ & $\mathrm{C} 2$ & $\mathrm{C} 3$ & $\mathrm{C} 4$ & $\mathrm{C} 5$ & $\begin{array}{c}\text { Custo } \\
\mathrm{R} \$\end{array}$ \\
\hline $\mathrm{P} 1$ & $\begin{array}{l}\text { Criação de comitê de integração entre as cidades } \\
\text { do APL }\end{array}$ & 3 & 3 & 2 & 4 & 3 & 95000 \\
\hline $\mathrm{P} 2$ & Portal com vagas de trabalho & 5 & 5 & 5 & 4 & 5 & 145000 \\
\hline P3 & Desburocratização da abertura de empresas & 5 & 5 & 5 & 5 & 5 & 137000 \\
\hline $\mathrm{P} 4$ & Suporte gerencial aos empreendedores & 5 & 5 & 5 & 4 & 5 & 150000 \\
\hline P5 & Sistema de segurança para o centro da cidade & 4 & 5 & 5 & 5 & 5 & 130000 \\
\hline P6 & \begin{tabular}{|l} 
Evento de network para mulheres \\
empreendedoras
\end{tabular} & 4 & 4 & 5 & 5 & 4 & 132000 \\
\hline P7 & Curso de corte e costura para mulheres & 5 & 5 & 4 & 5 & 4 & 150000 \\
\hline P8 & $\begin{array}{l}\text { Empreendedorismo na escola: incentivando o } \\
\text { setor têxtil }\end{array}$ & 4 & 3 & 3 & 3 & 3 & 80000 \\
\hline P9 & $\begin{array}{l}\text { Sistema de integração entre as secretárias para } \\
\text { assuntos e projetos relacionados ao APL }\end{array}$ & 3 & 3 & 4 & 5 & 3 & 100000 \\
\hline P10 & Plataforma para vendas (e-commerce) & 5 & 5 & 5 & 5 & 2 & 151000 \\
\hline P11 & Tratamento e reutilização de água na produção & 3 & 3 & 3 & 4 & 3 & 80000 \\
\hline $\mathrm{P} 12$ & $\begin{array}{l}\text { Destinação adequada de resíduos sólidos da } \\
\text { produção }\end{array}$ & 3 & 3 & 3 & 4 & 3 & 90000 \\
\hline P13 & Calendário de ações de marketing & 4 & 5 & 5 & 5 & 3 & 132500 \\
\hline P14 & Calendário de ações de endomarketing & 4 & 4 & 5 & 5 & 3 & 161000 \\
\hline P15 & Consultoria em gestão de design & 4 & 4 & 4 & 3 & 3 & 100000 \\
\hline P16 & $\begin{array}{l}\text { Formação de base de dados de empreendedores } \\
\text { e trabalhadores }\end{array}$ & 5 & 4 & 4 & 5 & 3 & 137000 \\
\hline P17 & $\begin{array}{l}\text { Desenvolver software de gestão para empresas } \\
\text { do APL }\end{array}$ & 4 & 4 & 4 & 5 & 3 & 100000 \\
\hline P18 & Evento para integração / workshop & 3 & 4 & 4 & 5 & 3 & 87000 \\
\hline
\end{tabular}

Fonte: Produzido pelo autor.

Na etapa 2.1 que consiste em efetuar a modelagem da preferência, foram realizadas algumas entrevistas com o decisor para obter informações que direcionassem para a estrutura de preferências e racionalidade adequadas para representar o decisor. A partir da comparação 
de pares de consequências entre diferentes alternativas foi identificado que as propriedades de ordenabilidade e transitividade eram atendidas e que as relações de preferência estrita e indiferença eram suficientemente adequadas para representar estrutura de preferência do decisor. Também foi identificado que poderia ser assumida uma racionalidade compensatória. Dessa forma, nesta etapa fica definida a utilização do modelo aditivo.

Da etapa 2.2, na qual realiza-se a avaliação intracritério foi obtido a tabela 5, a seguir.

Tabela 10 - Avaliação intracritério.

\begin{tabular}{|c|c|c|c|c|c|c|c|}
\hline Cod & $\mathrm{C}_{\text {Alternativas }}^{\text {Critério }}$ & $\mathrm{C} 1$ & $\mathrm{C} 2$ & $\mathrm{C} 3$ & $\mathrm{C} 4$ & $\mathrm{C} 5$ & $\begin{array}{c}\text { Custo } \\
\mathrm{R} \$\end{array}$ \\
\hline $\mathrm{P} 1$ & $\begin{array}{l}\text { Criação de comitê de integração } \\
\text { entre as cidades do APL }\end{array}$ & 0,00 & 0,00 & 0,00 & 0,50 & 0,33 & 95000 \\
\hline $\mathrm{P} 2$ & Portal com vagas de trabalho & 1,00 & 1,00 & 1,00 & 0,50 & 1,00 & 145000 \\
\hline P3 & $\begin{array}{l}\text { Desburocratização da abertura de } \\
\text { empresas }\end{array}$ & 1,00 & 1,00 & 1,00 & 1,00 & 1,00 & 137000 \\
\hline $\mathrm{P} 4$ & $\begin{array}{l}\text { Suporte gerencial aos } \\
\text { empreendedores }\end{array}$ & 1,00 & 1,00 & 1,00 & 0,50 & 1,00 & 150000 \\
\hline P5 & $\begin{array}{l}\text { Sistema de segurança para o centro } \\
\text { da cidade }\end{array}$ & 0,50 & 1,00 & 1,00 & 1,00 & 1,00 & 130000 \\
\hline P6 & $\begin{array}{l}\text { Evento de network para mulheres } \\
\text { empreendedoras }\end{array}$ & 0,50 & 0,50 & 1,00 & 1,00 & 0,67 & 132000 \\
\hline $\mathrm{P} 7$ & $\begin{array}{l}\text { Curso de corte e costura para } \\
\text { mulheres }\end{array}$ & 1,00 & 1,00 & 0,67 & 1,00 & 0,67 & 150000 \\
\hline P8 & $\begin{array}{l}\text { Empreendedorismo na escola: } \\
\text { incentivando o setor têxtil }\end{array}$ & 0,50 & 0,00 & 0,33 & 0,00 & 0,33 & 80000 \\
\hline P9 & $\begin{array}{l}\text { Sistema de integração entre as } \\
\text { secretárias para assuntos e projetos } \\
\text { relacionados ao APL }\end{array}$ & 0,00 & 0,00 & 0,67 & 1,00 & 0,33 & 100000 \\
\hline P10 & $\begin{array}{lll}\text { Plataforma para vendas } & \text { (e- } \\
\text { commerce) } & & \end{array}$ & 1,00 & 1,00 & 1,00 & 1,00 & 0,00 & 151000 \\
\hline P11 & $\begin{array}{l}\text { Tratamento e reutilização de água } \\
\text { na produção }\end{array}$ & 0,00 & 0,00 & 0,33 & 0,50 & 0,33 & 80000 \\
\hline
\end{tabular}




\begin{tabular}{|c|c|c|c|c|c|c|c|}
\hline $\mathrm{P} 12$ & $\begin{array}{l}\text { Destinação adequada de resíduos } \\
\text { sólidos da produção }\end{array}$ & 0,00 & 0,00 & 0,33 & 0,50 & 0,33 & 90000 \\
\hline P13 & Calendário de ações de marketing & 0,50 & 1,00 & 1,00 & 1,00 & 0,33 & 132500 \\
\hline P14 & $\begin{array}{l}\text { Calendário de ações de } \\
\text { endomarketing }\end{array}$ & 0,50 & 0,50 & 1,00 & 1,00 & 0,33 & 161000 \\
\hline $\mathrm{P} 15$ & Consultoria em gestão de design & 0,50 & 0,50 & 0,67 & 0,00 & 0,33 & 100000 \\
\hline P16 & $\begin{array}{l}\text { Formação de base de dados de } \\
\text { empreendedores e trabalhadores }\end{array}$ & 1,00 & 0,50 & 0,67 & 1,00 & 0,33 & 137000 \\
\hline P17 & $\begin{array}{l}\text { Desenvolver software de gestão } \\
\text { para empresas do APL }\end{array}$ & 0,50 & 0,50 & 0,67 & 1,00 & 0,33 & 100000 \\
\hline P18 & Evento para integração / workshop & 0,00 & 0,50 & 0,67 & 1,00 & 0,33 & 87000 \\
\hline
\end{tabular}

Fonte: Produzido pelo autor.

Na etapa 2.3 de realização da avaliação intercritério para elicitação das constantes de escala foi utilizado o método SMARTS. Este método foi escolhido por ter sido considerada uma racionalidade compensatória para o problema e por conduzir a um procedimento mais rápido. Dado que o tempo do decisor para participar da aplicação era escasso, optou-se por priorizar as reuniões para obtenção de dados de input do estágio 1, ao invés de realizar um procedimento mais complexo e cansativo para elicitação. Uma alternativa ao SMARTS seria o tradeoff, no entanto, apesar de possuir uma estrutura axiomática mais rigorosa e robusta, exige mais questionamentos ao decisor e consequentemente maior esforço cognitivo, maior possibilidade de erros de elicitação e mais tempo para o procedimento (KEENEY E RAIFFA, 1976), tornando-o incompatível com as condições necessárias para a aplicação.

Em seguida, como o método SMARTS, elícita os pesos através de procedimento que utiliza escala intervalar para normalizar as consequências, foi realizada a devida conversão das constantes de escala para o contexto de escala razão através do procedimento sugerido por De Almeida et al. (2014). A tabela 6 apresenta todos estes dados obtidos nesta etapa.

Tabela 11 - Avaliação dos critérios.

\begin{tabular}{|l|l|l|l|}
\hline Ordenação & Critério & $\begin{array}{l}\text { Constante } \\
\text { de escala } \\
\text { original }\end{array}$ & $\begin{array}{l}\text { Constante } \\
\text { de escala } \\
\text { convertida }\end{array}$ \\
\hline 5 & Urgência da implantação & 0,04 & 0,028 \\
\hline
\end{tabular}




\begin{tabular}{|l|l|l|l|}
\hline 4 & Atração de empreendimentos e consumidores & 0,09 & 0,096 \\
\hline 1 & Geração de empregos & 0,458 & 0,49 \\
\hline 3 & Aumento da contribuição para o PIB municipal & 0,156 & 0,113 \\
\hline 2 & Aumento do poder de compra dos indivíduos & 0,256 & 0,273 \\
\hline
\end{tabular}

Fonte: Produzido pelo autor.

Na etapa 2.4 ocorre a avaliação das propostas de projetos foi obtida a tabela 7 , abaixo. Contendo a função valor de cada projeto.

Tabela 12 - Obtenção de função valor.

\begin{tabular}{|c|c|c|c|c|c|c|c|}
\hline Cod & Descrição & $\mathrm{C} 1$ & $\mathrm{C} 2$ & $\mathrm{C} 3$ & $\mathrm{C} 4$ & $\mathrm{C} 5$ & $\begin{array}{l}\text { Função } \\
\text { valor }\end{array}$ \\
\hline P1 & $\begin{array}{l}\text { Criação de comitê de } \\
\text { integração entre as cidades } \\
\text { do APL }\end{array}$ & 0,6 & 0,6 & 0,4 & 0,8 & 0,6 & 0,60 \\
\hline $\mathrm{P} 2$ & Portal com vagas de trabalho & 1 & 1 & 1 & 0,8 & 1 & 0,98 \\
\hline P3 & $\begin{array}{l}\text { Desburocratização } \\
\text { abertura de empresas }\end{array}$ & 1 & 1 & 1 & 1 & 1 & 1,00 \\
\hline P4 & $\begin{array}{l}\text { Suporte gerencial aos } \\
\text { empreendedores }\end{array}$ & 1 & 1 & 1 & 0,8 & 1 & 0,98 \\
\hline P5 & $\begin{array}{l}\text { Sistema de segurança para o } \\
\text { centro da cidade }\end{array}$ & 0,8 & 1 & 1 & 1 & 1 & 0,90 \\
\hline P6 & $\begin{array}{l}\text { Evento de network para } \\
\text { mulheres empreendedoras }\end{array}$ & 0,8 & 0,8 & 1 & 1 & 0,8 & 0,84 \\
\hline P7 & $\begin{array}{l}\text { Curso de corte e costura para } \\
\text { mulheres }\end{array}$ & 1 & 1 & 0,8 & 1 & 0,8 & 0,97 \\
\hline P8 & $\begin{array}{l}\text { Empreendedorismo na } \\
\text { escola: incentivando o setor } \\
\text { têxtil }\end{array}$ & 0,8 & 0,6 & 0,6 & 0,6 & 0,6 & 0,70 \\
\hline P9 & $\begin{array}{l}\text { Sistema de integração entre } \\
\text { as secretárias para assuntos e } \\
\text { projetos relacionados ao } \\
\text { APL }\end{array}$ & 0,6 & 0,6 & 0,8 & 1 & 0,6 & 0,66 \\
\hline
\end{tabular}




\begin{tabular}{|c|c|c|c|c|c|c|c|}
\hline P10 & $\begin{array}{l}\text { Plataforma para vendas (e- } \\
\text { commerce) }\end{array}$ & 1 & 1 & 1 & 1 & 0,4 & 0,98 \\
\hline P11 & $\begin{array}{l}\text { Tratamento e reutilização de } \\
\text { água na produção }\end{array}$ & 0,6 & 0,6 & 0,6 & 0,8 & 0,6 & 0,62 \\
\hline P12 & $\begin{array}{l}\text { Destinação adequada de } \\
\text { resíduos sólidos da produção }\end{array}$ & 0,6 & 0,6 & 0,6 & 0,8 & 0,6 & 0,62 \\
\hline P13 & $\begin{array}{l}\text { Calendário de ações de } \\
\text { marketing }\end{array}$ & 0,8 & 1 & 1 & 1 & 0,6 & 0,89 \\
\hline P14 & $\begin{array}{l}\text { Calendário de ações de } \\
\text { endomarketing }\end{array}$ & 0,8 & 0,8 & 1 & 1 & 0,6 & 0,84 \\
\hline P15 & $\begin{array}{l}\text { Consultoria em gestão de } \\
\text { design }\end{array}$ & 0,8 & 0,8 & 0,8 & 0,6 & 0,6 & 0,78 \\
\hline P16 & $\begin{array}{l}\text { Formação de base de dados } \\
\text { de empreendedores } \\
\text { trabalhadores }\end{array}$ & 1 & 0,8 & 0,8 & 1 & 0,6 & 0,91 \\
\hline P17 & $\begin{array}{l}\text { Desenvolver software de } \\
\text { gestão para empresas do } \\
\text { APL }\end{array}$ & 0,8 & 0,8 & 0,8 & 1 & 0,6 & 0,81 \\
\hline P18 & $\begin{array}{l}\text { Evento para integração / } \\
\text { workshop }\end{array}$ & 0,6 & 0,8 & 0,8 & 1 & 0,6 & 0,72 \\
\hline
\end{tabular}

Fonte: Produzido pelo autor.

Na etapa 2.5 de seleção do portfólio de projetos, utilizando a ferramenta desenvolvida por Vasconcelos et al (2014) e com o orçamento limitado em R\$1.100.000,00, foram selecionados 10 projetos, cujo somatório dos custos corresponde à 100,00\% do orçamento disponível. Este portfólio selecionado representa 8,11 da função valor, enquanto o conjunto total avaliado, composto pelos 18 projetos, corresponde a 14,80 da função valor. Os projetos selecionados a partir dos valores globais e de acordo com o orçamento disponível são apresentados na tabela 8 .

Tabela 13 - Seleção do portfólio.

\begin{tabular}{|l|c|l|}
\hline $\begin{array}{l}\text { Projetos } \\
\text { selecionados }\end{array}$ & $\begin{array}{c}\text { Custo } \\
\text { R \$ }\end{array}$ & $\begin{array}{l}\text { Função } \\
\text { valor }\end{array}$ \\
\hline
\end{tabular}




\begin{tabular}{|l|l|l|}
\hline P2 & 145000 & 0,98 \\
\hline P3 & 137000 & 1,00 \\
\hline P5 & 130000 & 0,90 \\
\hline P8 & 80000 & 0,70 \\
\hline P10 & 151000 & 0,98 \\
\hline P11 & 80000 & 0,62 \\
\hline P12 & 90000 & 0,62 \\
\hline P15 & 100000 & 0,78 \\
\hline P17 & 100000 & 0,81 \\
\hline P18 & 87000 & 0,72 \\
\hline Somatório & 1100000 & 8,11 \\
\hline
\end{tabular}

Fonte: Produzido pelo autor.

Na etapa 3.1 de definição dos parâmetros da análise de sensibilidade, a partir de todo o levantamento realizado pela revisão da literatura a respeito dos problemas de multicritério, da seleção de portfólio, do método SMARTS e da otimização inversa foi verificado que as constantes de escala realmente são parâmetros que merecem uma análise mais aprofundada, devido a incerteza envolvida em sua elicitação e a grande influência no fornecimento da solução, além disso também influenciam na transmissão de confiança ao decisor, já que as constantes de escala representam as preferências do decisor e são calculadas a partir de um procedimento que utiliza indiretamente os valores que o decisor expressa.

Sendo assim, a análise de sensibilidade com Simulação Monte Carlo foi realizada por meio da variação nas constantes de escala. Foi também definida uma estimativa pelo decisor de que a variação é considerada em $30 \%$, em relação ao intervalo e à distribuição de probabilidade considerada. Posteriormente, o tratamento dessa incerteza também será realizado pela análise da variação mínima sobre os pesos usando a otimização inversa.

Na etapa 3.2 foi realizada a análise de sensibilidade com simulação Monte Carlo e com variação de $30 \%$ nas constantes de escala, também utilizando a fermenta de Vasconcelos et al (2014). Foram então gerados 100.000 de casos. A tabela 9 apresenta o resultado desta variação.

Tabela 14 - Output da análise de sensibilidade.

\begin{tabular}{|l|l|l|l|}
\hline \multirow{2}{*}{$\begin{array}{l}\text { Identificação } \\
\text { do portfólio }\end{array}$} & \multicolumn{2}{|l|}{ Mudanças no portfólio } & Porcentagem \\
\cline { 2 - 4 } & Entrada & Saída & $\begin{array}{l}\text { de } \\
\text { recomendação }\end{array}$ \\
\hline A & P4 & P10 & $32,40 \%$ \\
\hline
\end{tabular}




\begin{tabular}{|c|c|l|l|}
\hline B & P9 e P13 & P2 e P12 & $0,00002 \%$ \\
\hline
\end{tabular}

Na simulação, o portfólio original foi recomendado $67,60 \%$, porém dois novos portfólios também surgiram como recomendação.

Na Etapa 3.3 de identificação de novas soluções, verificou-se que a solução se mostrou bastante robusta, já que mesmo com uma variação abrupta a simulação só sugere duas combinações novas, uma delas inclusive bastante rara. Na solução A, mais frequente, houve apenas a mudança de um único projeto, enquanto na solução $B$, mais rara, houveram a troca de dois projetos. Dessa forma, qualquer análise pode ser realizada apenas sobre os projetos que são trocados entre as soluções, uma vez que o resto da combinação é igual.

A etapa 3.4 de análise da variação mínima sobre os pesos foi realizada através de uma ferramenta baseada no LpSolver e utilizando as normas $\mathrm{L}_{1}$ e $\mathrm{L}_{\infty}$. A duas formas de tratamento são modos alternativos de análise, baseadas em informações diferentes, de acordo com a norma utilizada e, portanto, fornecem solução adequadas a esta informação. Esta análise explora, justamente, os projetos que se modificam na solução original e nas soluções obtidas com a análise de sensibilidade.

A análise da mínima variação é realizada para eleger como ótima a solução nova identificada na análise de sensibilidade, buscando identificar qual a mínima variação relativa, mensurada com as normas $\mathrm{L}_{\infty}$ e $\mathrm{L}_{1}$, necessária para que a nova solução se iguale ou supere a solução ótima original e qualquer outra solução com desempenho superior e, assim, se torne a nova ótima. Como na análise de sensibilidade foram identificadas duas novas soluções a análise de variação mínima foi realizada para cada uma dessas soluções, denominadas A e B.

O PROISP para o $\mathrm{L}_{\infty}$ fornece a variação máxima, em cada um dos critérios, necessária para eleger a solução A como ótima. Na tabela 10 são apresentadas as variações necessárias em cada um dos critérios, impondo a máxima variação em cada um dos critérios identificados na linha da tabela a cada iteração, para a solução A ser eleita a solução ótima, superando a ótima original e todas as outras soluções com desempenho superior a ela.

Tabela 15 - Avaliação entre a solução A e a solução original para Lœ

\begin{tabular}{|c|l|l|l|l|l|}
\hline$\Delta_{\mathrm{j}}$ & $\mathrm{C} 1$ & $\mathrm{C} 2$ & $\mathrm{C} 3$ & $\mathrm{C} 4$ & $\mathrm{C} 5$ \\
\hline$\Delta_{\mathrm{w}}=\mathrm{MAX}_{\mathrm{j}}\left(\Delta_{\mathrm{j}}\right.$ & & & & & \\
\hline $\mathrm{C} 1$ & $+0,05940$ & $-0,05940$ & $-0,05788$ & $-0,05940$ & $+0,05940$ \\
\hline $\mathrm{C} 2$ & $-0,02672$ & $+0,05940$ & 0 & $-0,05940$ & $+0,05940$ \\
\hline
\end{tabular}




\begin{tabular}{|l|l|l|l|l|l|}
\hline C3 & $-0,01374$ & 0 & $+0,05940$ & $-0,05940$ & $+0,05940$ \\
\hline C4 & $+0,0064$ & 0 & 0 & $-0,05940$ & $+0,05940$ \\
\hline C5 & $+0,0064$ & 0 & 0 & $-0,05940$ & $+0,05940$ \\
\hline
\end{tabular}

Fonte: Produzido pelo autor.

As células da tabela que estão em cinza são os critérios que devem ter a maior variação, ou seja, que determinam a distância em $\mathrm{L}_{\infty}$. De fato, estes critérios apresentaram a maior variação apesar de que outros critérios podem apresentar a mesma variação, inclusive em sentidos diferentes. Como todos os critérios com variação máxima apresentaram o valor de 0,05940, este é considerado a menor distância no $\mathrm{L}_{\infty}$. Para este problema analisando a solução A, os critérios 4 e 5 apresentam em todas as iterações a maior variação porquê é entre eles que ocorre a transferência que mais contribui para reduzir a distância que torna a solução A ótima, já que nestes critérios as soluções possuem desempenho diferentes e isso contribui para que uma solução tenha vantagem sobre as outras.

O PROISP para $\mathrm{L}_{\infty}$, aplicado à solução B tem seus resultados apresentados na tabela 11. Assim como a tabela anterior, são fornecidas as variações necessárias em cada um dos critérios para a solução B ser eleita a solução ótima, superando a ótima original e todas as outras soluções com desempenho superior a ela, inclusive a solução A. Impondo variação máxima em cada critério representado na linha da tabela a cada iteração.

Tabela 16 - Avaliação entre a solução B e a solução original para Lœ

\begin{tabular}{|c|c|c|c|c|c|}
\hline$\Delta_{\mathrm{j}}$ & $\mathrm{C} 1$ & $\mathrm{C} 2$ & $\mathrm{C} 3$ & $\mathrm{C} 4$ & $\mathrm{C5}$ \\
\hline $\mathrm{C} 1$ & \multicolumn{5}{|c|}{ Não há solução! } \\
\hline $\mathrm{C} 2$ & \multicolumn{5}{|c|}{ Não há solução! } \\
\hline $\mathrm{C} 3$ & $-0,2957$ & $+0,2600$ & $+0,3000$ & $+0,3000$ & $-0,1234$ \\
\hline $\mathrm{C} 4$ & $-0,2957$ & $+0,2600$ & $+0,3000$ & $+0,3000$ & $-0,1234$ \\
\hline $\mathrm{C} 5$ & \multicolumn{5}{|c|}{ Não há solução! } \\
\hline
\end{tabular}

Fonte: Produzido pelo autor.

Este PPL não apresentou solução para todas as iterações, de modo que impor que a maior variação ocorra no critério C1, C2 ou C5 causaria a inversão na ordenação dos critérios C1 e C2.

O PROISP para L1 fornece o somatório das variações em todos os critérios, necessária para eleger a solução A e depois a solução B como ótima. Na tabela 12 são apresentadas as 
variações necessárias em cada um dos critérios para obter a mínima soma das variações nos critérios necessárias para a solução A e posteriormente em segunda análise a solução B ser eleita como solução ótima, superando a ótima original e todas as outras soluções com desempenho superior a ela.

Tabela 17 - Avaliação entre as soluções para L1

\begin{tabular}{|c|l|l|l|l|l|}
\hline Solução & C1 & C2 & C3 & C4 & C5 \\
\hline A & 0 & 0 & 0 & $-0,03741$ & $+0,08417$ \\
\hline B & $-0,2957$ & $+0,2600$ & $+0,3$ & $+0,3$ & $-0,1234$ \\
\hline
\end{tabular}

Fonte: Produzido pelo autor.

O PPL encontrou solução para as duas análises. Na análise para a solução A, a transferência foi realizada entre os critérios $\mathrm{C} 4$ e C5, nos quais uma pequena redução em $\mathrm{C} 4$ era suficiente para aumentar C5 de modo que A supere a ótima original e se torne a nova ótima. $\mathrm{Na}$ análise para a solução $\mathrm{B}$, a transferência que mais contribui ocorre reduzindo $\mathrm{C} 1$ e $\mathrm{C} 5$, e aumentando C2, C3 e C4. Inclusive, C4 é o critério que mais contribui para a solução B adquirir vantagem de desempenho sobre as demais soluções.

\subsection{Discussão dos resultados}

De um modo geral, a transferência que contribui para eleger a nova solução como ótima é realizada entre os critérios nos quais as soluções analisadas apresentam desempenhos diferentes. E os critérios nos quais as soluções apresentam o mesmo desempenho sofrem variações que acomodam as mudanças de valor absoluto para não afetar a normalização e ordenação dos critérios.

Os resultados obtidos mostram que na análise de variação mínima do PROISP usando $\mathrm{L}_{1}$ e $\mathrm{L}_{\infty}$ para a solução $\mathrm{A}$, os critérios $\mathrm{C} 4$ e C5 apresentam a transferência que mais contribui para A se igualar ou superar a original e as demais, já que C4 é o critério onde a solução original tem melhor desempenho e C5 o critério no qual a solução nova tem melhor desempenho. Já a solução B possui valor inferior à solução A originalmente, de forma que os pesos conseguem variar para tornar ótima a solução A sem que a solução B a alcance. O PPL, considerando a norma $L \infty$, teve soluções para todas as iterações correspondentes a cada um dos critérios, a partir delas foi possível identificar o movimento de redução dos pesos de $\mathrm{C} 4$ e aumento dos 
pesos de C5, enquanto o movimento nos demais critérios é aleatoriamente realizado para acomodar aumentos e reduções que buscam manter a normalização e a ordenação dos critérios.

Quando a variação máxima é imposta para o C1, os critérios C2, C4 e C5 apresentam a mesma variação, apenas C3 apresentam uma variação um pouco menor. Para a solução A ser eleita, impondo que a variação em $\mathrm{C} 1$ seja a máxima, é necessário que os pesos de C1 e de C5 sejam aumentados, porém como a variação é relativa e $\mathrm{C} 1$ possui o maior peso, o aumento considerando o valor absoluto é relativamente alto de modo que nenhum dos outros critérios consegue sozinho suprir a necessidade de aumento de C1. Sendo assim, os critérios C2, C3 e $\mathrm{C} 4$ reduziram seus pesos para fornecê-los a C1 e C5. O peso original de C1 influência de tal forma que não seria possível uma redução neste mesmo valor, já que os outros critérios não teriam capacidade de receber a variação proveniente de $\mathrm{C} 1$.

Com a imposição de variação máxima em C2, os critérios C4 e C5 apresentam a mesma variação, apenas C1 apresentam uma variação um pouco menor, e C3 não apresenta nenhuma variação. Para a solução A ser eleita é necessário que os pesos de C2 e de C5 sejam aumentados, porém é priorizada a redução em $\mathrm{C} 4$, de modo que o restante para aumentar C2 e C5 provêm de $\mathrm{C} 1$.

Impondo a máxima variação em C3, os critérios C4 e C5 apresentam a mesma variação, C1 apresenta uma variação menor e C2 não apresenta variação. Ocorre uma situação semelhante à máxima variação em $\mathrm{C} 2$, na qual a variação de redução em dois critérios é suficiente para suprir o aumento de outros dois critérios que contribuem para eleger A como ótima, dessa forma não há necessidade de variar mais um critério no qual há o mesmo desempenho entre as soluções.

O PPL com variação máxima em C4 e C5, apresenta a mesma solução. Isto acontece devido a transferência que mais contribui para eleger A como ótima, ocorrer entre estes critérios. A transferência ocorre reduzindo $\mathrm{C} 4$ e aumentando $\mathrm{C} 5$, de modo que como o peso de C4 é maior que o peso de C5, o valor excedente de C4 foi direcionada para aumentar o peso de C1.

Nesta análise para a solução B no PROISP usando $\mathrm{L}_{\infty}$, a transferência que mais contribui para a eleger B como ótima ocorre entre os critérios $\mathrm{C} 1$ e $\mathrm{C} 4$, De modo que o peso de $\mathrm{C} 4$ aumenta e o de $\mathrm{C} 1$ diminui. Com o peso de $\mathrm{C} 1$ é muito alto, $\mathrm{C} 4$ não consegue receber todo o peso que $\mathrm{C} 1$ perde, passando a variar C3, para tornar ótima a solução B. Mas no geral, a transferência ocorre reduzindo os critérios $\mathrm{C} 1$ e C5, e aumentando os critérios C2, C3 e C4. Para a norma L $\infty, C 3$ e C4 obtém a mesma solução já que são critérios que contribuem bastante para tornar B a solução ótima e conseguem variar até o limite de $30 \%$ sem inverter a ordem dos 
critérios. Apesar de o critério C1 contribuir mais do que os outros, uma variação relativa próxima de $30 \%$ causaria uma inversão de ordem, de forma que o peso de C2 se tornaria maior.

$\mathrm{Na}$ análise para o PROISP usando $\mathrm{L}_{1}$, para a solução A apenas é necessário que ocorra variação em dois critérios para que A supere as demais soluções, e esta transferência representa o vetor com menor soma de variações. Para a solução B, o resultado obtido foi idêntico ao resultado da solução $B$ para $L_{\infty}$, por coincidência as únicas soluções que permitem mínima variação nos critérios C3 e C4 também é a solução que fornece a o vetor com menor somatório de variações.

A partir dos teoremas é possível entender melhor o comportamento dos resultados obtidos. Os teoremas 2 e 5 abordam características tanto da resolução com a norma $\mathrm{L}_{\infty}$ quanto para a norma $\mathrm{L}_{1}$. O teorema 2 explica que a soma da variação entre os pesos deve ser igual a zero. Esta é uma característica essencial para os parâmetros que estão sendo utilizados, já que os pesos estão normalizados de forma que seu somatório é igual a 1, e se as variações não se anulam elas influenciam nesse somatório de modo que os pesos deixam de estar normalizados. Característica que pode ser facilmente verificada com a soma dos pesos para eleger qualquer solução nova como ótima, lembrando que o somatório das variações absolutas é zerado, mas isto não se aplica as variações relativas.

O teorema 5 explica que a contribuição para aproximar a distância entre duas soluções está relacionado com o peso do critério, quanto maior mais ele vai poder contribuir aumentando ou reduzindo, e a diferença de desempenho entre a soluções neste critério, já que quanto maior a diferença no desempenho, mais a mudança no peso acentuará a vantagem de uma solução sobre a outra. O que pôde ser visualizado claramente na análise para a solução B para $\mathrm{L}_{1}$ e $\mathrm{L}_{\infty}$, na qual para as soluções obtidas foi percebido uma variação maior no critério 4, de modo que o critério 5 também poderia ter essa variação, mas não foi priorizado devido a uma contribuição menor para eleger a solução como ótimo devido ao peso e a diferença nos desempenho dos critérios.

O teorema 3 explica que sem impedimentos devido as demais restrições, além da não negatividade e normalização, os critérios nos quais as soluções apresentam desempenho igual não sofrerão variações. O teorema 4 expande esse efeito para os problemas restritos, quando a variação não alcança o limite de nenhuma restrição. Na análise de $\mathrm{L}_{1}$ para a solução $\mathrm{A}$, ocorreu exatamente este comportamento, pois apesar de ser um problema que não possui apenas as duas restrições mencionadas, a variação não foi suficiente para encontrar o limite dessas restrições, de forma que todos os critérios com desempenho igual entre as alternativas não sofreram variação. 
Sendo assim, o proposto modelo estrutura o problema permitindo a obtenção de uma recomendação consistente e confiável. Os resultados obtidos fornecem ao decisor a recomendação obtida inicialmente pela avaliação multicritério, além de recomendações muito próximas de serem obtidos a partir de variações nos pesos através de simulação. E para complementar fornece qual a variação necessária para haver uma troca na recomendação, que ao invés de fornecer a solução original vai fornecer uma das soluções apontadas pela análise de sensibilidade.

Na perspectiva do decisor o modelo de seleção de projetos utilizando otimização inversa contribui para realização de uma decisão mais consistente e racional, apoiada em fundamentos científicos. De forma prática a análise da mínima variação fornece mais informações e, assim, transmite maior segurança ao decisor com relação a recomendação. Ela informa ao decisor o quanto de imprecisão é permitido em relação à determinado critério sem que a recomendação seja trocada. Assim, o decisor tem a possibilidade de verificar se sua incerteza afetaria a solução obtida originalmente. De forma complementar, fornece a nova recomendação resultante de uma incerteza que ultrapassa a variação máxima que mantém a recomendação original.

Os cinco critérios organizados de acordo com a importância e influência que possuem sobre a decisão são: 1- "Geração de empregos", 2- "Aumento do poder de compra dos indivíduos", 3- "Aumento da contribuição para o PIB municipal”, 4- "Atração de empreendimentos e consumidores" e 5- "Urgência da implantação". De modo que os critérios posicionados inicialmente na ordenação possuem um potencial de afetar de maneira mais forte a troca da solução, mas este não é o único fator que deve ser analisado. De modo que esta ordem dita a ordem na qual o critério pode contribuir mais recebendo ou cedendo seu peso a outro critério, já que a variação ocorre em relação ao peso original. No entanto, é preciso lembrar que a priorização do critério que vai sofrer variação está relacionada com a diferença de desempenho entre as soluções avaliadas em determina critério e não apenas com o peso do critério.

Para a análise usando $\mathrm{L}_{\infty}$, a solução A é eleita como ótima principalmente devido a contribuição que a transferência de peso que sai do critério "Atração de empreendimentos e consumidores" e vai para o critério "Urgência da implantação" exerce para que esta solução obtenha vantagem sobre as demais. Para a solução B, a transferência principal ocorre saindo do critério "Geração de empregos" e seguindo para o critério "Atração de empreendimentos e consumidores". Para a análise usando $\mathrm{L}_{1}$, as principais influências dos critérios se apresentam da mesma forma que para a norma $\mathrm{L}_{\infty}$. 
As figuras 9 e 10, mostram a influência da variação dos pesos, para tornar a solução A ótima, na perspectiva do decisor.

Figura 9: Variação dos pesos no $\mathrm{L}_{\infty}$

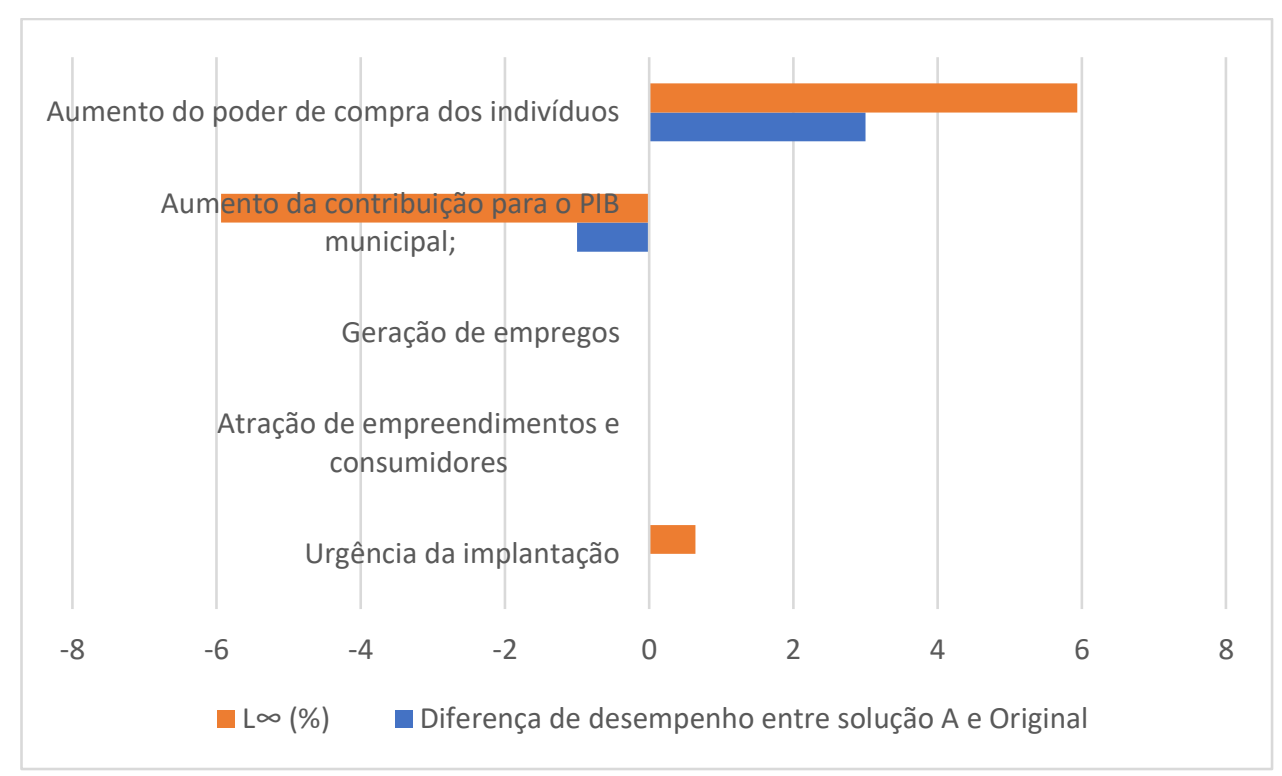

Fonte: Produzido pelo autor.

Figura 10: Variação dos pesos no $\mathrm{L}_{1}$

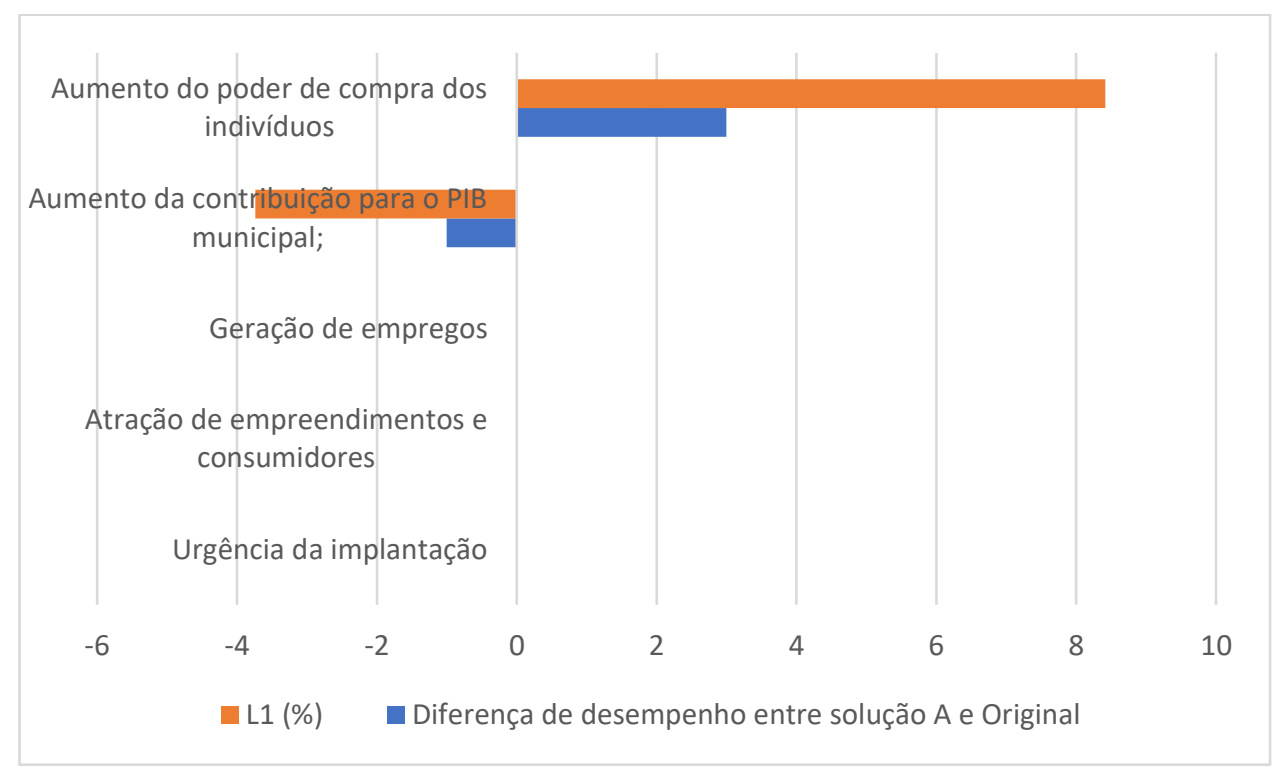

Fonte: Produzido pelo autor.

Em ambos os casos mostrados nas figuras, a solução A apresenta vantagem no critério C1 sobre a solução original, enquanto a solução original possui vantagem sobre a solução A no critério C2. Quando o peso do critério C1 aumenta, consequentemente aumenta o valor que a vantagem da solução A tem para o decisor. Quando o peso do critério C2 diminui, consequentemente diminui o valor da vantagem da solução original para o decisor. Por 
exemplo, na figura 10 quando o peso do critério $\mathrm{C} 1$ aumenta $8,417 \%$ e o peso do critério $\mathrm{C} 2$ diminui em 3,41\% o valor da vantagem da solução A aumenta para o decisor, enquanto a vantagem da solução original diminui de tal forma que o valor da solução A não apenas se torna maior ou igual que o valor da solução original, mas torna ótima a solução A.

O decisor declarou estar bastante satisfeito com a recomendação obtida, apesar de não possuir nenhum contato anterior com a abordagem multicritério para tomada de decisão. Ele acompanhou todo o processo e declarou ter confiança, já que considerou o processo claro e coerente. Também destacou que o procedimento de seleção que utilizam não considera tantos aspectos e nem se preocupa em trata-los de modo adequado considerando suas diferenças. Além disso, se mostrou ainda mais satisfeito e confiante com a utilização da análise de sensibilidade e da análise da variação mínima, acreditando que suas preferências foram respeitadas e que a recomendação está alinhada com seus objetivos. Quanto a análise da variação mínima, o decisor concluiu que sua imprecisão estava dentro da variação mínima obtida, sendo assim a solução original foi a escolhida para ser implementada. 


\section{CONCLUSÃO}

A seleção de investimentos públicos para os APLs é muito importante para a economia regional, já que apoia o desenvolvimento de empresas menores. No entanto, é uma área de seleção de investimentos públicos que não havia sido explorada anteriormente utilizando a abordagem multicritério e de portfólio combinadas. A revisão da literatura forneceu o embasamento teórico para o desenvolvimento das contribuições práticas e metodológicas que o presente estudo fornece. Foi necessário conhecer as principais características dos APLs, assim como conhecer o contexto das políticas públicas direcionadas aos APLs, no âmbito mundial e nacional. Assim como explorar as características gerais da abordagem multicritério e do método SMARTS e também as especificidades relacionadas à aplicação dos mesmos à problemática de portfólio. Foi necessário, principalmente, um trabalho minucioso para reunir o que acredita-se ser boa parte do material que traz grande contribuição sobre aplicação da otimização inversa nos pesos obtidos com avaliação multicritério, material este bastante difícil de ser rastreado na literatura devido à falta de conexão entre os estudos pioneiros e à não utilização do termo otimização inversa. Em seguida foram organizadas e avaliadas as contribuições que estes estudos fornecem de modo a identificar lacunas e propor um modelo que envolva contribuições que enriqueçam o processo de tomada de decisão.

Este estudo se propõe a fornecer soluções personalizadas ao problema e decisor envolvido, permitindo a adaptação às especificidades que a seleção de políticas públicas possui enfatizando as particularidades de cada APL e do nível de poder público que está implementando a política. O presente estudo, auxilia o setor público na tomada de decisão relacionada com a seleção de projetos, que representam políticas públicas para investimento visando apoiar o desenvolvimento e implementação de políticas municipais direcionadas aos APLs. Também colabora para o alcance dos objetivos das instituições públicas de modo a obter o maior retorno sobre investimento, de acordo com os objetivos estabelecidos e respeitando as restrições financeiras, além de contribuir retirando a informalidade e fundamentando as decisões em dados realísticos e metodologia embasada cientificamente.

A análise da mínima variação nas constantes de escala utilizando otimização inversa é uma abordagem que pode ser realizada em conjunto com a análise de sensibilidade ou com algoritmos geradores de soluções fronteira, para aumentar a confiança do decisor nas recomendações de problema multicritério. Esta análise fornece o tratamento da incerteza que provêm do próprio decisor. A informação da análise consiste na variação mínima necessária que faz com que uma determinada solução, que não a ótima original, ocupe a posição de ótima. 
Além disso, esta análise possui comprometimento com as preferências expressas pelo decisor sob a forma de ordenação dos critérios. Outras análises, como a estatística, são mais caras e não fornecem informação precisa e nem sempre respeitam a ordenação dos critérios.

O modelo consiste em acrescentar a análise de mínima variação com otimização inversa, como um terceiro componente ao já comum uso da abordagem multicritério com análise de sensibilidade, ou até mesmo substituindo a análise de sensibilidade por algoritmos de geração de soluções fronteira. De modo que primeiro realiza-se a avaliação multicritério, em seguida é realizada a análise de sensibilidade e, por fim, utilizando os resultados das etapas anteriores é realizada a análise da variação mínima sobre os pesos, na qual, para cada solução que surge na análise de sensibilidade é realizada uma análise da variação mínima que permite eleger uma dessas soluções. O modelo também envolve uma estrutura matemática que permite compreender o comportamento das soluções obtidas e das variações de peso.

A aplicação foi realizada em um dos municípios que compõem o APL de confecções do Agreste, o decisor é gestor de uma das secretarias diretamente relacionadas com decisões relacionadas ao APL. De modo que foram obtidos 18 projetos, direcionados ao APL, provenientes de todas as secretarias deste município.

Como resultado da seleção multicritério de portfólio foi recomendado um portfólio composto por 10 projetos denominado de solução original, e que consume o total dos recursos disponíveis. Em seguida, a análise de sensibilidade mostrou que outras duas soluções, denominadas A e B, surgiam como soluções para o problema de seleção. Por fim, a análise da mínima variação, realizada separadamente para cada uma destas novas soluções, avaliou quanto minimamente os pesos teriam que mudar para eleger A ou B como ótima.

Os resultados obtidos convergem com o comportamento definido pelos teoremas, lemas e corolários estabelecidos. De modo que as transferências que mais contribuem para tornar uma solução ótima ocorre entre os pesos nos quais as soluções apresentam desempenhos diferentes. A transferência reduz o peso dos critérios nos quais a solução nova tem desvantagem para aumentar os pesos dos critérios nos quais a solução nova tem vantagem sobre as demais, o que indica a priorização de mudança em pesos de determinados critérios. A contribuição em eleger como ótima uma solução está fortemente relacionada com o peso do critério e a diferença de desempenho das soluções neste critério. Já a modificação nos pesos dos critérios nos quais as soluções apresentam desempenho igual é motivada pelas restrições que impedem que os pesos sejam alterados de forma inconsistente com suas características e com as características do problema. 
A contribuição deste estudo na utilização da análise da mínima variação nos pesos está relacionada, principalmente, com a incorporação da manutenção da ordenação dos critérios que é uma informação valiosa em problemas multicritério, pois manter a consistência desta informação é essencial para alcançar o objetivo de fornecer maior confiança ao decisor. Associado a isto, o presente estudo contribui com a aplicação desta análise em problemas de seleção de portfólio, a partir de um procedimento consistente que utiliza abordagens bem aceitas na comunidade acadêmica, como a avaliação multicritério, a análise de sensibilidade e os algoritmos geradores de solução fronteira.

Para trabalhos futuros pode ser desenvolvido um modelo que considere implicações regulamentadoras e legislatórias que orientam o investimento de recursos públicos. De modo que forneça um suporte para lidar com este tipo de restrição que é mais específico. 


\section{REFERÊNCIAS}

AHUJA, R.K.; ORLIN, J.B. Inverse optimization. Operations Research 49(5), pp. 771-783, 2001.

ARRATIA, M.N.M., LÓPEZ, I.F., SCHAEFFER, S.E., CRUZ-REYES, L. Static R\&D project portfolio selection in public organizations. Decision Support Systems 84, pp. 53-63, 2016.

BARRON, H; SCHMIDT, C. P. Sensitivity analysis of additive multiattribute value models. Operations Research 36(1), pp. 122-127, 1988.

BELGACEM, T; HIFI, M. Sensitivity analysis of the knapsack sharing problem: Perturbation of the profit of an item. International Transactions in Operational Research 15(1), pp. 35-49, 2008 a.

BELGACEM, T; HIFI, M. Sensitivity analysis of the optimum to perturbation of the profit of a subset of items in the binary knapsack problem. Discrete Optimization 5(4), pp. 755-761, 2008 b.

BERIA, P., MALTESE, I., MARIOTTI, I. Multicriteria versus Cost Benefit Analysis: A comparative perspective in the assessment of sustainable mobility. European Transport Research Review 4(3), pp. 137-152, 2012.

BERTSIMAS, D; GUPTA, V; PASCHALIDIS, I.Ch. Inverse optimization: A new perspective on the Black-Litterman model. Operations Research 60(6), pp. 1389-1403, 2012.

BRASIL. Ministério do Desenvolvimento Indústria e Comércio Exterior. Secretaria de Desenvolvimento da Produção. Relatório Executivo dos 10 anos do GTP ALP: Secretaria de Desenvolvimento da Produção. - Brasília: MDIC/SDP, 2014. Disponível em: < http://portalapl.ibict.br/export/sites/ap1/galerias/Biblioteca/Relatxrio_10_Anos_do_GTP-

APL.compressed.pdf>

BRASIL. Portaria Interministerial no 200, de 02 de agosto de 2004. Instituição do Grupo de Trabalho Permanente para Arranjos Produtivos Locais (GTP APL). Diário Oficial União. 03 ago 2004a; Seção 2:17.

BRASIL. Termo de Referência para Política Nacional de Apoio ao Desenvolvimento de Arranjos Produtivos Locais, 2004b. Disponível em: http://portalapl.ibict.br/export/sites/apl/galerias/biblioteca/dwnl_1289322946.pdf>

BURTON, D; Ph. L. TOINT. On an instance of the inverse shortest paths problem. Math. Programming 53 45-61, 1992.

BURTON, D; Ph. L. TOINT. On the use of an inverse shortest paths algorithm for recovering linearly correlated costs. Math. Programming 63 1-22, 1994.

CAFISO, S; DI GRAZIANO, A; KERALI, H; ODOKI, J. Multicriteria analysis method for pavement maintenance management. Transportation Research Record (1816), pp. 73-84, 2002.

ÇAĞLAr, M; GÜREL, S. Public R\&D project portfolio selection problem with cancellations. OR Spectrum 39(3), pp. 659-687, 2017.

CARDOSO, U. C; CARNEIRO V. L. N; RODRIGUES, É. R. Q. APL: arranjo produtivo local. Brasília: Sebrae, 2014. Disponível em: http://www.bibliotecas.sebrae.com.br/chronus/ARQUIVOS_CHRONUS/bds/bds.nsf/b8126fa768f699 29a146f38122da570b/\$File/5197.pdf > 
CIOMEK, K., FERRETTI, V., KADZIŃSKI, M. Predictive analytics and disused railways requalification: Insights from a Post Factum Analysis perspective. Decision Support Systems 105, pp. 34-51, 2018.

CRASS, D; RAMMER, C; ASCHHOF, B. Geographical clustering and the effectiveness of public innovation programs. Journal of Technology Transfer pp. 1-32, 2017.

CHEN, H; WOOD, M.D; LINSTEAD, C; MALTBY, E. Uncertainty analysis in a GIS-based multicriteria analysis tool for river catchment management. Environmental Modelling and Software 26(4), pp. 395-405, 2011.

CHUNG, Y; DEMANGE, M. On inverse traveling salesman problems. 4OR 10(2), pp. 193-209, 2012.

DANESH, D; RYAN, M.J; ABBASI, A. Multi-criteria decision-making methods for project portfolio management: a literature review, Int. J. Management and Decision Making, Vol. 17, No. 1, pp.75-94, 2018.

DE ALMEIDA, A.T. Processo de Decisão nas Organizações: Construindo Modelos de Decisão Multicritério. 1a Edição. São Paulo: Editora Atlas, 2013.

DE ALMEIDA, A. T; VETSCHERA, R. A note on scale transformations in the PROMETHEE V method. European Journal of Operational Research 219(1), pp. 198-200, 2012.

DE ALMEIDA, A. T; VETSCHERA, R; ALMEIDA, J. A. Scaling Issues in Additive Multicriteria Portfolio Analysis. In: Dargam F; Hernández J. E; Zaraté P; Liu S; Ribeiro R; Delibasic B; Papathanasiou J. Decision Support Systems III - Impact of Decision Support Systems for Global Environments. LNBIP 184 (Lecture Notes in Business Information Processing), Springer. pp. 131-140, 2014.

DE ALMEIDA, A.T; DE ALMEIDA, J.A; COSTA, A.P.C.S; DE ALMEIDA-FILHO, A.T. A new method for elicitation of criteria weights in additive models: Flexible and interactive tradeoff. European Journal of Operational Research 250(1), pp. 179-191, 2016.

DELGADO, M; PORTER, M.E; STERN, S. Defining clusters of related industries. Journal of Economic Geography 16(1), pp. 1-38, 2016.

DOAN, N.A.V; DE SMET, Y. An alternative weight sensitivity analysis for PROMETHEE II rankings. Omega (United Kingdom) 80, pp. 166-174, 2018.

EDWARDS,W; BARRON, F.H. SMARTS and SMARTER: Improved Simple Methods for Multiattribute Utility Measurement. Organizational Behavior and Human Decision Processes Volume 60, Issue 3, December 1994, Pages 306-325, 1994.

EILAT H; GOLANY B; SHTUB A. Constructing and evaluating balanced portfolios of R\&D projects with interactions: a DEA based methodology. European Journal of Operational Research 172(3), pp. 1018-1039, 2006. 
ELVIK, R. Cost-benefit analysis of road safety measures: Applicability and controversies. Accident Analysis and Prevention 33(1), pp. 9-17, 2001.

FERNANDEZ, E., FELIX, L.F., MAZCORRO, G. Multiobjective optimization of an outranking model for public resources allocation on competing projects, International Journal of Operational Research 5 , 190-210, 2009.

FERNANDEZ, E; LOPEZ, E; MAZCORRO, G; OLMEDO, R; COELLO COELLO, C.A. Application of the non-outranked sorting genetic algorithm to public project portfolio selection. Information Sciences 228, pp. 131-149, 2013.

FROMHOLD-EISEBITH, M; EISEBITH, G. How to institutionalize innovative clusters? Comparing explicit top-down and implicit bottom-up approaches. Research Policy 34(8), pp. 1250-1268, 2005.

GASSNER, E. The partial inverse minimum cut problem with L1-norm is strongly NP-hard. RAIRO Oper. Res. 44, 241-249, 2010.

GARCÍA-MELÓN, M; POVEDA-BAUTISTA, R; DEL VALLE, M., J.L. Using the strategic relative alignment index for the selection of portfolio projects application to a public Venezuelan Power Corporation. International Journal of Production Economics 170, pp. 54-66, 2015.

GARONE, L. F; MAFFIOLI, A; DE NEGRI, J.A; RODRIGUEZ, C.M; VÁZQUEZ-BARÉ, G. Cluster development policy, SME's performance, and spillovers: evidence from Brazil. Small Business Economics 44(4), pp. 925-948, 2015.

GRECHUK, B; ZABARANKIN, M. Inverse portfolio problem with mean-deviation model. European Journal of Operational Research 234(2), pp. 481-490, 2014.

GRECHUK, B; ZABARANKIN, M. Inverse portfolio problem with coherent risk measures. European Journal of Operational Research 249(2), pp. 740-750, 2016.

GUAN, X; PARDALOS, P.M; ZUO, X. Inverse Max + Sum spanning tree problem by modifying the sum-cost vector under weighted lo Norm. Journal of Global Optimization 61(1), pp. 165-182, 2015.

GUAN, X; PARDALOS, P.M; ZHANG, B. Inverse max+sum spanning tree problem under weighted 11norm by modifying the sum-cost vector. Optimization Letters 12(5), pp. 1065-1077, 2018.

GTP-APL, Grupo de trabalho permanente. Arranjo Produtivo Local - APL. 2011. Disponível em: <http://portalapl.ibict.br/menu/itens_menu/apls/apl_o_que_sao.html>. Acesso em: 21 abr 2018.

HAKANEN, J; MIETTINEN, K; SAHLSTEDT, K. Wastewater treatment: New insight provided by interactive multiobjective optimization. Decision Support Systems 51(2), pp. 328-337, 2011.

HEUBERGER, C. Inverse Combinatorial Optimization: A Survey on Problems, Methods, and Results. Journal of Combinatorial Optimization 8(3), pp. 329-361, 2004.

HIFI, M; MHALLA, H. Sensitivity analysis to perturbations of the weight of a subset of items: The single knapsack case study. Electronic Notes in Discrete Mathematics 36(C), pp. 439-446, 2010. 
HIFI, M; MHALLA, H. Sensitivity analysis to perturbations of the weight of a subset of items: The knapsack case study. Discrete Optimization 10(4), pp. 320-330, 2013.

HIFI M; MHALLA H; SADFI S. Sensitivity of the optimum to perturbations of the profit or weight of an item in the binary knapsack problem. Journal of Combinatorial Optimization, 10 (3), pp. 239-260, 2005 .

HSIEH, T. Y; LU, S.-T; TZENG, G. H. Fuzzy MCDM approach for planning and design tenders selection in public office buildings. International Journal of Project Management 22(7), pp. 573-584, 2004.

HOSPERS, G.-J; BEUGELSDIJK, S. Regional cluster policies: Learning by comparing? Kyklos Volume 55, Issue 3, 2002, Pages 381-402, 2002.

HUANG, X. A review of credibilistic portfolio selection. Fuzzy Optim Decis Making 8:263-281, 2009.

HUANG, X. A review of uncertain portfolio selection. Journal of Intelligent \& Fuzzy Systems 32, $4453-$ 4465, 2017.

HYDE, K.M., MAIER, H.R., COLBY, C.B. A distance-based uncertainty analysis approach to multicriteria decision analysis for water resource decision making. Journal of Environmental Management 77(4), pp. 278-290, 2005.

IEMI - Inteligência de Mercado. Estudo da Competitividade dos Setores Têxtil e Confeccionista no Estado de Pernambuco. Dezembro de 2017. Disponível em: < file:///C:/Users/layra/Downloads/NTCPE\%20-

$\% 20$ Estudo\%20Competitividade\%20Setor\%20T\%C3\%AAxtil\%20de\%20Pernambuco\%202016-

3\%C2\%AA\%20Parte\%20-\%20nova\%20vers\%C3\%A3o.pdf > Acessado em :10 de Dezembro de 2018.

JEFFERY, M; LELIVELD, I. Best practices in IT portfolio management. MIT Sloan Management Review 45(3), pp. 41-49+94, 2004.

JUGEND, D; SILVA, S. L; SALGADO, M. H.; MIGUEL, P. A. C. Product portfolio management and performance: Evidence from a survey of innova-tive Brazilian companies. Journal of Business Research, 69(11), 5095-5100, 2016.

KADZIŃSKI, M; CIOMEK, K; RYCHŁY, P; SŁOWIŃSKI, R. Post factum analysis for robust multiple criteria ranking and sorting. Journal of Global Optimization 65(3), pp. 531-562, 2016.

KEENEY, R. L; RAIFFA, H. Decision with Multiple Objectives: Preferences and Value Trade-offs. John wiley \& Sons, 1976.

LASTRES, H. M. M.; CASSIOLATO, J. E. (coord.). Glossário de arranjos e sistemas produtivos e inovativos locais. Rio de Janeiro: Instituto de Economia, UFRJ, nov. 2003. Disponível em: < http://www.ie.ufrj.br/redesist >. Acesso em: 24 Abril. 2018. 
LEHMANN, E.E; MENTER, M. Public cluster policy and performance. Journal of Technology Transfer, 15 September 2017, Pages 1-35, 2017.

LI, S; ZHANG, Z; LAI, H. J. Algorithm for constraint partial inverse matroid problem with weight increase forbidden. Theoretical Computer Science 640, pp. 119-124, 2016.

LI, X; ZHANG, Z; DU, D. Z. Partial inverse maximum spanning tree in which weight can only be decreased under lp -norm. Journal of Global Optimization 70(3), pp. 677-685, 2018.

LIKERT, R. A Technique for the Measurement of Attitudes. Archives of Psychology, 140: 1-55, 1932.

LIMA, L. N. D; ALMEIDA, J. A. MODELO MULTICRITÉRIO COM USO DO MÉTODO SMARTS PARA SELEÇÃO PROJETOS PÚBLICOS DE INCENTIVO AO APL DE CONFECÇÕES NO AGRESTE DE PERNAMBUCO. In: L Simpósio Brasileiro de Pesquisa Operacional. Campinas: GALOÁ. 2018. Disponível em: <https://proceedings.science/sbpo/papers/modelo-multicriterio-comuso-do-metodo-smarts-para-selecao-projetos-publicos-de-incentivo-ao-apl-de-confeccoes-no-agrest $>$ Acessado: 15 nov. 2018a. (Resumo).

LIMA, L. N. D; ALMEIDA, J. A. MODELO MULTICRITÉRIO PARA SELEÇÃO DE INVESTIMENTOS PÚBLICOS EM PROJETOS VISANDO APOIAR O APL DE CONFECÇÕES NO AGRESTE CENTRAL DE PERNAMBUCO. In: XXXVIII ENCONTRO NACIONAL DE ENGENHARIA DE PRODUÇÃO, Maceió. 2018. Disponível em: <http://www.abepro.org.br/biblioteca/TN_WPG_263_510_35069.pdf > Acessado: 15 nov. 2018b.

MARESCHAL, B. Weight stability intervals in multicriteria decision aid. European Journal of Operational Research 33(1), pp. 54-64, 1988.

MARKOWITZ, H. Portfolio Selection. The Journal of Finance, Vol. 7, No. 1. (Mar., 1952), pp. 77-91, 1952.

MARSHALL, A. Principles of economics. 8th. Ed. London: Macmillan, 1920.

MAVROTAS, G; DIAKOULAKI, D; CALOGHIROU, Y. Project prioritization under policy restrictions. A combination of MCDA with 0-1 programming. European Journal of Operational Research 171(1), pp. 296-308, 2006.

MDIC-Ministério de desenvolvimento, indústria e comércio. Arranjo Produtivo Local - APL. 2018. Disponível em: <http://www.mdic.gov.br/index.php/competitividade-industrial/arranjos-produtivoslocais $>$. Acessado em: 2018-02-05.

MOUSSEAU, V; ÖZPEYNIRCI, Ö; ÖZPEYNIRCI, S. Inverse multiple criteria sorting problem. Annals of Operations Research 267(1-2), pp. 379-412, 2018.

NISHIMURA, J. E; OKAMURO, H. Subsidy and networking: The effects of direct and indirect support programs of the cluster policy. Research Policy 40(5), pp. 714-727, 2011. 
NISHIZAKI, I., KATAGIRI, H., HAYASHIDA, T. Sensitivity analysis incorporating fuzzy evaluation for scaling constants of multiattribute utility functions. Central European Journal of Operations Research 18(3), pp. 383-396, 2010.

OECD - Organisation for Economic Cooperation and Development. Policies to support clusters, generally understood to be geographic concentrations of inter-connected firms and related actors (specialized service providers, universities, etc.). 2010. Disponível em: <http://www.oecd.org/innovation/policyplatform/48137710.pdf> Acessado em: 2018-02-05.

OECD - Organisation for Economic Cooperation and Development. Better policies for better lives. 2011. Disponível em: < https://www.oecd.org/about/47747755.pdf> Acessado em: 2018-02-05.

OPRICOVIC, S., TZENG, G.-H. Compromise solution by MCDM methods: A comparative analysis of VIKOR and TOPSIS. European Journal of Operational Research 156(2), pp. 445-455, 2004.

PARDALOS, P. M; SANDSTR"OM, M; ZOPOUNIDIS, C. On the use of optimization models for portfolio selection: A review and some computational results. Computational Economics, 7(4):227-244, 1994.

PORTER, M.E. The competitive advantage of nations. New York: The Free Press, 1990a.

PORTER, M. E. The competitive advantage of nations. Harvard Business Review, 68(2), 73-93, 1990b.

PORTER, M. E. Clusters and the new economics of competition. Harvard Business Review, Cambridge, v. 76, n. 6, p. 77-90, 1998.

PROAPL-PE, Programa de Produção e Difusão de Inovações para a Competitividade de Arranjos Produtivos Locais do Estado de Pernambuco. Arranjo Produtivo Local - APL de Confecções do Agreste Plano de Melhoria de Competitividade - PMC. 2013.

PUJADAS, P; PARDO-BOSCH, F; AGUADO-RENTER, A; AGUADO, A. MIVES multi-criteria approach for the evaluation, prioritization, and selection of public investment projects. A case study in the city of Barcelona. Land Use Policy Volume 64, 1 May, Pages 29-37, 2017.

RINGUEST, J.L. LP-metric sensitivity analysis for single and multi-attribute decision analysis. European Journal of Operational Research 98(3), pp. 563-570, 1997.

ROLAND, J; FIGUEIRA, J.R; DE SMET, Y. The inverse 0, 1-knapsack problem: Theory, algorithms and computational experiments. Discrete Optimization 10(2), pp. 181-192, 2013.

ROLAND, J; FIGUEIRA, J.R; DE SMET, Y. Finding compromise solutions in project portfolio selection with multiple experts by inverse optimization. Computers and Operations Research 66, pp. 12-19, 2016.

ROY, B. Multicriteria methodology for decision aiding. Kluwer Academic Publishers, 1996.

ROY, B; SLOWINSKI, R. Questions guiding the choice of a multicriteria decision aiding method. EURO J Decis Process 1(1-2), pp. 69-97, 2013. 
SAATY, T. L. (1980). The analytic hierarchy process. New York: McGraw- Hill, 1980.

SARABANDO, P., DIAS, L.C. Multiattribute choice with ordinal information: A comparison of different decision rules. IEEE Transactions on Systems, Man, and Cybernetics Part A:Systems and Humans 39(3), pp. 545-554, 2009.

SEBRAE - Serviço Brasileiro de Apoio às Micro e Pequenas Empresas. Termo de Referência para Atuação do Sistema SEBRAE em APL. Brasília: Editora SEBRAE, 2003. Disponível em < http://cppg.am.sebrae.com.br/apl/popup.htm > Acessado em: 24 de abril de 2018.

SEBRAE - Serviço Brasileiro de Apoio às Micro e Pequenas Empresas. Estudo Econômico do Arranjo Produtivo Local de Confecções do Agreste Pernambucano. Relatório Final, Recife, Maio de 2013. Disponível em: <http://www.sebrae.com.br/Sebrae/Portal\%20Sebrae/Anexos/Estudo\%20Economico\%20do\%20APL $\% 20 \mathrm{de} \% 20$ Confeccoes\%20do\%20Agreste $\% 20$ $\% 20 \% 2007 \% 20$ de $\% 20$ MAIO\%202013\%20\%20docx.pdf> Acesso em 10 de dezembro de 2018

SCHMIEDEBERG, C. Evaluation of Cluster Policy: A Methodological Overview. Evaluation 16(4), pp. 389-412, 2010.

SCHMITZ, H; NADVI, K. Clustering and Industrialization: Introduction. World Development, Elsevier, v. 27, n. 9, p. 1503-1514, 1999.

SOWLATI, T; ASSADI, P; PARADI, J.C. Developing a mathematical programming model for sensitivity analysis in analytic hierarchy process. Int. J. Mathematics in Operational Research, Vol. 2, No. 3, pp.290-301, 2010.

TARANTOLA, A. Inverse Problem Theory: Methods for Data Fitting and Model Parameter Estimation. Elsevier, Amsterdam, 1987.

TAVANA, M; KERAMATPOUR, M; SANTOS-ARTEAGA, F.J; GHORBANIANE, E. A fuzzy hybrid project portfolio selection method using Data Envelopment Analysis, TOPSIS and Integer Programming. Expert Systems with Applications 42(22), pp. 8432-8444, 2015.

TÖPFER, S; CANTNER, U; GRAF, H. Structural dynamics of innovation networks in German Leading-Edge Clusters. Journal of Technology Transfer pp. 1-24, 2017.

TRIANTAPHYLLOU, E., SÁNCHEZ, A. A sensitivity analysis approach for some deterministic multicriteria decision-making methods. Decision Sciences 28(1), pp. 151-185, 1997.

NEUBAUER, T; STUMMER, C. Interactive selection of Web services under multiple objectives. Information Technology \& Management, 11(1):25-41, 2010.

UNCTAD-CONFERÊNCIA DAS NAÇÕES UNIDAS SOBRE COMÉRCIO E DESENVOLVIMENTO. Promoting and sustaining SME clusters and networks for development. Geneva, 2-4 Sep. 1998. Disponível em: < http://unctad.org/en/docs/c3em5d2.pdf> 
UNCTAD-CONFERÊNCIA DAS NAÇÕES UNIDAS SOBRE COMÉRCIO E DESENVOLVIMENTO. PROSPERITY FOR ALL. 2017. Disponível em: <https://unctad.org/en/PublicationsLibrary/osgciomisc2017_en.pdf?user=17>

VASCONCELOS, D. S. ; KRYM, E. M. ; ALMEIDA, J. A. ; ALMEIDA, A. T. DE . Portfolio Aditivo com função valor linear e análise de sensibilidade por simulação de Monte Carlo e comparação gráfica de output - Código PU-A2MMG-DF1. 2014.

VETSCHERA, R. Composite alternatives in group decision support. Annals of Operations Research 51(5), pp. 195-215, 1994.

VETSCHERA, R. Learning about preferences in electronic negotiations - A volume-based measurement method. European Journal of Operational Research 194(2), pp. 452-463, 2009.

VETSCHERA, R; DE ALMEIDA, A.T. PROMETHEE- based approach to portfolio selection problems. Computers \& Operations Research, 39 (5): 1010-1020, 2012.

WALCZAK, D ; RUTKOWSKA, A. Project rankings for participatory budget based on the fuzzy TOPSIS method. European Journal of Operational Research 260(2), pp. 706-714, 2017.

WOLTERS, W.T.M; MARESCHAL, B. Novel types of sensitivity analysis for additive MCDM methods. European Journal of Operational Research 81(2), pp. 281-290, 1995.

ZANAKIS, S.H; MANDAKOVIC, T; GUPTA, S.K; SAHAY, S; HONG, S. A review of program evaluation and fund allocation methods within the service and government sectors. Socio-Economic Planning Sciences, 1995. 